\title{
Beyond booms: fundamentals and mechanisms of housing markets in decline
}

Citation for published version (APA):

Lindenthal, T. (2011). Beyond booms: fundamentals and mechanisms of housing markets in decline.

[Doctoral Thesis, Maastricht University]. Maastricht University. https://doi.org/10.26481/dis.20110325tl

Document status and date:

Published: 01/01/2011

DOI:

10.26481/dis.20110325tl

Document Version:

Publisher's PDF, also known as Version of record

\section{Please check the document version of this publication:}

- A submitted manuscript is the version of the article upon submission and before peer-review. There can be important differences between the submitted version and the official published version of record.

People interested in the research are advised to contact the author for the final version of the publication, or visit the DOI to the publisher's website.

- The final author version and the galley proof are versions of the publication after peer review.

- The final published version features the final layout of the paper including the volume, issue and page numbers.

Link to publication

\footnotetext{
General rights rights.

- You may freely distribute the URL identifying the publication in the public portal. please follow below link for the End User Agreement:

www.umlib.nl/taverne-license

Take down policy

If you believe that this document breaches copyright please contact us at:

repository@maastrichtuniversity.nl

providing details and we will investigate your claim.
}

Copyright and moral rights for the publications made accessible in the public portal are retained by the authors and/or other copyright owners and it is a condition of accessing publications that users recognise and abide by the legal requirements associated with these

- Users may download and print one copy of any publication from the public portal for the purpose of private study or research.

- You may not further distribute the material or use it for any profit-making activity or commercial gain

If the publication is distributed under the terms of Article $25 \mathrm{fa}$ of the Dutch Copyright Act, indicated by the "Taverne" license above, 


\section{Beyond Booms: \\ Fundamentals and Mechanisms of Housing Markets in Decline}

\section{DISSERTATION}

to obtain the degree of Doctor

at the Maastricht University,

on the authority of the Rector Magnificus,

Prof.dr. G.P.M.F. Mols,

in accordance with the decision of the Board of Deans,

to be defended in public

on Friday, March 25th, 20II, at Io hours by

Heiner Thies Edmund Lindenthal 
Supervisor

Prof.dr. Piet Eichholtz

Assessment Committee

Prof.dr. Franz Palm (voorzitter)

Prof.dr. John Quigley (University of California, Berkeley)

Prof.dr. Peter Schotman

This dissertation received financial support from

Maastricht Research School of Economics of Technology and Organizations (METEOR)

\section{(C)20II, Thies Lindenthal}

No part of this publication may be reproduced, stored in automated data-systems or transmitted in any form or by any means, electronic, mechanical or photocopying, recording, or otherwise, without the prior written permission of the author.

Cover artwork by Antonia Kühn (http://www. antoniakuehn.de)

Fonts: Vollkorn, Myriad Pro

Typesetting: $\mathrm{LT}_{\mathrm{E}} \mathrm{X}$ 


\section{Contents}

$\begin{array}{ll}\text { Introduction } & \text { I3 }\end{array}$

I House Prices and Fundamentals 19

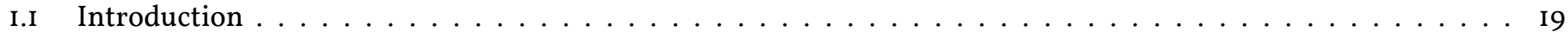

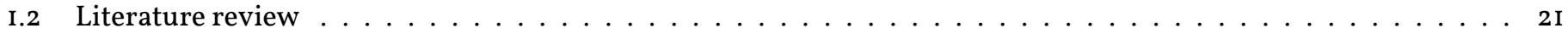

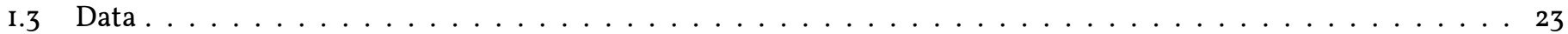

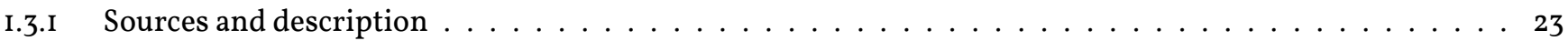

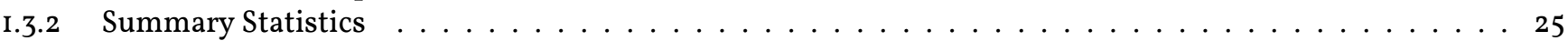

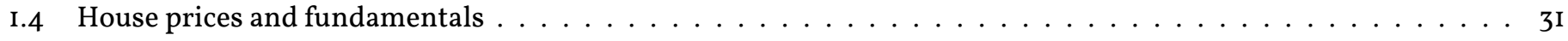

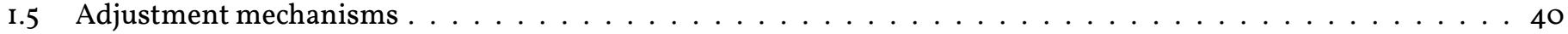

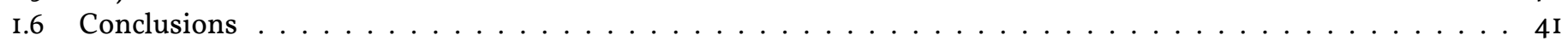

2 Real Options and Price Volatility 47

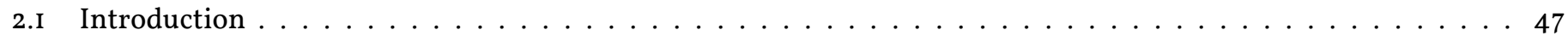

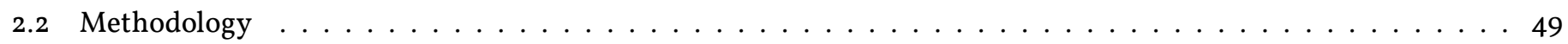

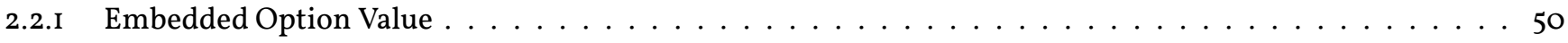

$2.2 .2 \quad$ Empirical Specification with Embedded Option Value $\ldots \ldots \ldots \ldots \ldots \ldots \ldots \ldots \ldots$ 


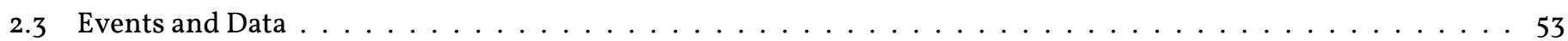

2.3.I Events Associated with the Creation and Destruction of Option Value . . . . . . . . . . . . 53

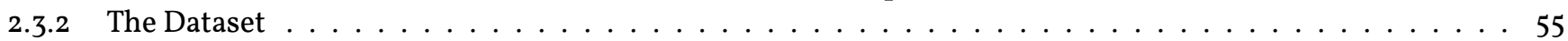

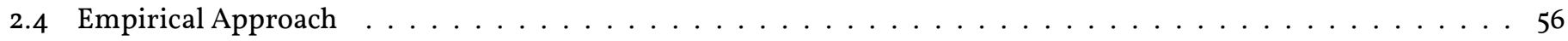

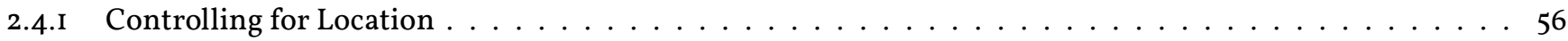

2.4.2 Comparing Fully Developed to High Option Value Sales, Same Neighborhood . . . . . . . . . . . . . 59

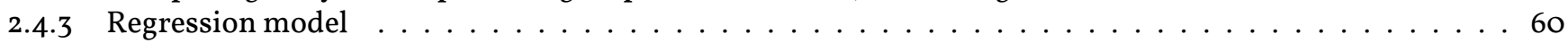

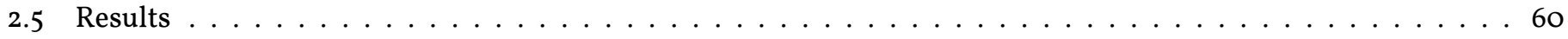

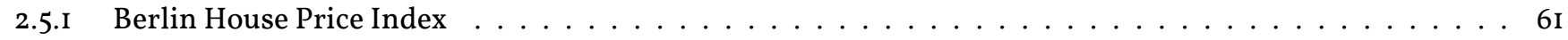

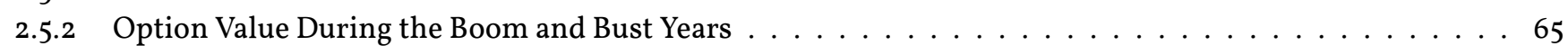

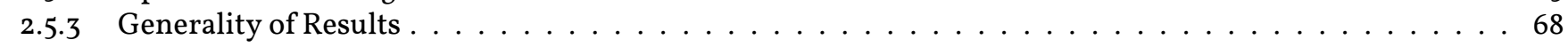

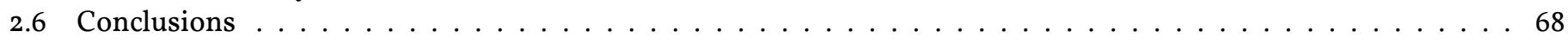

3 Demographics and Housing Demand 73

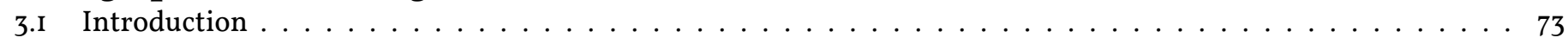

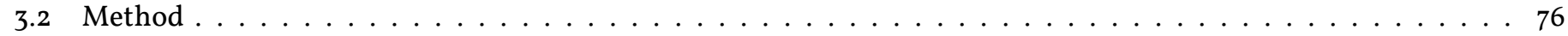

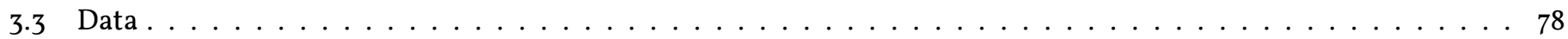

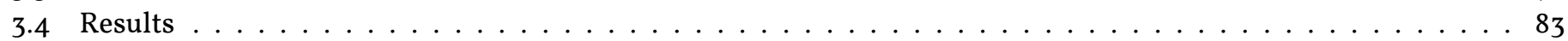

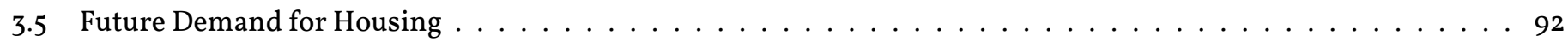

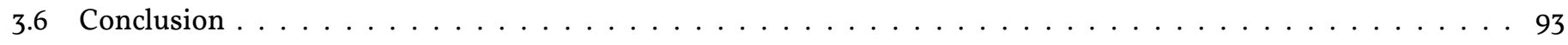

4 Local price dynamics within cities 97

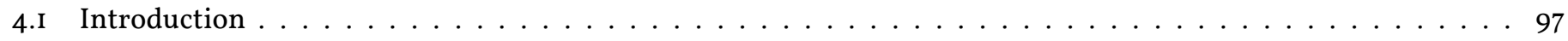

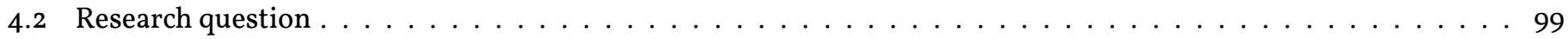

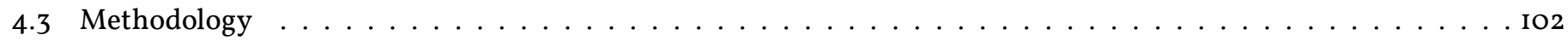

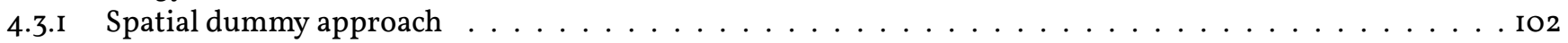

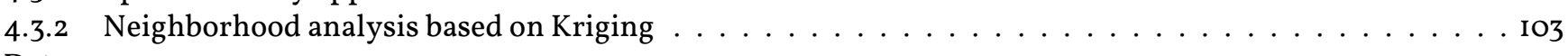

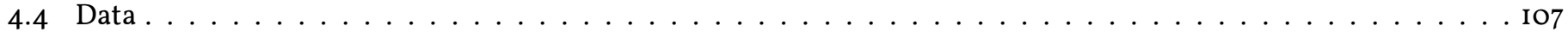




\section{CONTENTS}

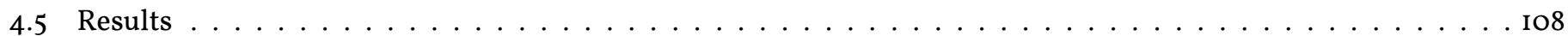

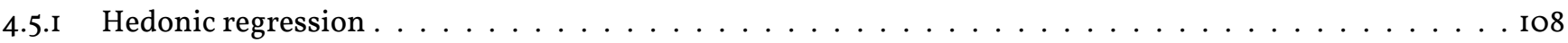

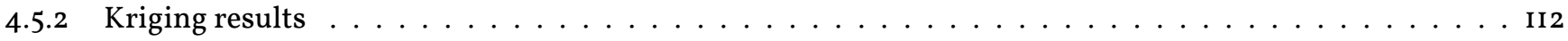

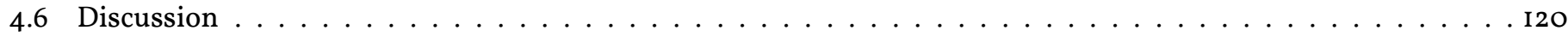

5 Conclusion $\quad 123$

Nederlandse Samenvatting (Summary in Dutch) 129

Curriculum Vitae 133 
CONTENTS 


\section{List of Figures}

I Projected change of total population for European countries $\ldots \ldots \ldots$

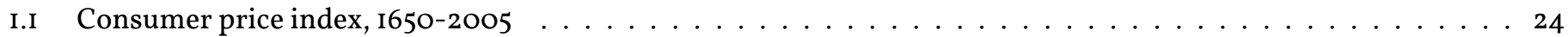

I.2 Nominal rents and house prices, $1650-2005 \ldots \ldots \ldots \ldots$

I.3 Real rents and house prices, $1650-2005 \ldots \ldots \ldots \ldots \ldots$

I.4 Nominal bond yields, $1783-2005 \ldots \ldots \ldots \ldots$

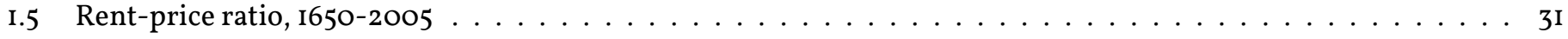

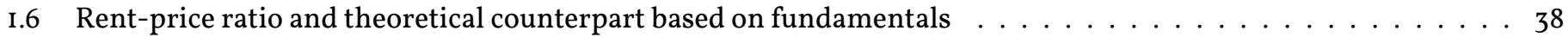

I.7 Rent-price ratio error $\epsilon$ in $\operatorname{logs}, \mathrm{I} 825-2005 \ldots \ldots \ldots \ldots$

I.8 Yearly VAR coefficient estimates and $95 \%$ confidence intervals . . . . . . . . . . . . . . . 44

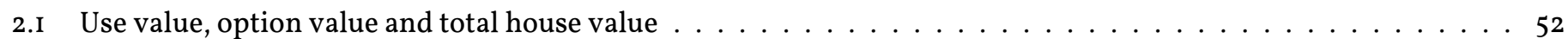

2.2 Geographic distribution of single-family home transactions in West Berlin. . . . . . . . . . . . . . . . 58

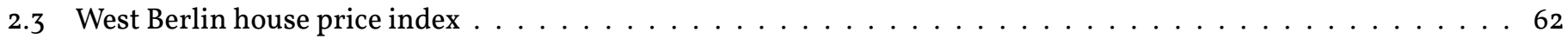

3.I Income dynamics for British households $\ldots \ldots \ldots$

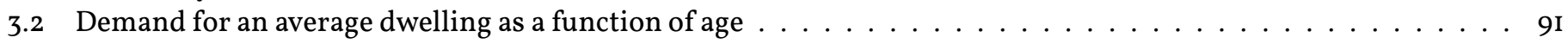

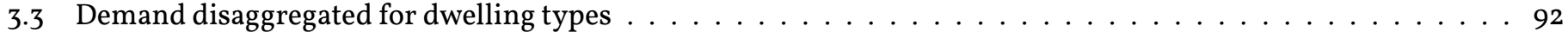




\section{LIST OF FIGURES}

3.4 Aggregate housing demand growth projections, England 2005-2030 . . . . . . . . . . . . . 94

4.I Decreasing home values and relative prices levels across neighborhoods . . . . . . . . . . . . . . IOo

4.2 Four phases in the latest Dutch house price cycle . . . . . . . . . . . . . . . . . . . . IO7

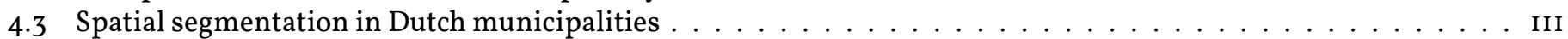

4.4 Variograms for Dutch detached homes through time . . . . . . . . . . . . . . . . . . II4

4.5 Index surface for detached home prices, The Netherlands, 2007QI-2008QI . . . . . . . . . . . . . . II5

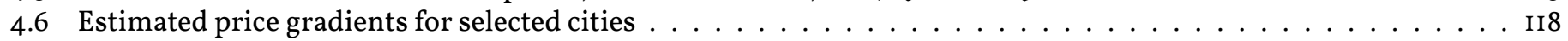




\section{List of Tables}

I.I Amsterdam's housing market throughout the centuries . . . . . . . . . . . . . . . . 30

I.2 Description of data sources and selected time series properties for (sub-)indices . . . . . . . . . . . 32

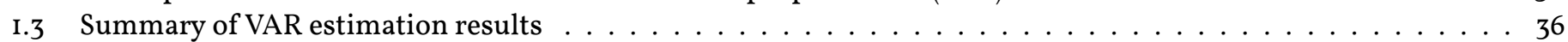

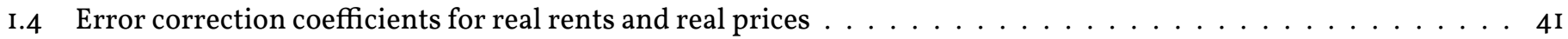

I.5 Unit root tests for levels of real rent and house price indices $\ldots \ldots \ldots \ldots$

I.6 Unit root tests for first differences of real rent and house price indices . . . . . . . . . . . . . . 45

2.I Summary statistics comparing matched sample with complete sample . . . . . . . . . . . . . . 6I

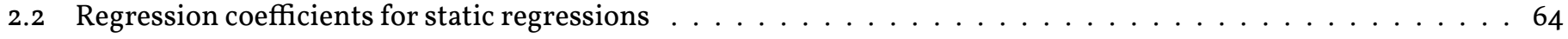

2.3 Regression coefficients for time-varying option value models . . . . . . . . . . . . . . . . 66

2.4 Share of option value in total home value in boom and bust period . . . . . . . . . . . . . . . . . . . 69

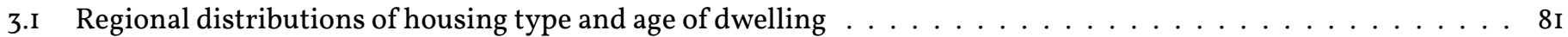

3.2 Total number of dwellings, tenure, average dwelling price . . . . . . . . . . . . . . . . . 82

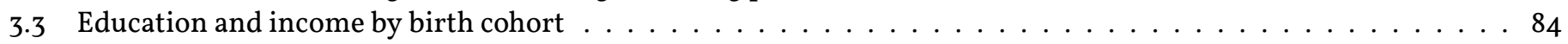

3.4 Marginal prices $q_{i}$ for hedonic characteristics $\ldots \ldots \ldots \ldots$

3.5 Demographic regression - selected results $\ldots \ldots \ldots \ldots \ldots$ 


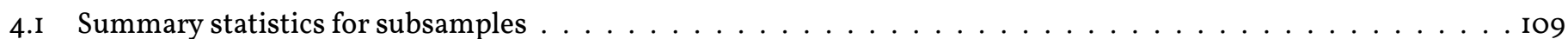

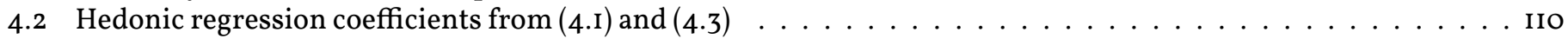

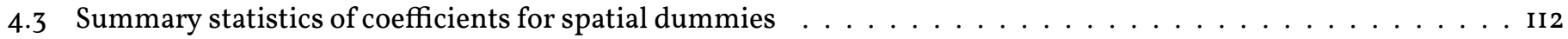

4.4 Regression coefficients for neighborhood analysis $(4.2) \ldots \ldots \ldots \ldots$

4.5 Summary statistics of index surface estimates for four sub-periods . . . . . . . . . . . . . . . . . II7

4.6 Regression results on changes in index surface during boom and bust $(4.6) \ldots \ldots$. . . . . . . . . . . . II9

4.7 Regression results on changes in index surface during boom and bust, alternative specification (4.7) . . . . . . II9 


\section{Acknowledgements}

Writing a dissertation was never a childhood dream of mine. Now I think it should have been. The last four years have been terrific. Locking jaws with a challenging topic was a great adventure and a wonderful intellectual voyage. A large group of colleagues and friends made this endeavor possible. I will remain deeply indebted to all of them.

It is not just out of politeness and custom that I mention Piet Eichholtz first. I really am in his debt. He was a strict academic supervisor to me and he did not suffer from the 'notinvented-here syndrome'. His own curiosity gave me the freedom to try out my own research ideas, ranging from analyzing rents in I6th century Belgium to spatial econometrics in declining cities.

The Dutch call a supervisor a begeleider which has the connotation of a companion, coach, or mentor who fosters the development of a protégé. Piet was that coach. He constantly pushed me out of my comfort-zone, opened up many opportunities to speak at conferences, to travel, and to work with other scholars.
In traditional German, Piet's label would be Doktorvater. I do not want to overuse this metaphor, but a certain fatherlike role is undeniable. He would do things for others without expecting anything in return. He freely shared his time, experience, knowledge, and tremendous network and was happy if I could make use of it.

During the last few years, I also had the privilege to work closely with Brent Ambrose and John Clapp. These true masters in their fields remain inspiring teachers for me. I also benefited enormously from discussions and feedback provided by many outstanding scholars at numerous conferences and seminars.

David Bloom and John Quigley are thanked for their hospitality and the chance to visit (at)the Harvard School of Public Policy and the University of California, Berkeley.

My fellows students Bart Diris, Daniel Hann, Simone Wies, Kathrin Nies, Daniela Osterrieder, Nils Holinski, and Robert Vermeulen became very dear to me and I am sure we will stay in close contact. If Piet is my 'doctor father', 
then Nils Kok is my academic elder brother. Helping, caring and always a good sport! Maastricht University overall is a friendly environment for its PhD students. I already miss my colleagues and friends at the Finance Department.

Franz Palm, Peter Schotman, and John Quigley are thanked for serving on my evaluation committee and for their invaluable feedback.

I have thousands of reasons to thank Hjördis - in this context I will keep personal things private and acknowledge just three turning points in my life where she played a crucial role: She was the one who made sure I did not drop out of school before finishing my A-levels. A few years later, after I had 'paused' my computer science studies and had founded my first company, she encouraged me to give university a second try. Another three years later, she was the reason why I curbed my wanderlust, did not go for that exotic Master's program far away, but came back to Maastricht. Without her, this dissertation would not have been written. 


\section{Introduction}

"What kind of research are you doing, sir?" a seriously looking border police agent at San Francisco Airport inquired. The answer "Real Estate Finance" immediately ended the immigration interrogation. I got my passport back with a smile and instead of taking my fingerprints, the officer switched to private chatter, asking for advice and market insights as he was planning to buy a new home. This was the moment I realized: Housing is big!

\section{Housing matters}

Housing is a massive factor in people's consumption. For industrialized nations, it is the biggest component in the basket of goods used for calculating the consumer price index. The Bureau of Labor Statistics (BLR 2OIO) estimates that American home owners spent about 23.8 percent of their total consumption on housing.

Buying a house to live in is the largest investment many households make. For The Netherlands, home owners had 60.5 percent of their total wealth in 2010 tied up in their home (CBS Statline, 20IO). Households invest into housing early in their investment life-cycle. Only later they accumulate the financial fat needed to invest into other asset classes. For households headed by a person aged 25-45, the share of housing in all investments is 72.0 percent, for households aged 46-64, the share is watered down to 58.2, and for households older than $64,52.2$ percent of all wealth still remains in the home.

Housing not only dominates the asset side of households' balance sheets. It is also the most prominent chunk within the liabilities. For Dutch households aged 25-45, the residential mortgage is worth 62.0 percent of total wealth (CBS Statline, 20IO). This huge exposure is eased in time as mortgages are paid off. For households beyond the age of 64 , the mortgage only plays a minor role (8.6 percent of total wealth).

Housing is big enough to leave a sizable footprint on the economy in general. The value of all owner occupied Dutch housing is estimated to be 1.7 trillion Euros in 2009 (CBS, 20IO), which is more than two times the value of the gross 
domestic product (GDP) and easily exceeds the total capitalization of all companies listed at the Amsterdam stock exchange. All outstanding residential mortgages in the United States amount to 76.2 percent of the American GDP in 2006, while the Danish and Dutch counterparts even reached a ratio of one hundred percent (IMF, 2008).

During the last years of the Greenspan era, the United States pulled themselves out of the dot-com crisis and the economic shock following the terrorist attacks on September II, 20OI, by fueling the housing sector with easy credit. The total new investment into US residential real estate had grown from 405.8 billion USD in 200 t to 653 billion USD in 2006 before collapsing to a meager 288.8 billion USD in 2009 (Bureau of Economic Analysis, 2010). House prices were perceived to enjoy never-ending growth. Between February 2000 and February 2006, the Case/Shiller home price index for 20 American cities increased by a breathtaking 105 percent. This price rally heated up the rest of the economy. Home equity loans and second mortgages channeled the new housing wealth into general consumption. We all know the end of this story: Collapsing home values in the US were the starting point of a global financial crisis that paralyzed the financial industry and grew into a full-fledged economic recession. This crisis has painfully demonstrated: Housing matters.

This dissertation comprises of 4 individual studies that analyze the fundamentals and mechanisms of housing mar- kets from two different directions. Chapters I and 2 research housing bubbles and house price volatility, while Chapters 3 and 4 look at the impact of demographic dynamics on housing markets.

Chapter I examines the long run relationship between prices and rents for houses in Amsterdam from I650 through 2005. It estimates the deviation of house prices from fundamentals and finds that these deviations can be persistent and long-lasting. Furthermore, it looks at the feedback mechanisms between housing market fundamentals and prices. It finds that market correction of the mispricing occurs mainly through prices, not rents. This correction back to equilibrium, however, can take decades.

The underlying factors of house price volatility are at the focus of Chapter 2. It is the first study that tests how the dynamics of house prices are affected by the option to rebuild or enlarge existing dwellings. It incorporates this option in a standard hedonic regression model, and shows how neighborhoods and houses with unrealized renovation potential can be identified. It uses an unexplored dataset of housing transactions in West Berlin, covering thirty years between 1978 and 2007. The empirical results show that house value has an elasticity of about 0.15 with respect to development potential, measured by the ratio between the square meters allowed by zoning and the existing house size. For high option value properties the elasticity increases to 0.23 .

The evidence presented in Chapter 2 suggests that the high uncertainty and high growth period between 1989 and 1994 
was associated with a significant increase in option value for the properties with substantial redevelopment potential; about 40 percent of the boom was due to increase in option value. During the Io year bust after 1994, about 50 percent of the decline was due to change in option value. Volatility of this magnitude applies to about Io percent of all properties sold during the sample period. More than 68 percent of all sales have increased volatility over the cycle due to unrealized option value.

\section{Demographic trends shape housing markets}

Demographic contraction is one of the key challenges many industrialized countries will face in the future or already experience today. To give a brief example, the United Nations Population Division (2007) estimates that Russia will lose 24 percent of its current population by the year 2050. For Bulgaria, the expected decline in total population is 35 percent in the same period, while neighboring Turkey will experience an impressive population growth of 29 percent (see Figure I). The populations of Japan and Germany will both drop by I8 percent. Within countries, huge regional differences can be observed. In Germany, for example, all Eastern states except Brandenburg experienced double digit population decline rates since 1990. Beside the rapid changes in total population numbers, societies age dramatically. In South Korea, for instance, the median age is increasing three years every five years and the share of inhabitants older than 60 years will increase from I 4 percent now to 42 percent in 2050 . The second part of this dissertation analyses how these changing demographics shape housing markets.

Will greying populations demand less housing or different kinds of housing services? Chapter 3 answers this question based on very detailed 200 I cross-sectional data of English households. It refines the existing methodology by distinguishing between life cycle variables that are expected to change with age for each household, and cohort variables that are determined by the household's birth-cohort and not by age.

The chapter's key results are that housing demand is mainly driven by human capital and that it does not decline with age. A scenario analysis with different population projections shows that in the case of stagnating household numbers total demand can still increase as the population grows older. These findings are relevant to many European countries that already experience population shrinkage.

Chapter 4 researches within-city home price dynamics in bullish and bearish residential real estate markets and different demographic environments. It contributes to the literature addressing the urban layout of cities by formulating and empirically testing a novel idea for changes in the price gradients across neighborhoods under different market regimes. The study finds that the combination of citywide falling home prices and declining population numbers hurts low-value neighborhoods most, while falling homeprices in cities with robust demographics do not lead to shifts 
in the within-city distribution of housing wealth.

A new level of spatial detailedness is achieved by combining a high-quality data-set for The Netherlands with estimation techniques borrowed from the geoscience domain. The data comprise of I.8 million single family home transactions and 0.8 million apartments sold by members of the Dutch Realtor Association (NVM). This is the first paper that estimates home price index surfaces for an entire country based on a spatial error model. 


\section{INTRODUCTION}

Figure 1: Projected change of total population for European countries

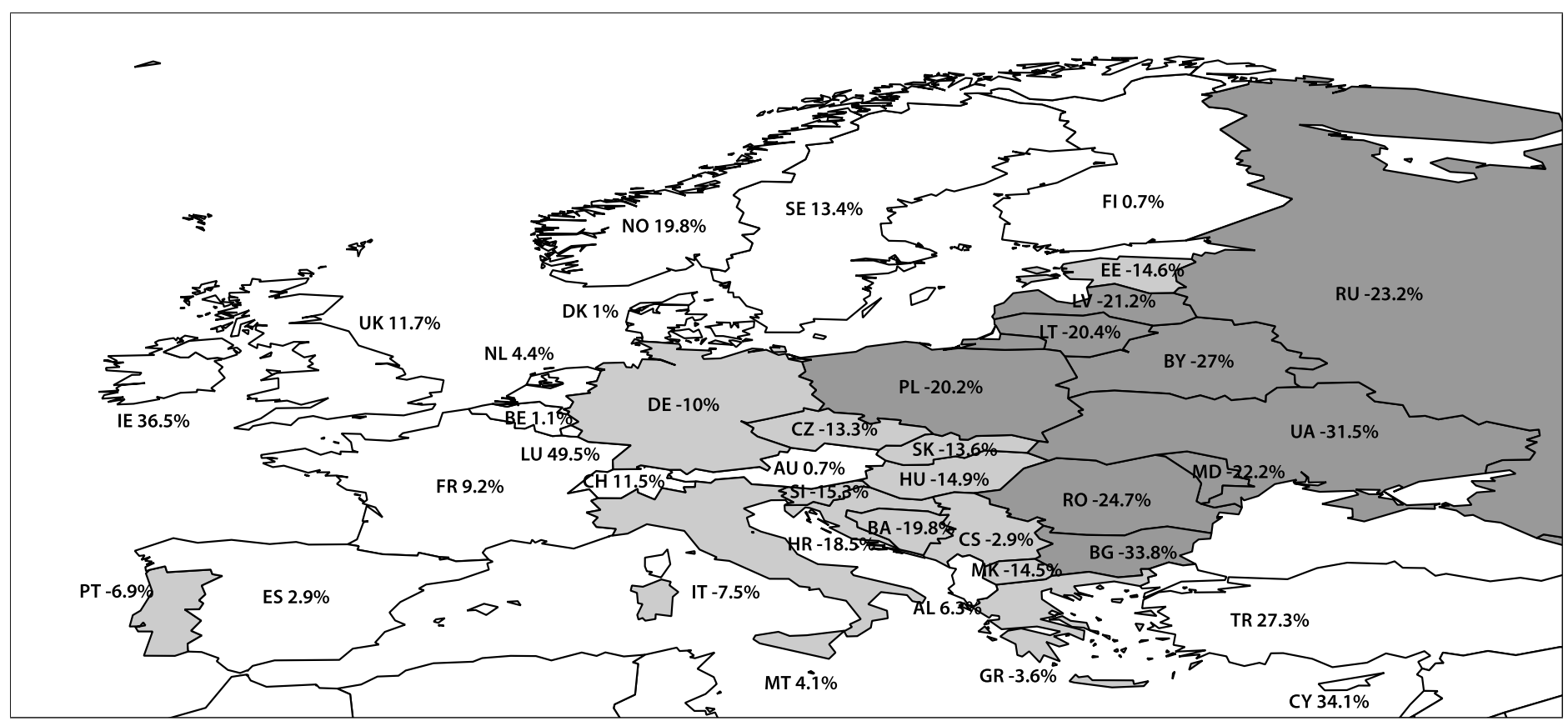

Notes: Map is based on the population forecasts developed by the United Nations Population Division (2007) 
INTRODUCTION 


\section{Chapter 1}

\section{House Prices and Fundamentals: 355 Years of Evidence}

\author{
This chapter is joint work with \\ Brent Ambrose (Pennsylvania State University) and \\ Piet Eichholtz (Maastricht University).
}

\subsection{Introduction}

The debate over whether a "housing bubble" existed recently in the U.S. and many other countries in the world is still not fully resolved. Numerous academic articles and popular press accounts point to mounting evidence of a U.S. housing bubble as house prices increased on average more than five percent per year from 2000 to 2006. On the local level, some markets experienced yearly price increases of more than 20 percent. As a result, even the former chairman of the Board of Governors of the Federal Reserve System, Alan
Greenspan, noted that some local markets showed signs of speculative activity. ${ }^{\mathrm{I}}$ The same holds for other countries. Spain and Ireland, for example, saw average house prices increase between 1997 and 2007 of nearly 190 percent and 240 percent, respectively. These countries have seen their house prices fall rapidly since then. More recently, the rapid rise in property values in China has raised concerns of a bubble forming there. ${ }^{2}$ However, the housing market experiencing one of the biggest rises of all, South Africa, has merely stabilized.

The worry of economists and policy makers is that asset

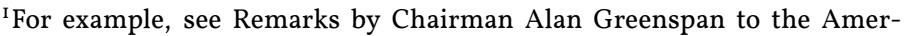
ican Bankers Association Annual Convention, Palm Desert, California (via satellite), September 26, 2005 (http://www. federalreserve.gov/ boardDocs/Speeches/2005/200509262/default.htm).

${ }^{2}$ For a discussion of current Chinese housing markets, see Mufson (2010). 
price bubbles may quickly turn into busts, resulting in economic contraction. In the last few years, the world has seen that such fears can be justified. Helbling and Terrones (2003), and Claessens et al. (2009) investigate the effects housing market declines have on recessions. Helbling and Terrones (2003) document 20 severe housing market declines in I4 countries over the period 1970 to 2002 . For the period from I960 to 2007, Claessens et al. (2009) look at I22 recessions and II 4 episodes of house price decline, of which 28 were characterized as busts. Both papers show that these housing market declines generally overlapped or coincided with recessions, and that recessions coinciding with housing market declines resulted in output losses roughly two to three times as big as other recessions. Claessens et al. (2009) conclude that the extent of the house price decline most consistently influences the depth of a recession, even after taking into account other financial variables like credit availability and equity prices.

Recognizing an asset price bubble prior to a price crash is notoriously difficult. A number of academic studies conducted in the early 2000 questioned whether the U.S. housing market was experiencing the characteristics of a housing price bubble. For example, Case and Shiller (2003) compared U.S. house price growth with income growth since 1985 and concluded that income growth could explain nearly all of the house price increase for over 40 states. Thus income growth, combined with low interest rates, made houses in most states more affordable than they had been in 1995. In addition,
McCarthy and Peach (2004) presented a critical analysis of the data and methods commonly used to support the claim of a housing bubble. After adjusting common housing market metrics (such as the ratio of the median price of existing homes to the median household income) to account for the effects of interest rate changes, McCarthy and Peach (2004) found little evidence supporting a bubble in the U.S. housing market.

The problem with identifying the presence (or lack thereof) of bubbles in asset markets is the lack of sufficiently long term data that would allow researchers to identify cases where asset prices significantly deviate from fundamental values. Furthermore, market price deviations from fundamental values over a short time period do not guarantee that market prices will decline - the often-predicted bubble crash. Rather, it may be possible that bubble conditions are sustained, followed by gradual restoration of the equilibrium relationship.

The purpose of this paper is to utilize a 355-year time series of real house prices and rents to demonstrate that substantial deviations of market prices away from market fundamental values can be persistent. In addition, we show that these "bubble condition" periods do not necessarily end with the bubble bursting but could as well be resolved by slow convergence of prices and fundamentals.

The following section presents a brief review of recent studies that have examined possible asset bubbles. Section 2 then presents the housing market data as well as the data 
concerning consumer prices and interest rates, while Section 3 presents the methods and results of our investigation of the relationship between house prices and fundamentals. This analysis of the Amsterdam housing market reveals that significant and long-lasting price deviations are possible, followed by corrections that can either be gradual or sharp. Section 4 examines the way these corrections transpire by analyzing the mechanisms of price and rent adjustment. Finally, Section 5 provides conclusions.

\subsection{Literature review}

Much of the popular press takes for granted that the recent house price increases seen around the world are evidence of a "bubble" in housing markets. For example, in a recent survey, McCarthy and Peach (2004) found that the high ratio of home prices relative to household income and of home prices relative to market rents for the equivalent property were "the most widely cited evidence of a bubble."

But the existence of house price "bubbles" remains a controversial topic in economics. For example, Case and Shiller (2003), using housing market fundamentals as proxied by state-level Per Capita Personal Income and house price indices from Fiserv CSW for the period 1985 to 2002 , concluded that house prices in most U.S. cities reflect fundamental values. Nevertheless, additional survey data from four cities showed evidence of speculative activity. ${ }^{3}$

However, McCarthy and Peach (2004) using data from 1977 to 2003 suggested that the evidence based on common fundamental value ratios is not conclusive because these ratios ignore the dramatic decline in mortgage interest rates during the I990s and the growth in housing demand resulting from demographic shifts in the population. After controlling for recent developments in the mortgage markets, McCarthy and Peach (2004) concluded that the benefits of the decline in mortgage interest rates during the I990s offset the increases in home prices.

Himmelberg, Mayer and Sinai (2005) also examined the traditional metrics of housing market fundamentals, including the house price growth rates, price-to-income ratio, and rent-to-price ratio, and noted that the absence of interest rates in such analysis can lead to false conclusions. Their main conclusion, based on the OFHEO repeated sales housing indices from 1980 to 2004 , was that the cost of home ownership rose moderately relative to the cost of renting, even though larger deviations from fundamentals occurred in some markets. Thus, the analyses of Himmelberg, Mayer and Sinai (2005) and McCarthy and Peach (2004) supported the conclusion of Case and Shiller (2003) that prices in most U.S. housing markets appeared to be in line with market fundamentals.

A number of recent studies have explored the connection

3 In addition, Higgins and Osler (1998) provide additional evidence that regional housing bubbles occurred around 1989. 
between prices and fundamentals. For example, Brunnermeier and Julliard (2008) studied the link between inflation and house prices, mainly based on quarterly data for the U.K. from 1966 to 2004 . They examined the relations between the rent-price ratio, interest rates, and inflation. The central idea of their paper is that potential home buyers may be suffering from money illusion and take insufficient account of the fact that inflation lowers future real mortgage costs. They found that the nominal interest rate, as opposed to the real rate, affects the house price-rent ratio. After decomposing this ratio into a rational and a mispricing component, they concluded that the latter component is strongly driven by movements in inflation. In addition, Gallin (2008), using U.S. data from I970 to 2003, showed that long-horizon regressions support the use of the rent-price ratio as an indicator of housing market value. ${ }^{4}$

Other papers that studied the rent-price ratio as the yardstick for fundamental valuation are Ayuso and Restoy (2006), Zhou and Sornette (2003), Chung and Kim (2004), Black, Fraser and Hoesli (2006), Lai and van Order (2006), and Hott and Monnin (2008). In general these papers found some evidence supporting the notion that (local) housing markets can deviate from fundamentals. This conclusion is in line with the main findings of Clayton(1996), who studied the Vancou-

${ }^{4}$ The use of the rent-price ratio as a measure of price movement relative to fundamental value is motivated by the similar use of the dividend-price ratio in stock market research (e.g. Leamer, 2002; and Campbell and Shiller, 200I) ver housing market for the period from I979 to I99I.

On the theoretical front, Abreu and Brunnermeier (2003) derived a model indicating that asset bubbles can persist over substantial periods of time, even in the presence of rational arbitrageurs. In their model, the inability of arbitrageurs to coordinate selling combined with individual incentives to time the market lead to bubble persistence. A more recent theoretical model developed by Scheinkman and Xiong (2003) showed that when short sales are constrained, as is the case in the housing market, significant asset price bubbles can occur even when traders have small differences in beliefs regarding asset fundamental values.

Furthermore, Glaeser and Gyourko (2009) argue that arbitrage between the housing rental market and the owner occupied market is difficult. Rental homes tend to be very different from owner occupied ones, both in terms of location and in terms of the building itself, and households only rarely switch from the one housing type to the other. They conclude that the no arbitrage assumption is difficult to maintain in the short run.

To conclude, the current literature concerning house prices and fundamentals suggests that prices may deviate from fundamentals over longer periods of time, and that financial arbitrage between owning and renting is difficult in the short run. This suggests that it is meaningful to investigate the relation between house prices and fundamentals in the (very) long run. However, nobody has been able to investigate this issue for a time period long enough to provide di- 
rect empirical evidence of these long-run relationships: the typical time series used in the studies cover at most 40 years. In contrast, we use a data series spanning more than three centuries to analyze the long-run relation between house prices and fundamentals.

\subsection{Data}

\subsubsection{Sources and description}

We use housing market data from multiple sources covering the period from I650 through 2005. First, we use an index for Amsterdam house prices based on the same data source as Eichholtz (1997). These data are from Van Eeghen, Bisschop, and Wijnman (1976), covering the period from I650 through 1965. The dataset covers all transactions of dwellings on the Herengracht, one of the central canals in Amsterdam. As noted in Eichholtz (1997), the Herengracht was constructed between 1585 and I660. By I680, most of the lots on the canal were developed and from I6I6 until the present day, the Herengracht has remained one of the most prestigious addresses in Amsterdam. The price index is computed based on the estimated coefficients from the following model:

$$
\Delta y_{i}=\mathbf{X G}+\epsilon_{i}
$$

where $y$ is the real log house price difference between transaction pairs, $\mathbf{X}$ is a matrix of time dummy variables, $\mathbf{G}$ is a coefficient vector, and $\epsilon_{i}$ is the error term. We follow methods outlined in Bailey, Muth and Nourse (1963) and Case and Shiller (1987) to create the matrix X. Eichholtz (1997) estimated a biennial index based on housing and commercial property transaction data, and then included a dummy for property use to control for the switch from residential to commercial use. Moreover, Eichholtz (1997) used the period I634 through 1973, thus including the tails of the sample period, in which transaction data were relatively thin. We focus on the housing transactions alone, and disregard the beginning and end of the Eichholtz' (1997) sample period to compute an annual repeat sales index.

The annual average number of transactions per year is I0.9 and the standard deviation is 6.8. The annual number of transactions is relatively high in the latter half of the nineteenth century and in the twentieth century. For 1945, we do not have any transactions, and the index observation for that year is an interpolated value.

We augment this index with house price data from the CBS, the Dutch national statistics bureau, and the NVM, the national organization of Dutch realtors, covering the period from 1965 through 2005. The CBS/NVM series covers approximately 60 percent of all housing transactions in the country, with relatively more weight in the western part of the Netherlands. The numbers denote median house prices for the year.

The rental index is also constructed from multiple sources. For the first 200 years, from I650 through I850, we use data 
CHAPTER 1. HOUSE PRICES AND FUNDAMENTALS

concerning residential rents for Amsterdam from Eichholtz and Theebe (2007). This series is a repeat market rent index, based on data reported in Lesger (1986) for a broad set of rental houses, varying in location and structural quality, and owned by the institutional investors of that time: orphanages, hospitals, and poor-relief boards. In all, this dataset covers 7,670 market rent observations for I,055 properties scattered across an area that is currently the center of Amsterdam. The market rents are observed at the beginning of new rent contracts. For the period from 1650 to 1850 , the average number of annual observations is $24 . \mathrm{I}$, and the minimum is 4 .

The sample of individual rent observations could not be extended beyond I850, unfortunately, since to our knowledge no sufficient number of rent records is available in the archives for Amsterdam after that year. Thus, we use two national house rent indices from I85I. The first series covers the period I85I through I9I3 and is from van Riel (2006). In the Netherlands, tax authorities estimated the potential rental income that could be generated from owner occupied residential real estate, since the imputed rents were treated as income and taxed. The rent capacity is not a percentage of the value of house, which would make the rent index a direct function of prices. Instead, the average rent of comparable houses in the vicinity was taxed, providing information on the development of market rents. The second dataset spans the remaining period I9I4 through 2005 , and is based on a range of publications from the Dutch Central Bureau of
Figure 1.1: Consumer price index, 1650-2005

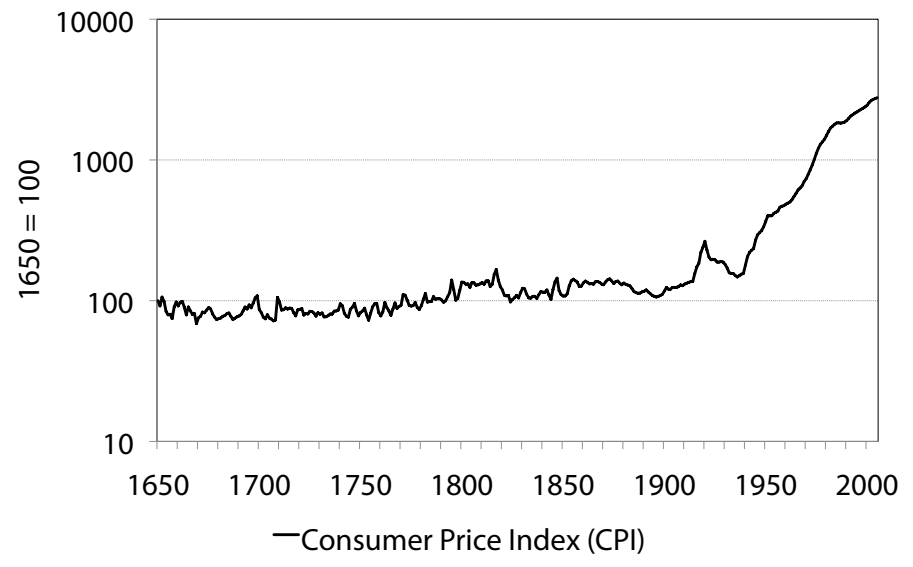

Notes: Over the first 250 years, the Dutch currency was based on gold, leading to stable consumer prices throughout the I8th and igth century. At the beginning of World War I, however, the gold standard could not be sustained anymore and money supply massively increased. As a consequence, consumer prices tripled until I9I8. In the years after the war, the banking sector suffered from the only banking crisis in its long history, caused by nonperforming loans originating from the war time. When The Netherlands returned to the gold standard in 1925 , prices gradually reverted to their historical means. In 1936, The Netherlands again had to move away from gold - and prices trended upwards since then. Graph is scaled in logarithms.

Sources: Please refer to Table I.2. 


\section{Statistics (CBS, 1939, 1948, 1999, 2008).}

Rent control was introduced in the Netherlands in $1916 / 17$, as part of a broader government policy concerning prices of basic needs. The 1916 "Distributiewet" regulated distribution and prices of basic foods, while the "Huurcommissiewet" of I9I7 introduced rent control, fixing rents at the I9I6 level, but later allowing controlled house rents to rise with inflation. Interestingly, while nominal rents had indeed been going up before that, causing public pressure for government intervention, rents in real terms had in fact been going down. Between I9I 4 and I9I6, real rents declined 22 percent. Most Dutch housing rents have been under the control of the government since then, so from I9I6 onwards the rent index mostly reflects controlled rents, and partly rents freely set in the market.

Overall, these price and rent series provide a yearly picture of the developments and growth in the Amsterdam housing market over a 355-year period from I650 to 2005 . In order to make adjustments for the cost of living, we use a long-run consumer price index, again based on different sources. Nusteling (1985) is the source for the development of the general consumer price level until I850. This index is based on a basket of consumer goods, including rye bread, beer, butter, meat, potatoes, peas, different types of fish, and various textiles. The basket changes with broad use of the products. For the period between I850 and I9I 3 we employ Van Riel (2006), who uses a similar basket of goods, and adds housing rental expenses. From I9I 4 onwards, we use the CPI calculated by the Dutch Central Bureau of Statistics.

\subsubsection{Summary Statistics}

Over the first 250 years of the sample period, the Dutch Guilder was based on gold, leading to stable consumer prices throughout the $18^{\text {th }}$ and $19^{\text {th }}$ century. At the beginning of World War I, however, the gold standard could not be sustained. The Dutch central bank tried to stabilize the exchange rate of the Guilder by maintaining stable interest rates. Nevertheless, money supply massively increased due to (still unregulated) private banks providing excessive loans to the economy. Consequently, consumer prices tripled until I9I8.

In the years after the war, many of these private bank loans defaulted resulting in a severe crisis for the Dutch banking sector. When The Netherlands returned to the gold standard in 1925 , a decade of deflation began. During this period prices gradually reverted to their historical means. However, after its main trading partners Germany and Great Britain left the gold standard, The Netherlands again moved away from gold in 1936 - and prices directly trended upwards (Hart; Jonker, and van Zanden, 1997). This was the beginning of a long period in which inflation, though not constant, became the norm.

Figures I.2 and I.3 provide graphs of the house price and rent indices, in nominal and in real terms. The graphs show that most of the increase in nominal house prices and rents occurred in the twentieth century. The indices follow each 
CHAPTER 1. HOUSE PRICES AND FUNDAMENTALS

Figure 1.2: Nominal rents and house prices, 1650-2005

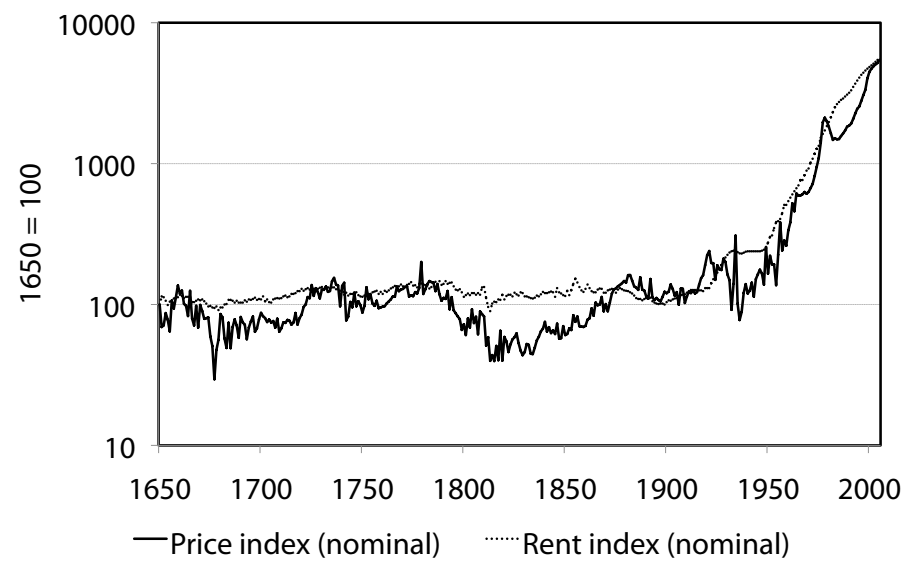

Notes: Graph is scaled in logarithms.

Sources: Please refer to Table I.2.

other closely over time, especially in their long-run movements, but often also in their year-by-year behavior. The series appear both stationary and volatile in the seventeenth and eighteenth century, showing a downward trend in the late eighteenth and early nineteenth century, and are rather stable throughout the remainder of that century.

The twentieth century is most volatile for both series, with large swings in real rents and prices, especially during the two world wars and in the inter-war period. Ironically, a
Figure 1.3: Real rents and house prices, $1650-2005$

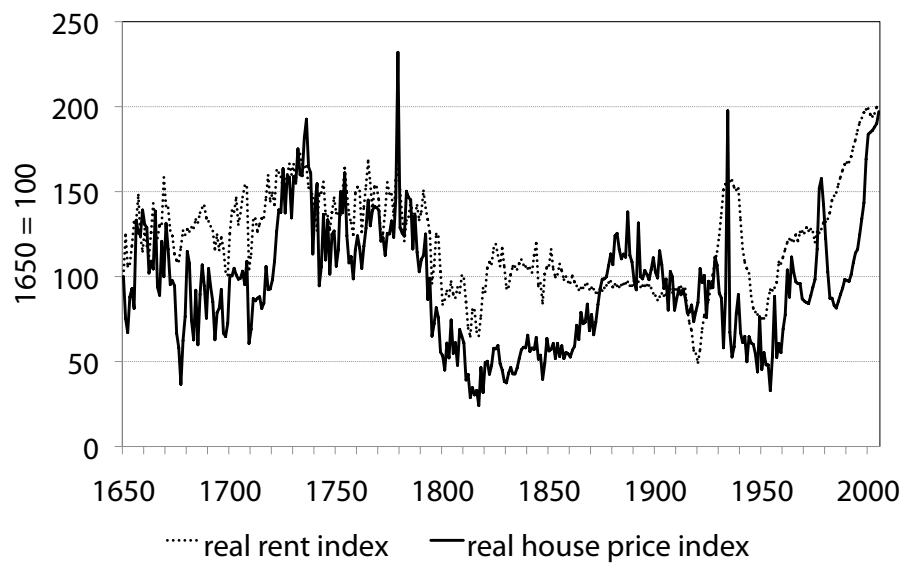

Notes: Neither the real price nor the real rent index increases dramatically in 355 years. The real price and rent indices, starting both at 100 in 1650 , reach respective levels of I97.I and 203.2 in 2005. However, for most of the sample period the indices vary around Ioo. The upward climb of real rents and house prices started only in the I950s, and they have now both reached the highest levels in history.

Sources: Please refer to Table I.2. 
government measure aimed at keeping rents at stable levels is the cause for the high volatility in real rents. In I9I7, the Dutch government fixed rents in the lower and middle housing market segments to I9I6 levels. Due to high inflation at the end of World War I, these fixed nominal rents resulted in a severe drop in real rents, before a period of deflation, caused by a return to the gold standard, drove real rents up to unprecedented levels (Nijssen, 2000). In I934, real rents peaked at 3 times their I9I8 level. It is interesting to observe that, although rent regulation was officially suspended in the period from 1927 through 1940, rents did not adjust downward despite the Dutch government's policies to deflate wages and prices. During the German occupation, rents were again fixed. After World War II rents stayed highly regulated with maximum annual increases being determined by law - a system still in place today. This has coincided with the longest consistent rise in the level of real rents in Amsterdam's history.

In sum, the year I916 can be seen as the beginning of a new regime. Before, rents were determined by the market and remained relatively constant in real terms. With substantial governmental intervention thereafter, rents developed very smoothly in nominal terms but displayed high volatility in real terms.

Real house prices appear more volatile than rents, with periods of large fluctuations when rents are stable. For example, in the early I670s, a very volatile decade for the Dutch republic, rents declined, but prices fell much further. Another example is the large peak in house prices around 1780 , which corresponds to the fourth Anglo-Dutch war(Eichholtz, I997). Also a notable price movement occurs in the late 1970s and early I980s. At the time the Dutch housing market experienced a house price bubble followed by a bust, but rents remained stable, as Figure I. 3 shows.

The second striking observation from Figure I. 3 is that neither the real price nor the real rent index increases dramatically in 355 years. The real price and rent indices, starting both at 100 in 1650 , reach respective levels of I97.I and 203.2 in 2005. However, for most of the sample period the indices vary around Ioo. The upward climb of real rents and house prices only started in the I950s; they have now both reached their highest levels ever.

Shiller (2007) provides an interesting comparison of our Netherlands price index with indexes for Norway and the U.S. over the period 1890 to 2010 . His analysis reveals that real prices in The Netherlands and Norway have substantially higher volatility than prices in the U.S. However, it is interesting to note that the three indices clearly show significant real price appreciation during the last decade such that by 2010 , real house prices in these countries are significantly higher than their respective long-term mean.

Besides house rents, we also use the market interest rate as a fundamental. Unfortunately, we do not have a single source covering the complete 355-year sample of housing market data, thus we combine several sources that allow us to go back to 1783 . For the period 1783 through 1795 , we calculate 
bond yields on the basis of information regarding prices and coupons for bonds issued by the Province of Holland as stated in van Zanden (2000). From I796 through I8I3, we rely on price-quotes of interest bearing government bonds issued by the Treasury of the City of Amsterdam, as provided by the official price list of the Amsterdam Stock Exchange.

In I8I4, the debt of the Dutch government was restructured, and in that year, a perpetual government bond was issued. Two more perpetual bonds were issued in I900. We use the government yield index created by Eichholtz and Koedijk (1996) on the basis of these bonds for the period from I8I4 through 1955. Since the Dutch government has been buying back these bonds in the last decades, their current market prices no longer reflect market interest rates, and therefore, we augment this data with a series of long government bond yields from the Central Bureau of Statistics (CBS) from 1956 onward. The nominal bond yields (Figure I.4) show two periods of relatively high yields: the Napoleonic era, and the second half of the twentieth century. In I8I3, the Dutch government defaulted requiring a restructuring of its government debt. As a result, the default risk premium on Dutch government debt rose substantially at that time. However, since then the Dutch government has never defaulted on its debt, resulting in a gradual decline in the default risk premium. The high yields observed beginning in the late I960s reflect an increasing inflation premium resulting from inflationary pressures in the I960s and I970s. The peak in interest rates reflects the Dutch government's monetary policy actions for
Figure 1.4: Nominal bond yields, 1783-2005

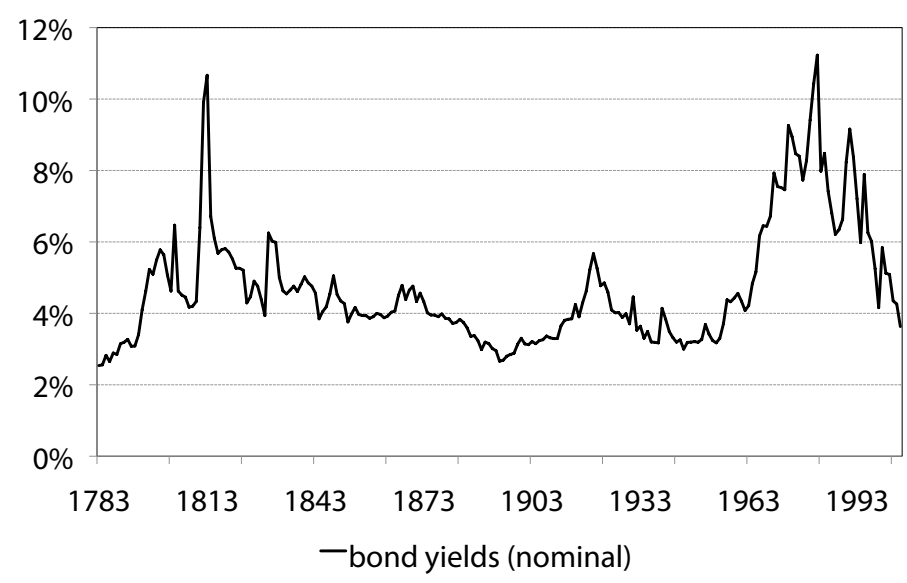

Sources: Please refer to Table I.2.

fighting inflation in 1980-1982. The implementation of those policies resulted in a significant reduction in inflation, and has led to a gradual reduction in the inflation risk premium.

Table I.I shows the mean annual change and volatility of house prices, rents, bond yields, and consumer prices over the period from I650 through 2005. We also provide this information for various sub-periods identified as having similar demographic and economic conditions in the city of Amsterdam. The majority of the growth in prices and rents oc- 
curred in the decades after World War II. In the period before that, including two world wars and the Great Depression, real house prices and rents fluctuated more than in any of the other sub-periods. Inflation during and directly after World War I first halved real values, followed by a unique period of deflation that led both prices and rents to peak in the I93os. The sub-period that had the strongest decline in real house prices and rents was from I78I to I8I4, which was the only extended period in Amsterdam's recorded history with a consistently declining population. This period saw real prices decline on average by approximately 3.9 percent per year (or -0.0385 in logarithmic terms). In contrast to bubble periods, we see a 33-year period of sustained price declines, implying a market implosion. Interestingly real rents decline also, but at a slower I.9 percent per year (or-0.0I86 in logarithms) pace. This evidence clearly contradicts the popular perception that housing prices only go up, and that even if they do go down, it will only be for short periods.

Regarding the interest rate, two striking features are evident in Table I.I. First is the very high real interest rate from I8I5 through I850. During this period, the real interest rate averaged over 5 percent per year. This period followed a sustained economic and political crisis, which resulted in a restructuring of government debt. As a result, Dutch government debt was probably not regarded as risk-free. The second striking feature is the extremely low real interest rate for the post-World War II period. We find an average interest rate of 0.24 percent between 1946 and 1973 .
Table I.2 provides more information regarding the statistical behavior of the indices and sub-indices. This table gives sources for each of the indices and their components, and also provides nominal means, standard deviations, and percentiles. These statistics show substantial differences between sub-indices, so the question is whether this is caused by differences in measurement, or by the fact that the subindices reflect different time periods and market regimes. We calculated the same statistics for sub-periods before and after the break points between sub-indices.

Concerning house prices, the statistical moments of the 1965-2005 sub-index differ strongly from those of the I650I965 index. However, the mean and standard deviation for house price changes between 1945 and 1965 are 0.065 and 0.300 , respectively. This mean lies very close to the one for the 1965-2005 period, which suggests that this shift in means in not caused by the index break point, but by real underlying changes in the economy. For example, inflation became a structural factor after the Second World War, which is likely to have been a cause of higher nominal mean house prices. On the other hand, the standard deviation between 1945 and I965 is much higher than in the subsequent period, possibly reflecting measurement error of the index, and the fact that the level of aggregation switches from a canal in Amsterdam to the country as a whole.

For rents, Table I.2 shows that the standard deviations for each of the three sub-indices are in the same range. When looking at smaller sub-periods around index change points, 
CHAPTER 1. HOUSE PRICES AND FUNDAMENTALS

Table 1.1: Amsterdam's housing market throughout the centuries

\begin{tabular}{|c|c|c|c|c|c|}
\hline Period & Period characterization & $\Delta_{1} \ln$ (Price) & $\Delta_{1} \ln ($ Rent $)$ & In(bond yields) & $\Delta_{1} \ln (C P I)$ \\
\hline $1650-2005$ & - & $\begin{array}{c}0.0116 \\
(0.1973)\end{array}$ & $\begin{array}{c}0.0111 \\
(0.0434)\end{array}$ & $\begin{array}{c}0.0457 \\
(0.0158)\end{array}$ & $\begin{array}{c}0.0096 \\
(0.0688)\end{array}$ \\
\hline $1650-1670$ & $\begin{array}{l}\text { Strong economy, } \\
\text { rapid urbanization, expanding city }\end{array}$ & $\begin{array}{c}0.0054 \\
(0.2676)\end{array}$ & $\begin{array}{c}0.0007 \\
(0.0479)\end{array}$ & - & $\begin{array}{r}-0.0081 \\
(0.1045)\end{array}$ \\
\hline $1671-1720$ & $\begin{array}{l}\text { Economic slowdown, } \\
\text { slow population growth }\end{array}$ & $\begin{array}{l}-0.0032 \\
(0.2058)\end{array}$ & $\begin{array}{c}0.0037 \\
(0.0302)\end{array}$ & - & $\begin{array}{c}0.0027 \\
(0.0797)\end{array}$ \\
\hline $1721-1780$ & $\begin{array}{l}\text { Economic slowdown, } \\
\text { stable population }\end{array}$ & $\begin{array}{c}0.0056 \\
(0.1719)\end{array}$ & $\begin{array}{c}0.0013 \\
(0.0327)\end{array}$ & - & $\begin{array}{c}0.0011 \\
(0.0731)\end{array}$ \\
\hline $1781-1814$ & $\begin{array}{l}\text { Economic crisis, } \\
\text { shrinking population }\end{array}$ & $\begin{array}{l}-0.0293 \\
(0.1911)\end{array}$ & $\begin{array}{l}-0.0094 \\
(0.0620)\end{array}$ & $\begin{array}{c}0.0449 \\
(0.0181)\end{array}$ & $\begin{array}{c}0.0092 \\
(0.0812)\end{array}$ \\
\hline $1815-1850$ & $\begin{array}{l}\text { Stabilizing economy, } \\
\text { modest population growth }\end{array}$ & $\begin{array}{c}0.0091 \\
(0.1808)\end{array}$ & $\begin{array}{c}0.0034 \\
(0.0434)\end{array}$ & $\begin{array}{c}0.0483 \\
(0.0061)\end{array}$ & $\begin{array}{l}-0.0043 \\
(0.0834)\end{array}$ \\
\hline $1851-1913$ & $\begin{array}{l}\text { Strong economy, } \\
\text { increasing population }\end{array}$ & $\begin{array}{l}0.0116 \\
(0.1219)\end{array}$ & $\begin{array}{c}0.0016 \\
(0.0396)\end{array}$ & $\begin{array}{c}0.0361 \\
(0.0051)\end{array}$ & $\begin{array}{c}0.0038 \\
(0.0339)\end{array}$ \\
\hline $1914-1945$ & $\begin{array}{l}\text { Turmoil economy, } \\
\text { stable population }\end{array}$ & $\begin{array}{c}0.0082 \\
(0.3118)\end{array}$ & $\begin{array}{c}0.0196 \\
(0.0300)\end{array}$ & $\begin{array}{c}0.039 \\
(0.0066)\end{array}$ & $\begin{array}{c}0.0212 \\
(0.0767)\end{array}$ \\
\hline 1946-1973 & $\begin{array}{l}\text { Economy very strong, } \\
\text { increasing population }\end{array}$ & $\begin{array}{c}0.0573 \\
(0.2597)\end{array}$ & $\begin{array}{c}0.0571 \\
(0.0382)\end{array}$ & $\begin{array}{c}0.0463 \\
(0.0152)\end{array}$ & $\begin{array}{c}0.0439 \\
(0.0272)\end{array}$ \\
\hline $1974-2005$ & $\begin{array}{l}\text { Strong economy, } \\
\text { increasing population }\end{array}$ & $\begin{array}{c}0.0594 \\
(0.0913)\end{array}$ & $\begin{array}{c}0.0484 \\
(0.0241)\end{array}$ & $\begin{array}{c}0.0689 \\
(0.0177)\end{array}$ & $\begin{array}{c}0.0344 \\
(0.0253)\end{array}$ \\
\hline
\end{tabular}

Notes: This table provides means and standard deviations (in brackets) of changes in the natural logarithms of nominal house prices and house rents, as well as the nominal interest rate and the consumer price index (CPI). Separation between periods is based on the economic development of Amsterdam, population growth, and city expansion. Interest rates are available for the period I796-2005. See Table I.2 for index sources. For period demarcations see De Vries (I984), Van Zanden (1994), Spies et al (I993), De Vries and Van der Woude (I995). 
we also observe that standard deviations do not change much. For example, Table I.I reports that the standard deviation of rent changes for $185 \mathrm{I}-\mathrm{I} 9 \mathrm{I} 3$ is 0.0396 , while it is 0.0300 for I9I4-1945. The mean nominal rent change is much higher for the period between I9I 4 and 2005. This is mostly caused by inflation. This suggests that the statistical behavior of our rent indices changes because of underlying changes in the economic situation rather than as an artifact of different measurement methods.

\subsection{House prices and fundamentals}

In the first step of our analysis we investigate the price-rent ratio in order to calculate potential price deviations from market fundamentals. Figure I. 5 shows the Amsterdam rentprice ratio for our complete sample period, as well as its average over that period. Obviously, when house prices are high relative to housing rents, the rent-price ratio is low. Thus, many market observers conclude that a rent-price ratio far below its historical average indicates that asset prices have increased beyond fundamental values (i.e. housing rents) suggesting a possible bubble in the housing market.

While the rent-price ratio is a measure of house prices relative to fundamentals, it does not give a complete picture of the housing market. For example, the period I78I through I8I5 saw a dramatic rise in the rent-price ratio from 4.6 percent to II.4 percent, suggesting that prices decreased relative
Figure 1.5: Rent-price ratio, 1650-2005

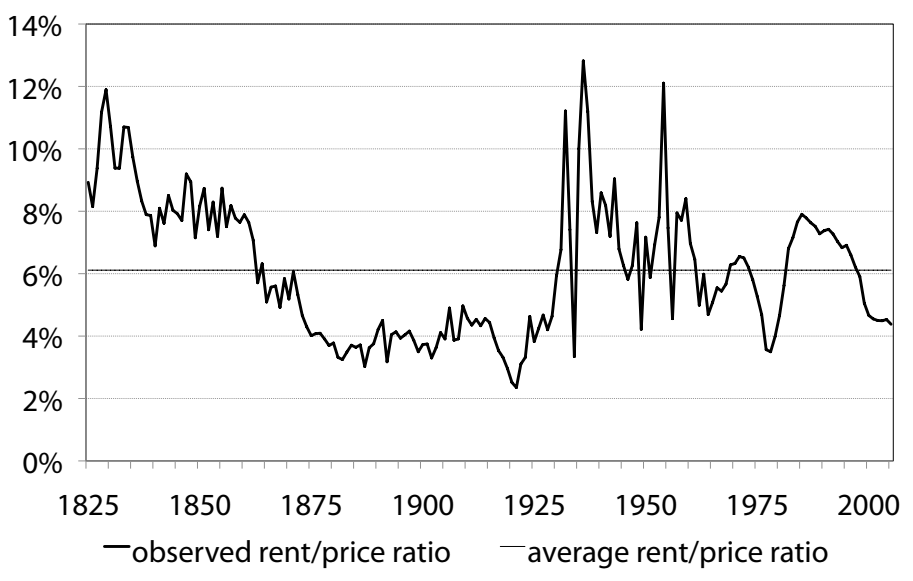

Notes: Information on both rents and prices are available for only very few houses and years at the same time in our sample, so we do not observe the rent-price ratio directly. We therefore rescale the aggregated rent-price ratio based on the rent and house price indices to 4.5 percent in 200I, which is the annual rental yield direct return on Dutch residential real estate as stated in the ROZ/IPD index for this year (ROZ, 2OO7). 
CHAPTER 1. HOUSE PRICES AND FUNDAMENTALS

Table 1.2: Description of data sources and selected time series properties for (sub-)indices

\begin{tabular}{|c|c|c|c|c|c|c|c|}
\hline Index & Years & Scope & Source & Mean & Std. & $5^{\text {th }} P$ & $95^{\text {th }} P$. \\
\hline \multicolumn{4}{|c|}{ House prices } & \multicolumn{4}{|c|}{$\Delta_{1} \ln ($ price index $)$} \\
\hline & $1650-1965$ & Herengracht A'dam & Eichholtz (1997) & 0.0060 & 0.2067 & -0.3400 & 0.3450 \\
\hline & $1965-2005$ & National & NVM (2008) & 0.0555 & 0.0843 & -0.0981 & 0.2187 \\
\hline \multirow[t]{4}{*}{ Rents } & & & & \multicolumn{4}{|c|}{$\Delta_{1} \ln ($ rent index $)$} \\
\hline & $1650-1850$ & Amsterdam & Eichholtz \& Theebe (2007) & 0.0004 & 0.0419 & -0.0678 & 0.0564 \\
\hline & $1850-1913$ & Amsterdam & Van Riel (2006) & 0.0016 & 0.0394 & -0.0629 & 0.0842 \\
\hline & $1914-2005$ & National & CBS $(1993 ; 1948 ; 1999 ; 2008)$ & 0.0411 & 0.0345 & -0.0062 & 0.0982 \\
\hline \multirow[t]{5}{*}{ Bond } & & & & \multicolumn{4}{|c|}{$\ln$ (bond yields) } \\
\hline & 1783-1795 & Province of Holland & $\begin{array}{l}\text { Own calc. based on van Zanden } \\
(2000)\end{array}$ & 0.0300 & 0.0040 & 0.0251 & 0.0402 \\
\hline & $1796-1813$ & Amsterdam & $\begin{array}{l}\text { Amsterdam Stock Exchange Offi- } \\
\text { cial Price List }\end{array}$ & 0.0546 & 0.0171 & 0.0409 & 0.1014 \\
\hline & 1814-1955 & National & Eichholtz \& Koedijk (1996) & 0.0398 & 0.0080 & 0.0295 & 0.0556 \\
\hline & 1956-2005 & National & CBS (2010b) & 0.0636 & 0.0177 & 0.0400 & 0.0899 \\
\hline \multicolumn{4}{|c|}{ Consumer price index (CPI) } & \multicolumn{4}{|c|}{$\Delta_{1} \ln (\mathrm{CPI})$} \\
\hline & $1650-1850$ & Amsterdam & Nusteling (1985) & 0.0009 & 0.0810 & -0.1261 & 0.1301 \\
\hline & 1850-1899 & Amsterdam & Van Riel (2006) & 0.0001 & 0.0356 & -0.0455 & 0.0543 \\
\hline & $1900-2005$ & National & CBS (2010a) & 0.0304 & 0.0479 & -0.0387 & 0.1080 \\
\hline
\end{tabular}

Notes: All numbers in nominal terms. 
to rents. However, during this period, rents and prices both declined at relatively similar rates: -3.9 percent and -I.9 percent, respectively. Thus, even with this small difference in relative declines, the rent-price ratio changed substantially.

In addition, another important observation to be made from Figure I. 5 is that the rent-price ratio has deviated from its long-run average for substantial periods of time. For example, the ratio is below the long-run average for most of the eighteenth century, and above it for the first 60 years of the nineteenth century. Clearly, the graph suggests that a deviation of the rent-price ratio from its own average is not a guarantee for a quick reversion to the average. In the last 75 years, the ratio has been rather volatile, especially so during the middle decades of the twentieth century. We note that in the last 20 years, the Amsterdam rent-price ratio has declined, but still remains within historical range. ${ }^{5}$

Our analysis builds on the methods employed by Campbell and Shiller (I988 and 200I), Brunnermeier and Julliard (2008), and Campbell et al (2009). This approach is based on the present value model: the former two papers have dividends and interest rates as the fundamentals underlying stock prices, whereas the latter two papers use rents and interest rates as fundamentals for house prices. Of course underlying dividends, rents and interest rates are them-

${ }^{5} \mathrm{We}$ formally test for the presence of unit roots in the rent and price indices. The Dickey-Fuller test statistics are reported in the appendix. They indicate that both series contain unit roots and are thus non-stationary. The first differences, however, are stationary. selves resting on deeper foundations, like economic development, demographics, technological change, and wars and other disasters. However, the method used by these authors assumes that interest rates and rents (or dividends) capture those fundamentals. As in Campbell et al (2009), we define the gross return on housing $\left(R_{h}\right)$ over the period from $t$ to $t+1$ as a function of the price of housing $(P)$ and the rental payment $(L)$ :

$$
R_{h, t+1}=\frac{P_{t+1}+L_{t+1}}{P_{t}}
$$

Taking logs and assuming the rent-price ratio is stationary, we can express $(2)$ as

$$
l_{t}-p_{t}=k+E_{t}\left[\sum_{j=0}^{\infty} \rho^{j} r_{h, t+1+j}-\sum_{j=0}^{\infty} \rho^{j} \Delta l_{t+1+j}\right]
$$

where $r_{h, t}$ is the log return to housing, $p_{t}$ is the log house price, $l_{t}$ is the log rent, $\Delta l_{t+1}$ is $l_{t+1}-l_{t}, \rho$ is defined as $\frac{1}{1+e^{(l-p)}}$ with $(\overline{l-p})$ the long-run average rent-price ratio, and $k$ is a constant of linearization that equals $(1-\rho)^{-1}[\ln (\rho)+(1-$ $\left.\rho) \ln \left(\frac{1}{\rho-1}\right)\right]$. Campbell et al (2009) show that by defining the return to housing as a function of an interest rate and a risk premium $\left(r_{h}=i+\pi_{h}\right)$, the rent-price ratio can be decomposed into three components consisting of the discounted expected future real interest rates, the discounted expected 
future rent growth, and the discounted housing risk premium. Thus, the rent-price ratio is expressed as:

$$
\begin{aligned}
l_{t}-p_{t}=k+\sum_{\tau=1}^{\infty} \rho^{\tau-1} \hat{E}_{t}\left[i_{t+\tau}\right] & +\sum_{\tau=1}^{\infty} \rho^{\tau-1} \hat{E}_{t}\left[\pi_{h, t+\tau}\right] \\
& -\sum_{\tau=1}^{\infty} \rho^{\tau-1} \hat{E}_{t}\left[\Delta l_{t+\tau}\right]
\end{aligned}
$$

where $\hat{E}_{t}$ is the conditional expectation computed from a $\tau$ period VAR forecast.

For each year between 1785 and 2005 , we compute $l_{t}-p_{t}$ using the Amsterdam house price and rent indices scaled to the 2002 ratio of 4.5 percent. ${ }^{6}$ At each period $t$, we calculate the average rent-price ratio over the prior 40-years $(t-1$ to $t-40)$ as an approximation of $(\overline{l-p})$. We then calculate $\rho$ and $k$ for each year based on our $(\overline{l-p})$ approximation. We approximate the discounted expected future rent growth, discounted expected future housing risk premium, and discounted expected real interest rate in (4) for each year $t$ based on 40-year forecasts for each variable obtained from the maximum likelihood estimation of a VAR(I) model over

${ }^{6}$ We cannot observe the rent-price ratio directly, as information on both rents and prices are available for only very few houses and years at the same time in our sample. We therefore rescale the aggregated rent-price ratio based on indices to 4.5 percent in 200I, which is the rental yield for that year on Dutch residential real estate as stated in the ROZ/IPD index for this year (ROZ, 2007). We find our results to be robust for different scales. the period $t-1$ to $t-40$. We chose a lag of I based on the Schwarz' Bayesian Information Criterion (SBIC) for the overall data series. Besides, we checked the robustness of our results under several VAR specifications, changing the number of lags and the time period on which the VAR is based. This did not markedly change the results.

Table I. 3 gives an overview of our VAR estimation results. For I8I years (Panel A: I825-2005), we estimate VAR models based on information from a 40 year rolling window. The forecasting models cover the real interest rate $(i)$, the housing risk premium $(\Pi)$, and the change in real rents $(\Delta l)$. The first section summarizes the coefficients for the real interest rate forecast model:

$$
i_{t}=\alpha_{0}+\alpha_{i} i_{t-1}+\alpha_{\Pi} \Pi_{t-1}+\alpha_{\Delta l} \Delta l_{t-1}+\epsilon_{t},
$$

while the second section describes the housing premia forecast model:

$$
\Pi_{t}=\beta_{0}+\beta_{i} i_{t-1}+\beta_{\Pi} \Pi_{t-1}+\beta_{\Delta l} \Delta l_{t-1}+\epsilon_{t} .
$$

The results from the real rent change forecast model:

$$
\Delta l_{t}=\gamma_{0}+\gamma_{i} i_{t-1}+\gamma_{\Pi} \Pi_{t-1}+\gamma_{\Delta l} \Delta l_{t-1}+\epsilon_{t}
$$

are displayed in the bottom section. Columns I, 2, and 3 display the inter-quartile values for the estimated coefficients for $i_{t-1}, \Pi_{t-1}, \Delta l_{t-1}$, respectively. Column 4 displays the results of the Wald test that none of the included regressors explains the dependent variable and the last column shows the distribution of the $R^{2}$ measure of model fit. 
The performance of our VAR models is surprisingly good when compared to studies based on modern data. For example, the $R^{2}$ statistics reported in Table I. 3 are about half of the values reported by Campbell et al (2009), who work with data on housing markets in U.S. metropolitan areas covering the years 1975-2007 and employ additional macro-economic variables that are not available with older data. In addition, we see that over half of the yearly estimated VAR models have Wald statistics that denote statistical significance at the 5 percent level, indicating that we can reject the null hypothesis that none of the model factors explain the dependent variable in over half of the years.

We find that the coefficients for the first lag of the variable have (on average) the highest statistical significance. Bond yields in year $t$, for instance, are mainly driven by bond yields in period $t-1$. For example, we find that 50 percent of the yearly estimated coefficients for $\alpha_{i}$ are significant at the 5 percent level. In contrast, rents and prices do not have a strong impact with 0.6 percent and 7 percent of the yearly coefficients for $\alpha_{\Delta l}$ and $\alpha_{\Pi}$ significant at the 5 percent level, respectively. In the second section of Panel A we also note that interest rates are an important factor impacting housing premia $(\Pi)$, which again is in line with previous work. For example, we see that 32 percent of the $\beta_{i}$ yearly estimated coefficients are significant at the 5 percent level. We also find that the lagged housing premium has a significant impact on the current housing premium with 78 percent of the yearly estimated coefficients for $\beta_{\Pi}$ significant at the 5 percent level.
Like Case and Shiller (1989, 1990) we find the predictability of housing returns in the opposite direction. In our data, housing excess returns are reverting to their mean, as indicated by negative coefficients for its lagged values. Throughout the centuries, the coefficients on the lagged housing premium are becoming less negative. In the last Io years of our sample, the coefficients turn positive, reconciling our findings with studies on modern data.

Table I. 3 also reports results for two sub-periods (from I825 through I9I5 and from I9I6 until 2005) to investigate the possible role of rent control in our results; the first period reflects completely free rental markets, while the other covers the regulated period. The introduction of rent control altered the predictability of changes in rents. In our "free" century (I825-1915), changes in rents were hardly predictable. For example, the coefficients for lagged values of rent changes $\left(\gamma_{\Delta l}\right)$ are negative and only significant at the 5 percent confidence level in 7 out of 9I years. In addition, the median $R^{2}$ for this model is II percent. In contrast, during the subset 1916-2005, the presence of rent control links the nominal rents to changes in CPI and thereby transmits the autoregressive properties of the inflation time series to rents. As a result, in the third section of Panel $C$ we note that the coefficients for lagged changes in rents $\left(\gamma_{\Delta l}\right)$ become positive and statistically more significant with 29 percent of the yearly coefficients being statistically significant at the 5 percent level. Furthermore, the median $R^{2}$ for this model increases to 33 percent. 
CHAPTER 1. HOUSE PRICES AND FUNDAMENTALS

Table 1.3: Summary of VAR estimation results

\begin{tabular}{|c|c|c|c|c|c|c|}
\hline \multirow[t]{2}{*}{ Dependent variable } & & \multicolumn{3}{|c|}{ Coefficient estimates } & \multirow{2}{*}{$\begin{array}{l}\text { p-value } \\
\text { (Wald) }\end{array}$} & \multirow[t]{2}{*}{$R^{2}$} \\
\hline & & $i_{t-1}$ & $\Pi_{t-1}$ & $\Delta l_{t-1}$ & & \\
\hline \multicolumn{7}{|l|}{ Panel A: 1825-2005 } \\
\hline \multirow[t]{4}{*}{$i_{t}$} & 25th percentile & 0.344 & -0.049 & -0.137 & 0 & 0.127 \\
\hline & Median & 0.459 & -0.015 & 0.016 & 0.007 & 0.235 \\
\hline & 75th percentile & 0.577 & 0.002 & 0.095 & 0.121 & 0.332 \\
\hline & Frac. of years sig. at $5 \%$ & 0.503 & 0.072 & 0.006 & 0.564 & NA \\
\hline \multirow[t]{4}{*}{$\Pi_{t}$} & 25th percentile & -1.531 & -0.529 & -0.021 & 0 & 0.118 \\
\hline & Median & -1.120 & -0.399 & 0.318 & 0.008 & 0.229 \\
\hline & 75th percentile & -0.577 & -0.304 & 0.867 & 0.148 & 0.340 \\
\hline & Frac. of years sig. at $5 \%$ & 0.320 & 0.779 & 0.155 & 0.613 & NA \\
\hline \multirow[t]{4}{*}{$\Delta l_{t}$} & 25th percentile & 0.062 & -0.053 & -0.214 & 0 & 0.103 \\
\hline & Median & 0.194 & -0.018 & 0.03 & 0.035 & 0.177 \\
\hline & 75th percentile & 0.379 & 0.016 & 0.438 & 0.204 & 0.331 \\
\hline & Frac. of years sig. at $5 \%$ & 0.127 & 0.133 & 0.182 & 0.519 & NA \\
\hline \multicolumn{7}{|l|}{ Panel B: 1825-1915 } \\
\hline \multirow[t]{4}{*}{$i_{t}$} & 25th percentile & 0.295 & -0.112 & -0.241 & 0.066 & 0.107 \\
\hline & Median & 0.366 & -0.048 & -0.115 & 0.119 & 0.128 \\
\hline & 75th percentile & 0.469 & -0.023 & 0.041 & 0.187 & 0.153 \\
\hline & Frac. of years sig. at $5 \%$ & 0.484 & 0.088 & 0.011 & 0.154 & NA \\
\hline \multirow[t]{4}{*}{$\Pi_{t}$} & 25th percentile & -1.281 & -0.577 & 0.128 & 0 & 0.232 \\
\hline & Median & -0.858 & -0.522 & 0.343 & 0.001 & 0.286 \\
\hline & 75th percentile & -0.366 & -0.396 & 0.839 & 0.007 & 0.394 \\
\hline & Frac. of years sig. at $5 \%$ & 0.429 & 0.967 & 0.264 & 0.912 & NA \\
\hline \multirow[t]{4}{*}{$\Delta l_{t}$} & 25th percentile & -0.005 & -0.116 & -0.26 & 0.070 & 0.095 \\
\hline & Median & 0.171 & -0.048 & -0.18 & 0.169 & 0.112 \\
\hline & 75th percentile & 0.440 & 0.052 & -0.049 & 0.239 & 0.15 \\
\hline & Frac. of years sig. at $5 \%$ & 0.165 & 0.253 & 0.077 & 0.187 & NA \\
\hline
\end{tabular}


CHAPTER 1. HOUSE PRICES AND FUNDAMENTALS

\begin{tabular}{llrrrrr}
\hline \multirow{2}{*}{ Dependent variable } & & \multicolumn{2}{c}{ Coefficient estimates } & p-value & $R^{2}$ \\
& & $i_{t-1}$ & $\Pi_{t-1}$ & $\Delta l_{t-1}$ & (Wald) & \\
\hline Panel C: 1916-2005 & & & & & & \\
\hline$i_{t}$ & 25th percentile & 0.441 & -0.013 & -0.021 & 0 & 0.267 \\
& Median & 0.537 & -0.003 & 0.047 & 0 & 0.327 \\
& 75th percentile & 0.641 & 0.018 & 0.118 & 0.002 & 0.431 \\
& Frac. of years sig. at 5\% & 0.522 & 0.056 & 0 & 0.978 & NA \\
\hline$\Pi_{t}$ & 25th percentile & -2.268 & -0.401 & -0.122 & 0.018 & 0.096 \\
& Median & -1.391 & -0.309 & 0.185 & 0.138 & 0.121 \\
& 75th percentile & -0.810 & -0.236 & 1.078 & 0.233 & 0.202 \\
& Frac. of years sig. at 5\% & 0.211 & 0.589 & 0.044 & 0.311 & $\mathrm{NA}$ \\
\hline \multirow{2}{*}{$\Delta l_{t}$} & 25th percentile & 0.086 & -0.03 & 0.105 & 0 & 0.252 \\
& Median & 0.197 & -0.005 & 0.438 & 0 & 0.331 \\
& 75th percentile & 0.320 & 0.009 & 0.529 & 0.004 & 0.407 \\
& Frac. of years sig. at 5\% & 0.089 & 0.011 & 0.289 & 0.856 & NA \\
\hline
\end{tabular}

Notes: For I8I years (I825-2005), we estimate a VAR model based on information from a 40 year rolling window. The forecasting models cover the real interest rate $i$, the housing risk premium $\Pi$, and the change in real rents $\Delta l$. The first panel summarizes the coefficients on the real interest rate forecast model $i_{t}=$ $\alpha_{0}+\alpha_{i} i_{t-1}+\alpha_{\Pi} \Pi_{t-1}+\alpha_{\Delta l} \Delta l_{t-1}+\epsilon_{t}$, while the second panel describes the housing premia forecast model $\Pi_{t-1}=\beta_{0}+\beta_{i} i_{t-1}+\beta_{\Pi} \Pi_{t-1}+\beta_{\Delta l} \Delta l_{t-1}+\epsilon_{t}$. The results from the real rent change forecast model $\Delta l_{t-1}=\gamma_{0}+\gamma_{i} i_{t-1}+\gamma_{\Pi} \Pi_{t-1}+\gamma_{\Delta l} \Delta l_{t-1}+\epsilon_{t}$ are displayed in the bottom panel. Column 4 displays the results of the Wald test that none of the included regressors explains the dependent variable. The last column shows the distribution of the $R^{2}$ measure of model fit. 


\section{CHAPTER 1. HOUSE PRICES AND FUNDAMENTALS}

Based on our estimates of the fundamental values driving the rent-price ratio, we calculate the pricing error as

$$
\epsilon_{t}=\left(l_{t}-p_{t}\right)-\left(\tilde{k}_{t}+\tilde{i}_{t}+\tilde{\pi}_{t}-\tilde{\Delta l}_{t}\right)
$$

where $\tilde{k}_{t}, \tilde{i}_{t}, \tilde{\pi}_{t}, \tilde{\Delta l}_{t}$ denote our calculated approximations of the constant of linearization, the future real rate, future housing risk premium, and future rental growth, respectively. This pricing error represents the price deviations from fundamentals and is the focus of our subsequent analysis.

Figure I.6 shows that the theoretical rent-price ratio based on fundamentals follows the actual rent-price ratio through time. The correlation between annual changes of observed and fundamental rent-price ratios is o.I9. However, the estimated correlations increase for shorter intervals. For example, over the period prior to I916 the correlation between the observed and fundamental rent-price ratios is 0.56 . However, in the second period (1916-2005), the correlation drops to -o.II. As a result, we see that the fundamentals-based ratio is less volatile during the crisis years of the inter-bellum, both in year to year changes and in long-term swings.

Figure I.7 depicts the difference between the rent-price ratio and its theoretical counterpart. This graph shows that prices (or rents) can deviate from fundamentals for extended periods of time. For example, throughout the second half of the $19^{\text {th }}$ century, the pricing error was continuously negative, indicating that actual rents were lower or the actual prices
Figure 1.6: Rent-price ratio and theoretical counterpart based on fundamentals

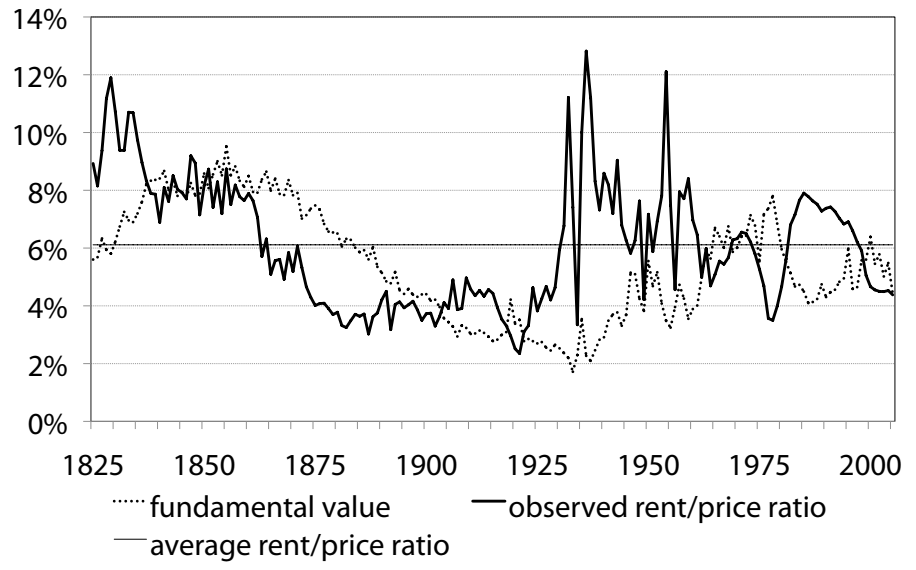

Notes: The theoretical rent-price ratio is expressed as

$l_{t}-p_{t}=k+\sum_{\tau=1}^{\infty} \rho^{\tau-1} \hat{E}_{t}\left[i_{t+\tau}\right]+\sum_{\tau=1}^{\infty} \rho^{\tau-1} \hat{E}_{t}\left[\pi_{h, t+\tau}\right]-\sum_{\tau=1}^{\infty} \rho^{\tau-1} \hat{E}_{t}\left[\Delta l_{t+\tau}\right]$

where $r_{h, t}$ is the log return to housing, $p_{t}$ is the log house price, $l_{t}$ is the log rent, $\Delta l_{t+\tau}$ is $l_{t+\tau}-l_{t}, \rho$ is defined as with the long-run average rent-price ratio, and $k$ is a constant of linearization that equals $(1-\rho)^{-1}[\ln (\rho)+(1-$ $\left.\rho) \ln \left(\frac{1}{\rho-1}\right)\right] . \hat{E}_{t}$ is the conditional expectation computed from a $\tau$-period VAR forecast 
higher than predicted by our model. Starting with World War I, a period of financial turbulences left its mark both on the actual rent-price ratio and on its fundamental counterpart. During World War I, The Netherlands first experienced a period of strong inflation, followed by deflation in the early I920s and during the early I930s, again followed by inflation in the late I930s and I940s. For both series, volatility shoots up, caused by huge swings in house prices and inflation. ${ }^{7}$ In these uncertain times, house prices seem to be more depressed than fundamentals suggest, indicating that investors attached a substantial discount to long term investments like housing.

Throughout the second half of the twentieth century the magnitude of the mispricing declines as the distortions from the turbulent (inter)war periods fade out. Alternating periods of relative over-/underpricing of homes with regard to fundamentals can be observed. For example, in the I970s, home prices appreciate much more than suggested, as low after-tax mortgage costs diminished in real terms through high inflation. This bubble lasts for a few years only. Residential real estate investors' exuberance tips over when real interest rates increase sharply in the I980s as the targeting of inflation becomes a prime concern of the monetary policy. The rent-price ratio not only returns to its fundamental value, but overshoots in the following years, indicat-

${ }^{7}$ In the actual rent-price ratio series, the direct impact of changes in the CPI cancels out. Expectations on future changes, however, are still incorporated into prices and to a lesser extent into rents.
Figure 1.7: Rent-price ratio error $\epsilon$ in logs, 1825-2005

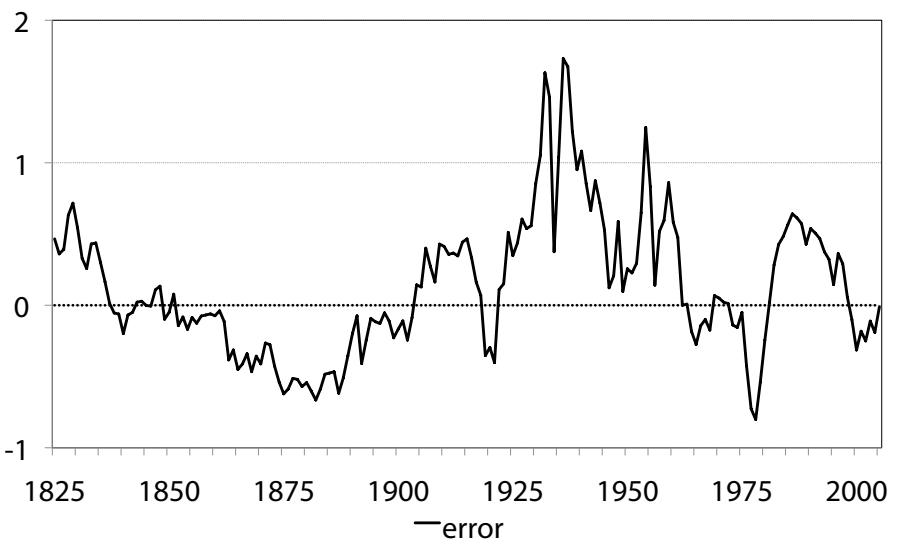

Notes: The rent-price ratio error represents the price deviations from fundamentals and is calculated as

$$
\epsilon_{t}=\left(l_{t}-p_{t}\right)-\left(\tilde{k_{t}}+\tilde{i_{t}}+\tilde{\pi_{t}}-\tilde{\Delta l_{t}}\right),
$$

Where $\tilde{k_{t}}, \tilde{i_{t}}, \tilde{\pi_{t}}, \tilde{\Delta l_{t}}$ denote our calculated approximations of the constant of linearization, the future real rate, future housing risk premium, and future rental growth, respectively. 
ing depressed market sentiments. From 1993 onwards, the rent-price ratio remains constantly below its fundamental counterpart, which suggests that the steep increase in house prices in the last decade may not be sustainable in the longer run.

\subsection{Adjustment mechanisms}

Since continuously negative or positive pricing errors have occurred over the varying time frames, the question emerges as to whether prices or rents will correct to eliminate the mispricing. Step three of our analysis deals with this question and investigates the rent-price ratio adjustment mechanism.

Following Gallin (2008), we estimate the following vector error correction model:

$$
\Delta y_{t}=\mathbf{A}_{\mathbf{o}} y_{t-1}+\mathbf{\mathbf { A } _ { \mathbf { r } }} \Delta y_{t-1}+\mathbf{A} x_{t-1}+\eta_{t}
$$

where $y_{t}$ is defined as $(\ln (R) \ln (P))^{\prime}$, and $x_{t-1}$ includes exogenous variables influencing $\Delta y_{t}$. Matrix $\mathbf{A}_{\mathrm{o}}$ represents the product of the cointegration vector and the matrix containing the error correction coefficients (Gallin 2008). We formally test for the existence of a cointegration vector for the price and rent series and whether it is different from (I - I). We find no evidence for the cointegration vector to differ from (I -I), which is in line with theory and allows for a more efficient estimation of the model. Since a positive (negative) error correction coefficient for prices implies that prices will decrease (increase) when the current rent-price ratio is low relative to the long run average, and vice versa for rents: a positive coefficient suggests falling (increasing) rents when the rent-price ratio is relatively low (high).

Table I.4 reports the estimated error correction coefficients for the full time-period as well as the rent-controlled (1916-2005) and non-regulated (1650-1915) periods. In general, we see that the error correction coefficients for prices are statistically and economically more significant than the coefficients for rents. For example, the estimated error correction coefficients for the $1650-2005$ period is positive and significant (at the I percent level) for prices but is not statistically significant for rents. However, we do see that for the sub-period 1916-2005, both estimated coefficients are statistically significant at the I percent level with prices being positive and rents being negative. Thus, the results indicate that when prices diverge from fundamentals both rents and prices can be the mechanism for restoring equilibrium. However, the absolute magnitude of the price coefficients is 6 to 7 times higher than the size of the rent coefficients. As a result, we conclude that rents and prices do adjust to imbalances, and, consistent with Gallin (2008), our results show that prices appear to adjust more than rents. Furthermore, we find that the prominent role of prices in the error correction process becomes even stronger in the years 1916-2005, when rent regulation hinders rental adjustments. 
CHAPTER 1. HOUSE PRICES AND FUNDAMENTALS

Table 1.4: Error correction coefficients for real rents and real prices

\begin{tabular}{ccc}
\hline Time period & \multicolumn{2}{c}{ Error correction coefficients } \\
\cline { 2 - 3 } & $\Delta \ln (P)$ & $\Delta \ln (R)$ \\
\hline $1650-2005$ & $0.154^{* * *}$ & -0.023 \\
& $(0.042)$ & $(0.017)$ \\
$1650-1915$ & $0.134^{*}$ & $-0.054^{*}$ \\
& $(0.068)$ & $(0.032)$ \\
$1916-2005$ & $0.182^{* * *}$ & $-0.038^{* * *}$ \\
& $(0.073)$ & $(0.015)$ \\
\hline
\end{tabular}

Notes: Standard errors in parentheses. ${ }^{*},{ }^{* *},{ }^{* *}$ indicate significance of coefficient at the $10 \%, 5 \%$, I\% confidence level.

The signs of all error correction coefficients are in line with expectations. For prices, the error correction coefficients are statistically and economically more significant than the coefficients for rents. This means that deviations in the rent-price ratio are mostly corrected for by price adjustments, not changes in rents. The role of prices in the error correction becomes even stronger in the years 1916-2005, when rent regulation hinders rent adjustments.

Overall, the results indicate that our key finding holds in both periods. That is, when the rent-price ratio indicates a disequilibrium situation, this disequilibrium may persist for a long time before prices and rents correct. Furthermore, our analysis suggests that when they do converge, prices will adjust faster than rents.

\subsection{Conclusions}

One of the primary problems associated with identifying the presence of pricing bubbles in asset markets is the lack of sufficiently long time-horizon data. Thus, the purpose of this paper is to utilize a 355 -year time series of real house prices and rents to investigate whether substantial deviations of market prices away from market fundamental values can persist.

Our analysis consisted of two parts. First, we estimated a measure of housing market mispricing based on the relationship between market fundamentals (expected rent growth and expected house price appreciation) and the price-rent ratio. Second, we investigated the link between the rent-price ratio and changes in rents and house prices over various time horizons.

Several lessons can be learned from our analysis. First, house prices and rents are cointegrated, indicating that the same underlying fundamentals likely influence both. Second, our analysis of the rent-price ratio reveals sustained periods of "bubble" and "crisis" conditions that can continue without a corresponding correction (or crash). Third, our analysis shows that changes in house prices and rents are both mechanisms for "correcting" imbalances between prices and fundamentals. Between these, prices appear to have greater importance in correcting disequilibria.

Based on these findings, our investigation into the longrun developments of house prices and rents has implications 
for the ongoing debate concerning the recent price increases and subsequent corrections in many of the worldwide housing markets. While it appears that many markets have had bubble characteristics, our study shows that bubble crashes are not always inevitable in the short run. While prices do revert back to fundamentals, this reversion may take decades. So the move towards equilibrium may be more a fading out than a crash. Recently, markets like Amsterdam, Cape Town, and Paris that have been characterized by strong price gains in the last decade and were widely thought of as overvalued, have nevertheless kept their value, while other markets experienced a free fall.

One of the implications of this analysis is that it is decidedly difficult to know when, or even if, an asset price bubble will collapse. The results suggest that it is unwise to use perfect hindsight to criticize lenders who originated mortgages at the peak of the market and subsequently suffered significant losses due to borrower defaults since historical trends show that it is possible for price bubbles to slowly deflate over long periods such that the losses may not have occurred. Finally, our results imply that lengthy periods of little or no house price appreciation are also possible. Thus, those looking for a speedy recovery in the housing market after the crisis may be disappointed. 


\section{Appendix}

\section{VAR Results in graphs}

The graphs in Figure I.8 provide plots of the yearly individual coefficients (and 95 percent confidence interval) for the VAR models (5), (6), and (7).

\section{Testing for Stationarity}

We use market rents and interest rates as proxies for housing fundamentals. The first step is to determine if the two indices are stationary using the Augmented Dickey-Fuller tests. A series is considered non-stationary if it contains a unit root. We follow David Dickey and Wayne A. Fuller (I98I) to determine the existence of a unit root and therefore whether the series is stationary. The Dickey-Fuller test requires estimating the following autoregressive $(\mathrm{AR}(p))$ process for the rent $(L)$ and price $(P)$ series:

$$
\begin{array}{r}
\Delta y_{t}=\mu+\beta^{*} y_{t-1}+\beta_{1}^{*} \Delta y_{t-1}+\beta_{2}^{*} \Delta y_{t-2} \\
+\ldots+\beta_{p-1}^{*} \Delta y_{t-p+1}+u_{t}
\end{array}
$$

where $y_{t}$ denotes the rent and price series, respectively, and $\beta^{*}=\left(\beta_{1}+\beta_{2}+\ldots+\beta_{p}\right)-1$. The rent and price series contain a unit root (and are non-stationary) if we fail to reject the null hypothesis that $\beta^{*}=1$ by comparing the estimated DF $t$-statistic to the critical values obtained from the DickeyFuller distribution.
Table 1.5 reports the augmented Dickey-Fuller (ADF) test statistics for the rent and price series. Based on the ADF statistics, we confirm that both series contain unit roots and thus are non-stationary. We repeat the test using first differences of each series (Table I.6), and find that we are able to reject the null hypothesis of non-stationarity.

The choice of lag-length when estimating the augmented Dickey-Fuller equation is not exact. Thus, we also test for unit roots using the Phillips-Perron non-parametric procedure (Peter Phillips and Pierre Perron, 1998), which corrects for autocorrelation. Tables I.5 and I.6 also report the PhillipsPerron test statistics, which confirm the presence of unit roots. 
Figure 1.8: Yearly VAR coefficient estimates and $95 \%$ confidence intervals

$i_{t}, i_{t-1}$

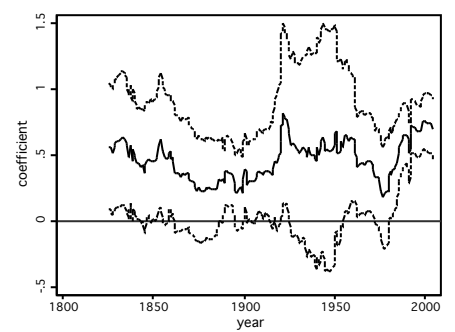

$\Pi_{t}, i_{t-1}$

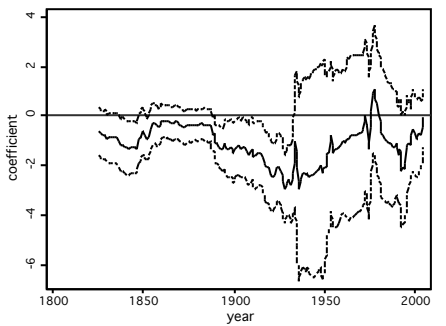

$\Delta l_{t}, i_{t-1}$

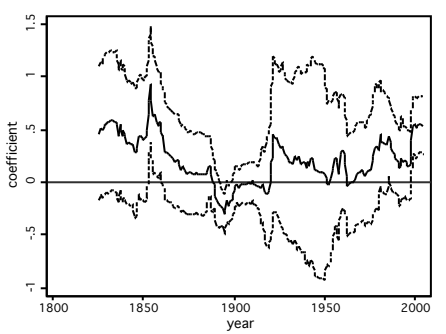

$i_{t}, \Pi_{t-1}$

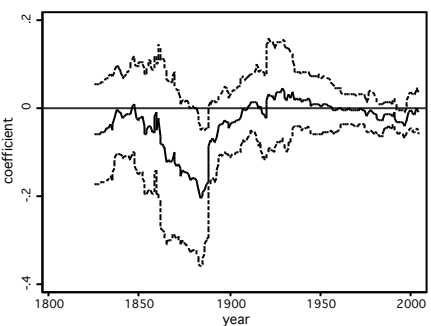

$\Pi_{t}, \Pi_{t-1}$

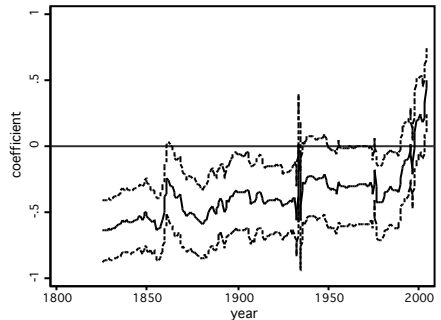

$\Delta l_{t}, \Pi_{t-1}$

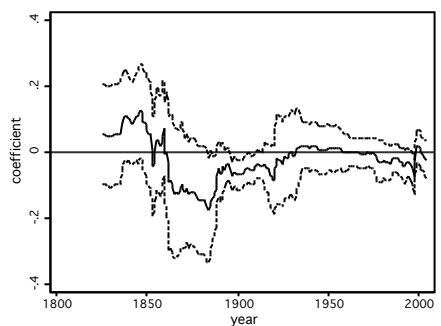

$i_{t}, \Delta l_{t-1}$

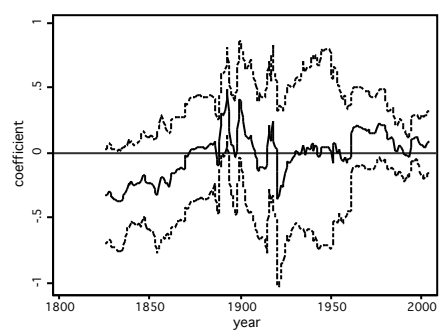

$\Pi_{t}, \Delta l_{t-1}$

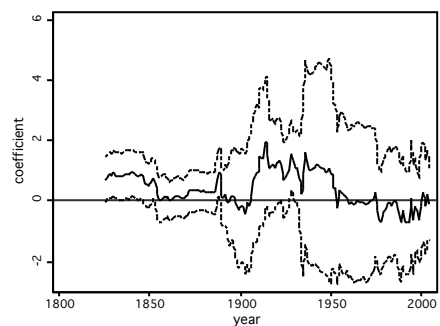

$\Delta l_{t}, \Delta l_{t-1}$

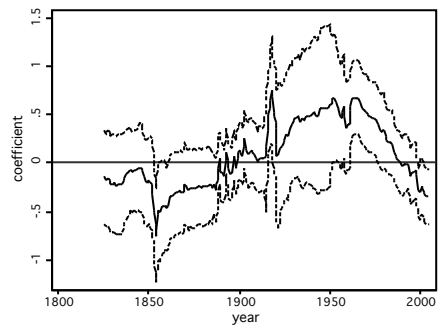


CHAPTER 1. HOUSE PRICES AND FUNDAMENTALS

Table 1.5: Unit root tests for levels of real rent and house price indices

\begin{tabular}{|c|c|c|c|c|c|c|}
\hline \multirow[t]{2}{*}{ Lag } & \multicolumn{2}{|c|}{$\ln$ (Rents) } & \multicolumn{2}{|c|}{$\ln$ (Prices) } & \multicolumn{2}{|c|}{$\ln ($ Price/Rent $)$} \\
\hline & ADF & PP & ADF & PP & ADF & PP \\
\hline 1 & $\begin{array}{c}6,44 \\
(0.9999)\end{array}$ & $\begin{array}{c}7,32 \\
(0.9999)\end{array}$ & $\begin{array}{c}0,79 \\
(0.9999)\end{array}$ & $\begin{array}{c}0,24 \\
(0.9999)\end{array}$ & $\begin{array}{c}-4,36 \\
(0.0005)\end{array}$ & $\begin{array}{c}-5,58 \\
(0.0001)\end{array}$ \\
\hline 2 & $\begin{array}{c}5,81 \\
(0.9999)\end{array}$ & $\begin{array}{c}7,18 \\
(0.9999)\end{array}$ & $\begin{array}{c}1,28 \\
(0.9999)\end{array}$ & $\begin{array}{c}0,57 \\
(0.9999)\end{array}$ & $\begin{array}{c}-3,59 \\
(0.0067)\end{array}$ & $\begin{array}{c}-5,46 \\
(0.0001)\end{array}$ \\
\hline 3 & $\begin{array}{c}5,58 \\
(0.9999)\end{array}$ & $\begin{array}{c}7,17 \\
(0.9999)\end{array}$ & $\begin{array}{c}1,76 \\
(0.9999)\end{array}$ & $\begin{array}{c}0,86 \\
(0.9999)\end{array}$ & $\begin{array}{c}-3,06 \\
(0.0315)\end{array}$ & $\begin{array}{c}-5,44 \\
(0.0001)\end{array}$ \\
\hline 4 & $\begin{array}{c}4,6 \\
(0.9999)\end{array}$ & $\begin{array}{c}7,04 \\
(0.9999)\end{array}$ & $\begin{array}{c}1,92 \\
(0.9999)\end{array}$ & $\begin{array}{c}0,99 \\
(0.9999)\end{array}$ & $\begin{array}{c}-2,91 \\
(0.0461)\end{array}$ & $\begin{array}{c}-5,56 \\
(0.0001)\end{array}$ \\
\hline 5 & $\begin{array}{c}3,7 \\
(0.9999)\end{array}$ & $\begin{array}{c}6,83 \\
(0.9999)\end{array}$ & $\begin{array}{c}2,04 \\
(0.9999)\end{array}$ & $\begin{array}{c}1,09 \\
(0.9999)\end{array}$ & $\begin{array}{c}-2,75 \\
(0.0667)\end{array}$ & $\begin{array}{c}-5,68 \\
(0.0001)\end{array}$ \\
\hline 6 & $\begin{array}{c}3,55 \\
(0.9999)\end{array}$ & $\begin{array}{c}6,68 \\
(0.9999)\end{array}$ & $\begin{array}{c}1,59 \\
(0.9999)\end{array}$ & $\begin{array}{c}1,01 \\
(0.9999)\end{array}$ & $\begin{array}{c}-3,01 \\
(0.0358)\end{array}$ & $\begin{array}{c}-5,89 \\
(0.0001)\end{array}$ \\
\hline
\end{tabular}

Notes: For each series we present the Augmented Dickey-Fuller (ADF) and Phillips-Perron (PP) test statistics for I-6 lags. Numbers in parentheses are asymptotic $\mathrm{p}$-values.
Table 1.6: Unit root tests for first differences of real rent and house price indices

\begin{tabular}{|c|c|c|c|c|}
\hline \multirow[t]{2}{*}{ Lag } & \multicolumn{2}{|c|}{$\ln$ (Rents) } & \multicolumn{2}{|c|}{$\ln$ (Prices) } \\
\hline & ADF & PP & ADF & PP \\
\hline 1 & $\begin{array}{c}-10,08 \\
(<0.0001)\end{array}$ & $\begin{array}{c}-15,35 \\
(<0.0001)\end{array}$ & $\begin{array}{c}-17,42 \\
(<0.0001)\end{array}$ & $\begin{array}{c}-26,7 \\
(<0.0001)\end{array}$ \\
\hline 2 & $\begin{array}{c}-8,14 \\
(<0.0001)\end{array}$ & $\begin{array}{c}-15,47 \\
(<0.0001)\end{array}$ & $\begin{array}{c}-14,35 \\
(<0.0001)\end{array}$ & $\begin{array}{c}-27,39 \\
(<0.0001)\end{array}$ \\
\hline 3 & $\begin{array}{c}-6,17 \\
(<0.0001)\end{array}$ & $\begin{array}{c}-15,58 \\
(<0.0001)\end{array}$ & $\begin{array}{c}-11,57 \\
(<0.0001)\end{array}$ & $\begin{array}{c}-28,08 \\
(<0.0001)\end{array}$ \\
\hline 4 & $\begin{array}{c}-4,89 \\
(<0.0001)\end{array}$ & $\begin{array}{c}-15,77 \\
(<0.0001)\end{array}$ & $\begin{array}{c}-9,97 \\
(<0.0001)\end{array}$ & $\begin{array}{c}-28,48 \\
(<0.0001)\end{array}$ \\
\hline 5 & $\begin{array}{c}-4,38 \\
(<0.0001)\end{array}$ & $\begin{array}{c}-16,03 \\
(<0.0001)\end{array}$ & $\begin{array}{c}-7,76 \\
(<0.0001)\end{array}$ & $\begin{array}{c}-28,62 \\
(<0.0001)\end{array}$ \\
\hline 6 & $\begin{array}{c}-3,62 \\
(<0.0001)\end{array}$ & $\begin{array}{c}-16,27 \\
(<0.0001)\end{array}$ & $\begin{array}{c}-7,54 \\
(<0.0001)\end{array}$ & $\begin{array}{c}-28,48 \\
(<0.0001)\end{array}$ \\
\hline
\end{tabular}

Notes:For each series we present the Augmented Dickey-Fuller (ADF) and Phillips-Perron (PP) test statistics for I-6 lags. Numbers in parentheses are asymptotic $\mathrm{p}$-values. 
CHAPTER 1. HOUSE PRICES AND FUNDAMENTALS 


\section{Chapter 2}

\section{Real Option Value and the Long Term Dynamics of House Prices}

This chapter is joint work with

John M. Clapp (University of Connecticut) and Piet Eichholtz (Maastricht University).

\subsection{Introduction}

To understand the effects of real option value on the dynamics of house prices, one needs to focus attention on the option embedded in existing dwellings. The literature regarding the value of the redevelopment option analyzes vacant land, ${ }^{\mathrm{I}}$ but for existing dwellings, option value derives from the possibility to add space, or to demolish and rebuild.

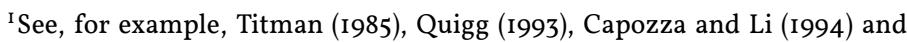
Capozza and Sick (1994).
The literature has developed a standard hedonic specification valuing houses and other real assets (Rosen, 1974). This model considers the value of the existing vector of asset characteristics, omitting explicit consideration of any value from the option to redevelop the property to a level consistent with current expectations for house prices. ${ }^{2}$ It is our contention that housing market changes from boom to bust will alter the value of the option to tear down and rebuild or substantially renovate the existing structure. ${ }^{3}$

${ }^{2}$ Rosen specifically excluded the value of durable assets from his theory (1974, p. 37).

${ }^{3}$ Note the asymmetry in option value during rising and falling markets. During declining markets, owners have little choice except to allow their properties to deteriorate, slowly reducing their investment: See Glaeser and Gyourko (2005) for extensive discussion of the asymmetry. We model the call option (i.e., the redevelopment option) rather than the put option (i.e. , the abandonment option). 
In order to investigate how option value drives the prices of existing homes, we combine insights from the hedonic pricing literature with real option value. We use a model in which the value of the redevelopment option is an additive term in a standard hedonic specification. ${ }^{4}$ In effect, the redevelopment option is an option to change the vector of hedonic characteristics of a dwelling.

We propose that option value is a positive function of the unrealized development potential of the lot, measured by the maximum structure allowed by zoning relative to the existing structure. If the existing configuration of the dwelling and the land it stands on is close to the optimum, then the strike price of the option is high because the use value of the existing vector is exchanged for the value of the new configuration. In this case, the value of the redevelopment option is low. Similarly, a small old house in a neighborhood with larger newer houses may have substantial option value.

We use a new database to document changes in real option values, analyzing their role in the pricing of the West Berlin housing market. Existing empirical tests of real option theory focus on cross sectional data. For an understanding of the influence of real option value on the dynamics of house prices, a longer term perspective is required. Our West Berlin data cover the period from 1978 through 2007. Besides that, there are two other reasons why these data are uniquely fit to study the effect of real option value on the price behav-

${ }^{4}$ Specifically, we provide a closed form solution to the model developed in Clapp and Salavei (2009) and we add drift in house prices. ior of existing homes.

First, our dataset of Berlin's residential real estate sales not only provides transaction prices, location and a - limited set of hedonic characteristics, but it also covers the degree of existing development for each dwelling, and the maximum development permitted by zoning, which allows for the assessment of the option value to redevelop existing dwellings. By employing this database, this paper is the first to use zoning limits for an empirical estimate of the real option value embedded in existing dwellings.

Second, during the 30 years covered by the database the city of Berlin experienced significant political and economic volatility, with important consequences for the West Berlin housing market. During the three decades from 1978 through 2007 the West Berlin housing market has experienced three very different phases of relative tranquility, boom and bust, which are likely to have affected option values in an economically significant way.

Berlin was a focal point of the Cold War when that was still in its early stages, but after 196I, when the Wall was constructed, West Berlin experienced a period of relative tranquility and prosperity. Sealed off from its direct surroundings by the iron curtain, protected by NATO against external threats, and financed by generous transfer payments from West Germany, the lucky western part of the divided city lived a quiet but comfortable life. This situation continued until I989. Our data show that house prices between 1978 and I989 grew steadily by an average of I.9 percent per year in real 


\section{terms.}

The quiet period ended abruptly and unexpectedly with the collapse of the communist rule in Eastern and Central Europe. Germany experienced three major political shocks during a three year period, popularly called the Big Bang period: the fall of the Berlin Wall in 1989, the reunification of East and West Germany in 1990, and the decision to return the federal government to Berlin in 199I. In Berlin, these events set in motion a real estate boom, both in housing and in commercial real estate. The real estate boom, which peaked in 1994 , is clearly visible in our data, which show that home prices markedly accelerated in the years just after the fall of the Wall in 1989, with real prices rising by an average of 4.6 percent per year for five years.

This boom ended just as the federal government started to move to Berlin in 1994. This move coincided with the pinnacle of the housing market boom, and the housing market went into a long-lasting decline after that. During the I3 years after 1994 the cumulative decline in real house prices was 45 percent, or 2.9 percent annually.

The main contribution of this paper is to give an insight in the extent to which real option value has exacerbated these swings in house prices: this study is the first to document the substantial role played by option value in long-run housing market volatility. For the boom period between 1989 and 1994, our results for houses with high option value show that increases in the redevelopment option value added about 40 percent to the growth in the real value. In the subse- quent bust, about 50 percent of the decline in the real value of these high option value houses was associated with reductions in their option value. But also for houses with low option value, the economic contribution of changes in option value appears to be important, and especially so in the bust phase of the cycle: 12 percent of the decline in real value can be attributed to changing real option value. This suggests that option value amplifies the long-term price swing of existing dwellings.

This paper proceeds with a section introducing the theoretical model we use for the analysis. It subsequently tells the story of the Berlin housing market in its urban economic setting, and provides details of the data we use. The next section provides the framework for the empirical analysis, and the section after that presents the empirical results, starting with the presentation of a constant-quality house price index for Berlin, subsequently presenting coefficient estimates for the hedonics and the redevelopment option, and ending with a calculation of the economic significance of the redevelopment option in the different phases of the Berlin housing market cycle. The paper ends with a summary and concluding section.

\subsection{Methodology}

The model we propose is a standard hedonic model with an additive redevelopment option value term: i.e., house value 
consists of use value plus option value. Intuitively, when existing houses trade, a lump sum for the redevelopment option value is embedded in the price. The option value term is motivated by the possibility of tearing down and rebuilding, or substantially remodeling and adding to the house, modifying the vector of hedonic characteristics.

\subsubsection{Embedded Option Value}

This section develops a simple hedonic model where market participants pay for the use value of the existing vector of characteristics and additionally for the option to redevelop to a different vector. The model provides a framework for specifying a regression capable of separately identifying the amount paid for the option and the amount paid for use of the existing vector. ${ }^{5}$ As shown here, the main empirical implication of the option value framework is that an additive nonlinear term is needed for option value.

Our theory is based on a certainty model: i.e. , there is no underlying stochastic process. Grenadier (1999 and 2002) motivates our use of the certainty model as a starting point: the NPV rule may be more empirically relevant than the

${ }^{5}$ Earlier real options theory developed by Rosenthal and Helsley (1994) deals with the case where the structure is valueless; only land value (i.e. , option value) remains. Quigg (1993) uses construction costs and assumed parameters with an option value formula to back out the option component from the value of vacant land. She uses the hedonic model only to estimate the value of an optimal structure. value arising from the variance of the underlying stochastic process.

In the certainty model, option value is generated by irreversibility, which occurs because it is costly to change the hedonic vector. Consider a vector of property characteristics $q_{i}^{0}$ that changes only by depreciation until the owner decides to redevelop - i.e. exercise a one-time call option at cost $\mathrm{k}$, the construction costs associated with the redevelopment. ${ }^{6}$ This is an exchange option: at time $T$, the depreciated vector $q_{i}^{0} e^{-\delta T}$ is exchanged for a new structure characterized by the vector $q_{i}^{n}$. The discount rate is $\rho$ and spot implicit rental rates are denoted by the vector $r$, which grows exponentially at rate $\mu \geq 0 .{ }^{7}$ To keep the model simple, the new vector is predetermined, not optimally chosen. Then the hedonic model with a redevelopment option becomes:

$$
\begin{gathered}
P_{i}=r^{\prime} q_{i}^{0} \int_{t}^{t=\infty} e^{(\mu-\rho-\delta) t}+ \\
\max \left(r^{\prime} q_{i}^{n} \int_{t=T}^{t=\infty} e^{(\mu-\rho-\delta) t} d t-r^{\prime} q_{i}^{0} e^{-\delta T} \int_{t=T}^{t=\infty} e^{(\mu-\rho) t} d t-k e^{-\rho T}, 0\right)
\end{gathered}
$$

${ }^{6}$ Depreciation is a scalar multiplied by each element of the rent vector. Likewise, change in implicit market rents will be modeled with a scalar multiplied by each element of the rent vector.

${ }^{7}$ I.e. , each element of the vector of implicit rents grows at the same exponential rate. Finite expected returns, and option value $\geq 0$, require that $1>\rho>\mu>0$. 
The first term on the right hand side of equation (2.I) is the value of the existing vector (i.e., the use value of the property); this is the only term included in the standard hedonic model. The term subject to maximization is the value of the option to redevelop. ${ }^{8}$ This exchange option - i.e., exchange of the depreciated vector of characteristics for a new one - is exercised at some time $T .{ }^{9}$ The last term is the present value of the cost of the exchange.

Notation can be simplified with the scalar values in today's money of the old vector of characteristics, $v_{i}^{0}$ and the new vector, $v_{i}^{n}$ :

$$
v_{i}^{0}=\frac{r^{\prime} q_{i}^{0}}{\rho+\delta-\mu} ; \quad v_{i}^{n}=\frac{r^{\prime} q_{i}^{n}}{\rho+\delta-\mu}
$$

As shown in the appendix, equation (2.I) can be rewritten as:

$$
\begin{array}{r}
P_{i}=v_{i}^{0}+ \\
\max \left(e^{(\mu-\rho) T} v_{i}^{n}-e^{(\mu-\rho-\delta) T} v_{i}^{0}\left[\frac{\rho+\delta-\mu}{\rho-\mu}\right]-k e^{-\rho T}, 0\right)+\epsilon_{i}
\end{array}
$$

A cross-sectional hedonic model with option value is an estimate of equation (2.3) at time $t=0$, when everything

${ }^{8}$ Further explanation of a certainty model similar to this one can be found on page 138 of Dixit and Pindyck (1994); page I46 adds uncertainty in the context of Tobin's $q$. Rosenthal and Helsley (1994), use a stochastic model that allows multiple redevelopment options to derive a similar equation. ${ }^{9} \mathrm{~A}$ necessary but not sufficient condition for positive option value is $r^{\prime}\left[q_{i}^{n}-\right.$ $\left.q_{i}^{0} e^{-\delta T}\right]>0$. is known except $T$, which is optimally chosen. Assuming $T^{*}>0$, the first order condition is:

$v_{i}^{n} e^{(\mu-\rho) T^{*}}=v_{i}^{0} e^{(\mu-\rho-\delta) T^{*}}\left[\frac{\rho+\delta-\mu}{\rho-\mu}\right]^{2}+k\left[\frac{\rho}{(\rho-\mu)}\right] e^{-\rho T^{*}}$

At the time of redevelopment $\left(T^{*}=0\right)$ the two terms on the right hand side differ from the NPV rule by the multipliers $\left[\frac{\rho+\delta-\mu}{\rho-\mu}\right]>1$ and $\left[\frac{\rho}{\rho-\mu}\right]>1$. These multipliers give the amount by which the value of the renovated property differs from the strike $\left(=v_{i}^{0}+\rho k\right){ }^{\mathrm{IO}}$

The appendix demonstrates that a simple closed form solution for equation (2.3) is available for the case where $\delta=0$ and $T^{*}>0:{ }^{\text {II }}$

$$
P_{i}=v_{i}^{0}+\left(\frac{\mu}{\rho-\mu}\right) k\left[\left(\frac{k}{v_{i}^{n}-v_{i}^{0}}\right) \frac{\rho}{\rho-\mu}\right]^{-\frac{\rho}{\mu}}+\epsilon_{i}
$$

This solution provides the main empirical implication of theory: option value is a nonlinear term added to the standard hedonic value, $v_{i}^{0}$, and option value declines in $v_{i}^{0}$.

Figure 2.I illustrates equation (2.5). The graph shows how the redevelopment option value and the total house value

${ }^{\text {Io }}$ As pointed out by Dixit and Pyndick (1994) the value of the new asset is appreciating at rate $\boldsymbol{\mu}$ whereas the cost $k$ is constant, motivating $\boldsymbol{T}^{*}>\mathbf{0}$. Here, depreciation further motivates waiting to invest.

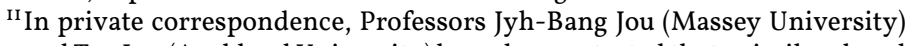
and Tan Lee (Auckland University) have demonstrated that a similar closed form solution is available in the case where $\delta>0$. 
CHAPTER 2. REAL OPTIONS AND PRICE VOLATILITY

change with different levels of an existing home's use value. Total house value (use value plus option value) is the upper line. In this example, we set parameters $\mu$ and $\rho$ at, respectively, 0.015 and 0.05, both in line with West Berlin history. We choose normalized parameter values for construction cost $(k=1)$, the value of a new house $\left(v_{i}^{n}=2\right)$, and the rent vector, which is a vector of ones. Different values for $k$ and $v$ will "stretch" the graphs but leave the implications of (2.5) unchanged. Please note that the total home value is not monotonically increasing in use value (as assumed by traditional hedonic models). Total value starts to increase again, once use value falls below a certain threshold. Casually speaking, it becomes easier to redevelop once the current structures have deteriorated enough. The option is rationally exercised at the tangency between the option payoff and the option value. In this example, this point corresponds to a use value of $0.57 \mathrm{I}$.

The appendix outlines the generalization of equation (2.5) to a valuation equation where implicit market prices follow a standard Wiener process. This generalization reveals that option value increases with the variance of the underlying stochastic process. It does not change the fact that option value is an additive power function as in equation (2.5).
Figure 2.1: Use value, option value and total house value

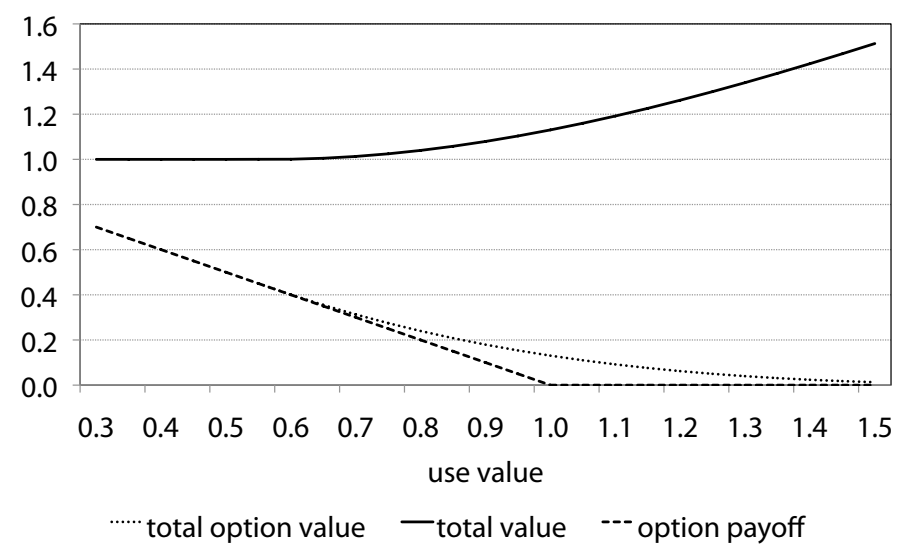

Notes: The dotted line is the second term of equation (2.5). The solid line is the sum of the two terms: use value (first term) plus option value (second term). Use value of the existing house, $v_{i}^{0}$ is on the $\mathrm{x}$-axis; the part of this that varies in cross-sectional is the quantity of existing characteristics, $q_{i}^{0}$. The option is rationally exercised at the tangency between the option payoff and the option value: where use value is $0.57 \mathrm{I}$ in this example. Parameters used here: $\mu=.015, \rho=.05$, both based on West Berlin history. Normalized numbers: Construction cost, $k=1$. Value of new house, $v_{i}^{n}=2$; the rent vector is a vector of ones, constant in cross section. 


\subsubsection{Empirical Specification with Embedded Option Value}

The purpose of this section is to derive empirically testable propositions from equation (2.5). In the housing literature, hedonic regressions are typically estimated in $\operatorname{logs}(\ln \mathrm{P}$ is the dependent variable). Therefore, we measure the option value variable with the natural logarithm of $\frac{v_{i}^{n}}{v_{i}^{0}}=r^{\prime} \frac{q_{i}^{n}}{q_{i}^{0}}$, where the vector of market rents is fixed in the cross-section: call this ratio "development potential", $D_{i}$. We measure the ratio between the old and new quantities by the maximum size of a house (in square meters) allowed on each lot by zoning divided by the size of the existing house. As suggested by theory, if the ratio is close to I (log close to zero), the property is close to optimal intensity and option value is likely to be low. ${ }^{12}$ A large development potential ratio suggests that the last term in equation (2.5) has the potential to be large if the parameters and current price level support an option that is at- or in-the-money.

The model suggests the following testable hypotheses:

HI: The coefficient for $\ln D_{i}$ will have a positive sign during periods of significant option value, zero during other periods. This can be tested against the

${ }^{12} \mathrm{Of}$ course, option value is also a function of the parameters of the model and the current level of house prices. This motivates our approach, which is to shift the regression parameter on the option value term over time so that it can respond to changes in the economic and political environment. alternative that the coefficients for $\ln D_{i}$ have negative signs.

H2: The effect of $D_{i}$ should be nonlinear: ${ }^{13}$ near zero over much of its range and significantly positive at high levels of $\mathrm{D}$.

An additional testable hypothesis follows from the dramatic events in Berlin between I989 and 1992: option value should be higher because expected drift and variance are expected to increase around these events. ${ }^{\mathrm{I}}$

$\mathrm{H}_{3}$ : The coefficients for $\ln D_{i}$ should be higher during the Big Bang period and lower before and after that time.

\subsection{Events and Data}

\subsubsection{Events Associated with the Creation and Destruction of Option Value}

After the end of World War II, the artificial border surrounding West Berlin became more and more impermeable, culminating in the erection of a heavily fortified physical barrier in

${ }^{13}$ Note that the way we define $\mathrm{D}$ = development potential, the value of which increases as one moves from right to left in Figure 2.I.

${ }^{14}$ When a Wiener process for rents is introduced as in the appendix, option value is a positive function of variance, and we expect variance to increase due to the uncertainty surrounding the fall of the Berlin Wall. 
196I. The Berlin Wall locked in the Eastern German population, making any free movement of people from the East to the West virtually impossible. Ironically, the Wall stabilized the political situation, and gradually, a period of business as usual took the place of the serial crises that had characterized the city between I945 and I96I: it all got quiet on the Eastern front.

This period of tranquility ended abruptly and unexpectedly in 1989. Even those who were witnessing political developments from within did not foresee the events that were to follow shortly. In June of I989, just a few months before the fall of the Wall, Gerhard Schröder, who would later become Germany's Chancellor, said: "After 40 years of Federal Republic of Germany, one should not lie to a new generation in Germany about a chance of re-unification. This chance does not exist." ${ }^{15}$

After Hungarian border officials gave up stopping East Germans driving into Austria, the East German regime had no choice but to open the border to the West as well. On the evening of November $9^{\text {th }}$, a member of the East German Politbureau announced the end of the border controls and in the very same night thousands of East Germans crossed the border into West Berlin (Schmemann, 1989). This political and economic "Big Bang" event evolved at a speed that was unheard of during the preceding 40 years of careful diplomacy. On October $3^{\text {rd }}$, 1990, East and West Germany were

${ }^{15}$ Gerhard Schröder on 12.6.1989 in Bild-Zeitung. Source: http://dipbt. bundestag.de/dip21/btp/13/13247.asc (retrieved on Dec. 15, 20IO) re-united, including a full integration of the monetary system, the administration, and the judicial system.

In a very close vote in June 199I, the unified German parliament decided to make Berlin the political capital of Germany again. Moving the government, parliament, and about half of the federal administration, including approximately 9,000 civil servants, started in 1994 and was finalized by 1999.

These events set in a period of great expectations, not least for the real estate sector. Plans were hatched to redevelop the center of Berlin, many areas of which had been largely untouched since their destruction in 1945 , and house prices started rising much more quickly than they had done in the years before. The boom from 1989 to 1994 fueled construction activity in Berlin, suggesting the exercise of development options: about 140,000 housing units were added to the housing stock from 1992 to 2002 , which is a net growth of 8 percent of the total stock.

But, soon after the shocks of the early nineties, Berlin's population started falling and its economy started stalling. While it was still a walled city, West Berlin received disproportionate transfers from the West German federal government, ultimately aimed at sustaining the city's population levels. After 1995, these subsidies were gradually phased out. From 1992 through 2002 the number of Berliners holding any kind of job declined by 6 percent (Destatis, 2009). The number of total hours worked decreased at a faster rate, indicating that full-time jobs vanished even more rapidly. De- 
spite the influx of government employees, Berlin's population numbers started to decline slightly in 1994 , and then declined more rapidly each year until 200I. ${ }^{16}$

\subsubsection{The Dataset}

Micro-data for housing transactions are difficult to obtain in Germany, as house sales are treated as private information. Every transaction of land or buildings, however, needs to be certified by a notary, who sends the title deed to the local land register. A copy of each contract is forwarded to local 'committees for land price valuation' (Gutachterausschuss für Grundstückswerte). These independent expert panels maintain transaction databases and disseminate aggregated information on price trends for land and buildings. In addition, they offer plot-specific appraisals for the government, the mortgage industry and private parties.

Third parties are not granted access to these databases due to strict privacy laws. Moreover, the databases exist on local level only. The committees for land price valuation are ruled by state law, which varies slightly in the degree of privacy protection across Germany. For the state of Berlin, universities are allowed to analyze the data as long as no information can be traced back to single transactions. ${ }^{17}$

${ }^{16}$ A recent paper by Glaeser and Gyourko(2005) shows how the combination of population decline and a durable housing supply is likely to cause substantial decline in house prices and new construction. Here, we associate the Big Bang events with the creation and destruction of option value.

${ }^{17}$ Schulz et al. (2003) and Schulz and Werwatz (2004) are the only papers we
We got access to a database including all transactions of single-family homes for West Berlin from 1978 through 1989 and for the united Berlin from 1990 through 2007. All records include the sales price and date, the address, and key hedonics

Our single-family dwellings data set comprises of 37,276 transactions between 1978 and 2007. ${ }^{18}$ The database contains measures of the building's interior floor space and the size and dimensions of the lot. We exclude 39 observations with plots larger than 4,000 $\mathrm{m}^{2}$ from the sample, as they are very special cases clustering around a single street in the outskirts of Berlin. We exclude an additional 403 observations with interior sizes below $20 \mathrm{~m}^{2}$ or above $500 \mathrm{~m}^{2} .19$

The database contains two additional hedonic variables: I) replacement value and 2) maximum floor space allowed by zoning. The former provides us with a proxy for building age and condition. The structure's replacement value is estimated by a professional appraiser during an external inspection conducted at the time the sale is entered into the

know of that use (subsets of) these data.

${ }^{18}$ For a city of the size of Berlin, this number of transactions seems very low, especially for a 30-year period. It can be explained by the fact that only I2 percent of homes in Berlin are owner-occupied, which is the lowest level among German states. Furthermore, the great majority of homes in Berlin is multifamily rather than single family.

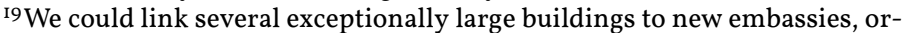
ganizational buildings, or other non-residential uses being established in residential areas. Other extremely small or large outliers are probably recording errors. 
database. The replacement value (adjusted with the consumer price index to the year 2000) is not only missing for incomplete records but for all sales of naked land that is zoned for residential use, but not developed yet. These transactions also include land with temporarily deviating uses like ad-hoc parking lots. We exclude 3,369 observations that lack replacement value.

The data item that makes the Berlin housing data unique is the information regarding the upper ceiling of developable floor space allowed under the zoning at the time of transaction. This is the crucial data item needed to assess the magnitude of the redevelopment option. Under the German zoning regime, the upper ceiling is expressed as a ratio of the total interior space allowed, divided by the lot size. This means that the development potential is a direct function of the space realized, the size of the land, and the zoning ratio. Even for neighborhoods where the zoning ratio is uniform, we have a substantial amount of variation, since lot sizes in Berlin are not standardized. That means we estimate the magnitude of the redevelopment option with some noise.

Based on the ratio of maximum interior area allowed by zoning divided by the current interior floor space, we calculate the unrealized space potential at the dwelling level. A quarter of our sample has a development potential ratio of one, which means that they are fully developed. We observe substantial variation of development potential within and across neighborhoods. In the Dahlem area, for instance, homes have been developed to on average of 8 I percent of the theoretical upper boundary, while those in Reinickendorf have only 43 percent of the theoretical maximum developed.

Before 1985, only a third of all records report the information on redevelopment potential, while it is included for most, but not all transactions after 1985 . In all, this information is missing for 6,543 transactions. ${ }^{20}$ Finally, excluding all observations in the Eastern part of the city reduces our sample to 19,825 transactions.

\subsection{Empirical Approach}

\subsubsection{Controlling for Location}

The quality of a location and our measure of space potential are interlinked. Better-located properties are likely to be redeveloped first, implying that option value is correlated with location value. At the other end of the spectrum, very high levels of development potential lose their economic meaning as zoning limits the development potential from a legal point of view only. In areas with lenient zoning and low attractiveness the option to add space to the building will be far out of the money while similar redevelopment possibilities in a prospering neighborhood will carry value. Thus, it is not sufficient to simply use our zoning variable to measure the amount of development potential, the $v_{i}^{n}-v_{i}^{0}$ term in equa-

${ }^{20} \mathrm{t}$-tests show that the reporting of this variable is not conditional on the value of any of the other hedonic variables. 
tion (2.5)

Our empirical strategy to control for location is first to match sales of fully developed properties with sales of neighboring properties that may or may not be fully developed. We focus on areas where our measure of development potential has economic meaning by identifying homes that are built on relatively large lots that have been fully developed. For these dwellings we believe that zoning is the limiting factor to redevelopment, rather than economic considerations like location quality or the state of the local housing market. Therefore, the redevelopment option may be in-the-money for transactions near sales of fully developed properties and within the same time period.

Technically, we select all fully developed properties on lots with sizes above the median lot size and pair them with all transactions within a circle with a half mile $(804 \mathrm{~m})$ radius $^{2 \mathrm{I}}$ that occurred in the same 3-year band (1978-I980, I98I-I983, $\ldots, 2005-2007)$ as the reference point. Requiring this temporal proximity besides spatial proximity makes our analysis robust to possible changes in Berlin's spatial equilibrium caused by the re-unification in 1990 . We exclude midpoints that have fewer than 9 comparables in the reference circle and time period. In total, 487 fully developed homes on large lots remain in our sample, augmented with 6,256 comparable transactions. For each of the 487 areas, we define spatial dummy variables. The comparables are not exclusive, as

${ }^{21}$ This setup to match properties by location has also been used in Eichholtz, Kok and Quigley (2010). observations can be located in the intersections of the halfmile-circles. Our strategy of isolating the sales with at least some development potential and matching them geographically to those with no development potential is required in order to adequately control for omitted location characteristics.

Figure 2.2 visualizes the distribution of the sample within West Berlin and its neighborhoods (shaded in light grey). Each location of a single-family home transaction is marked by a small black dot. The vast majority of these homes is located in Berlin's periphery, while the multi-unit-rental buildings dominate the city center. The 487 circles are marked by white dots surrounded by dark grey circles with a radius of half a mile. Overall, the circles cover 35 of the 49 western neighborhoods and adequately represent the geographic distribution of the full sample.

Finally, we refine the modeling of location within each circle by adding spatial variables such as distances to rivers or open space, primary school or kindergarten, public transport hubs or railway tracks. To calculate these distances, we first translate the street address into longitude and latitude coordinates through the Google Maps web service. ${ }^{22}$ Locations of railway tracks, parks, lakes, rivers, and other open spaces are derived from free GIS maps supplied by the OpenStreetmap project, ${ }^{23}$ while the complete list of subway-, railway-, and

${ }^{22}$ Detailed information on how to use the Google Maps toolbox for geocoding can be obtained from the authors on request.

${ }^{23}$ www.openstreetmap.org 
Figure 2.2: Geographic distribution of single-family home transactions in West Berlin.

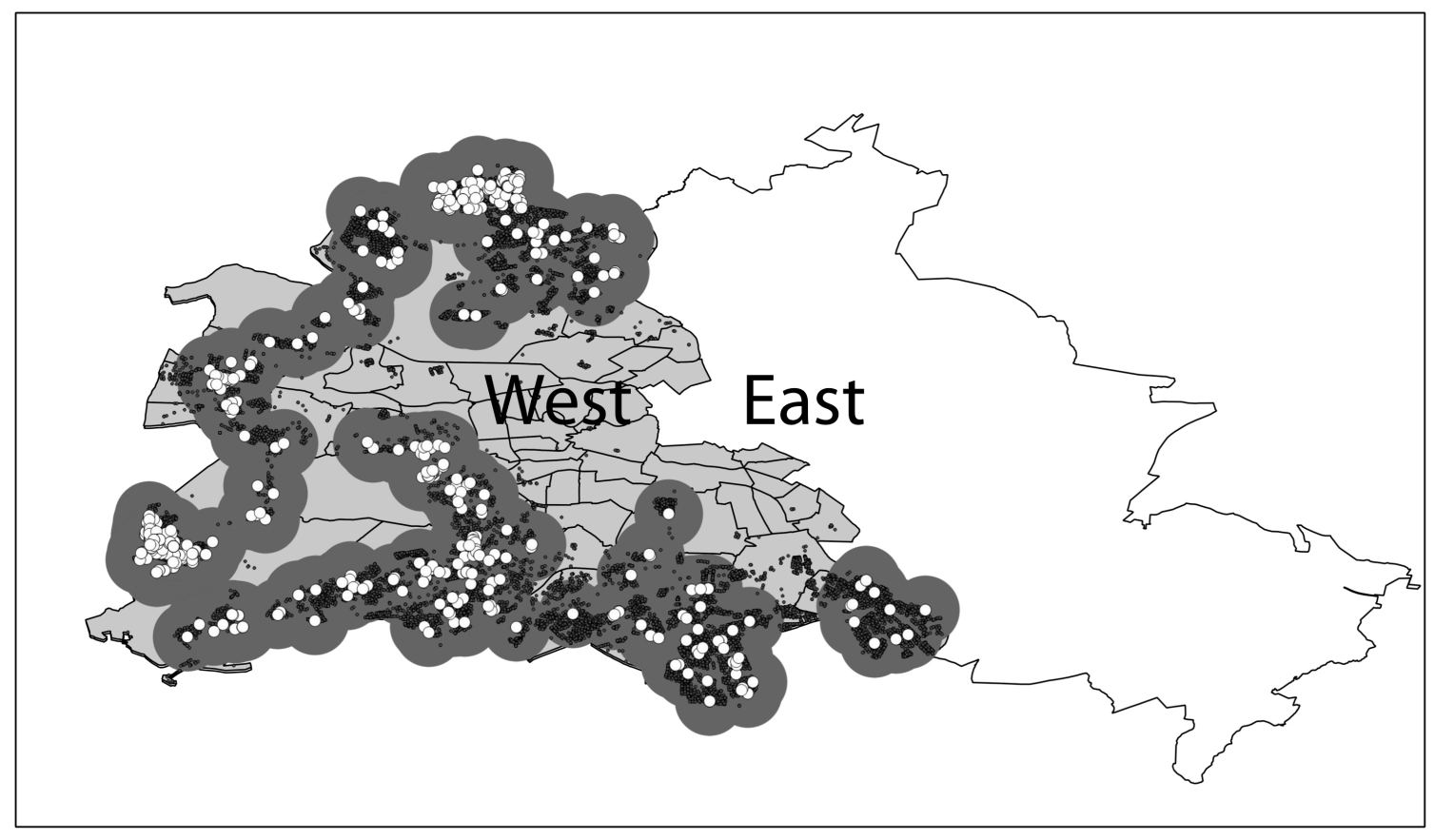

Notes: The Map shows the boundaries of Berlin and West Berlin's official neighborhood classifications (shaded in light grey). Each location of a single-family home transaction is marked by a small black dot. The vast majority of these homes are located in Berlin's periphery, while rental apartment buildings dominate in the city center. We match fully developed buildings, which have large lots (represented by white dots) with buildings that are within a half-mile circle (surrounding dark-grey circles) to control for the location of the buildings. 
light rail-stations was obtained from the Berlin transportation authorities. We calculate the fastest route to the center, which is a combination of the walking time to these public transport hubs and the subsequent commuting time to the center. We look up the commuting time on a Monday morning to Berlin central station for each of the public transport stations in the 2009 transportation schedules. ${ }^{24}$ The school administration's official address list reveals the location of all of primary schools and kindergartens. In addition, we define dummy variables for the distances to the (formerly) fortified East-West border (Berlin Wall and Brandenburg border).

\subsubsection{Comparing Fully Developed to High Op- tion Value Sales, Same Neighborhood}

Fully developed sales account for 26.3 percent of our sample. For these sales the option to add space has no value because zoning prohibits additional space. We defined high development potential as the upper $26.3^{\text {rd }}$ percentile of the distribution of development potential. It is these properties where we expect value to be increased most by the presence of the option after controlling for hedonic characteristics: lot area,

${ }^{24}$ The new central station is located in what can be considered the center of the united Berlin, close to government quarters and parliament. It is Berlin's central transportation hub. During the Cold War, Berlin Zoo station served as interim main station. It is about 4 train-minutes west of the new center. interior floor space and replacement value.

Table 2.I presents the summary statistics of the final sample, the subsample of matched dwellings in the half-mile circles, and the subsamples of high, low, and no option value dwellings. Average transaction values for singlefamily homes, at 2007 prices, were roughly between EUR 350,000 and EUR 375,000. When comparing the matched sample with the full sample, one can see that dwellings in the matched subsample have higher selling prices, larger lot sizes and a somewhat higher replacement value.

Next, we compare the descriptive statistics for high option value properties to those for fully developed properties. The average sales prices (in 2007 Euros) for the high option value sample are almost identical. By construction, the high option value sales are on larger lots and have less interior area. Not surprisingly, they have lower replacement value; the magnitude of the difference suggests that building age and depreciation are captured by replacement value. ${ }^{25}$

The location variables suggest that the half-mile radius circles successfully control for neighborhood. For example, both types of property are, on average, about 25 minutes from the city center by train (excluding the commuting time from the home to the nearest train station). Moreover, the standard deviation of this time is very similar. Likewise, comparisons of distance to water and distance to green space do not show a statistically significant difference.

${ }^{25}$ Maintenance will be optimally reduced for properties approaching the trigger point for redevelopment. 
About 12 percent of dwellings in both subsamples are located within 200 meters of a railroad track and each has 6-7 percent of dwellings located within 200 meters of the former border (e.g., the Wall) between East and West Berlin. This suggests that we have adequately matched the locations of the two types of property.

\subsubsection{Regression model}

In order to empirically investigate the effect of option value on the value of existing dwellings we propose an empirically testable form of equation (2.5):

$$
\begin{array}{r}
\ln \left(P_{i}\right)=\alpha+\mathbf{B}_{\mathbf{h}} \mathbf{X}_{\mathbf{i}}+\mathbf{B}_{\mathbf{s}} \mathbf{S}_{\mathbf{i}}+\mathbf{B}_{\mathbf{y}} \mathbf{Y}_{\mathbf{i}} \\
+\beta_{f} \text { Fulldev }+\beta_{h} H i g h O V+\beta_{D} \ln \left(D_{i}\right) H i g h O V+\epsilon_{i}
\end{array}
$$

where $i$ indexes properties sold at time $t$; the time subscript is suppressed to emphasize the essential cross-sectional nature of the regression. ${ }^{26}$ The vector of quality hedonics is given by $\mathbf{X}_{\mathbf{i}}$; location (distances and neighborhood dummies) are represented by the vector $\mathbf{S}_{\mathbf{i}}$ and time dummies by the vector $\mathbf{Y}_{\mathbf{i}}$. We allow for the nonlinearity illustrated by Figure 2.I with two dummy variables: Fulldev is one if $\ln D_{i}$ is zero, otherwise zero; $\mathrm{HighOV}$ is one for the sales with relatively high values for $\ln D_{i}$ (e.g. , upper $25^{\text {th }}$ percentile), otherwise

${ }^{26}$ The empirical estimates shift coefficients over time to allow option value to vary. zero. $^{27}$ The coefficients on $\ln D_{i}$ can now be interpreted as the elasticity of house price with respect to development potential. The coefficient before the interaction of $\ln D_{i}$ and $\mathrm{HighOV}$ can be interpreted as a measure of curvature, as the price elasticity for option value is allowed to change for high option value observations. $\epsilon_{i}$ is a noise term. Concerns over potential correlations between $\epsilon_{i}$ and omitted location variables are addressed by pairing high option value properties with neighboring fully developed properties, as explained in the previous section.

Equation (2.6) is estimated by Ordinary Least Squares (OLS). We further control for location in all regressions by calculating Huber-White robust standard errors with clustering for each of the 487 neighborhoods. ${ }^{28}$

\subsection{Results}

In order to test $\mathrm{HI}$ and $\mathrm{H}_{3}$, we need to split our full 30-year sample into sub-periods based on housing market circumstances. We base these sub-periods on house price changes, so to demarcate the sub-periods we need to a house price

${ }^{27}$ The log linear transformation given by equation $(2.6)$ is highly robust whereas a maximum likelihood estimation of the nonlinear form of equation (2.5) might not converge. Convergence is especially problematical during periods with very low option value, when the last term of the equation might plausibly be omitted.

${ }^{28}$ Cameron, Gelbach and Miller (2008) suggest that 487 neighborhoods provide enough variation to obviate the need for bootstrap methods. 
CHAPTER 2. REAL OPTIONS AND PRICE VOLATILITY

Table 2.1: Summary statistics comparing matched sample with complete sample

\begin{tabular}{|c|c|c|c|c|c|c|c|c|c|c|}
\hline \multirow[b]{2}{*}{ Price (inflated to 2007 EUR) } & \multicolumn{2}{|c|}{ Full sample } & \multicolumn{2}{|c|}{ Matched sample } & \multicolumn{2}{|c|}{ NoOV } & \multicolumn{2}{|c|}{ Low OV } & \multicolumn{2}{|c|}{ High OV } \\
\hline & 345 & $(211)$ & 377 & $(247)$ & 365 & (195) & 392 & $(241)$ & 364 & $(299)$ \\
\hline Lot size $\left(m^{2}\right)$ & 515 & $(269)$ & 572 & $(280)$ & 383 & $(184)$ & 569 & $(232)$ & 767 & $(304)$ \\
\hline Interior floor space $\left(\mathrm{m}^{2}\right)$ & 146 & $(53)$ & 155 & (59) & 167 & $(68)$ & 162 & (56) & 128 & $(47)$ \\
\hline Replacement value (2007 EUR) & 153 & $(121)$ & 164 & $(136)$ & 218 & $(124)$ & 171 & $(125)$ & 96 & $(139)$ \\
\hline Dist. to water $(m)$ & 2963 & $(1757)$ & 2860 & $(1637)$ & 2856 & $(1789)$ & 2926 & $(1614)$ & 2747 & $(1510)$ \\
\hline Dist. to green space $(m)$ & 1734 & $(1477)$ & 1504 & $(1298)$ & 1500 & $(1284)$ & 1514 & $(1320)$ & 1490 & $(1269)$ \\
\hline Dist. to kindergarten $(m)$ & 583 & (396) & 593 & (378) & 594 & (396) & 595 & (375) & 590 & $(364)$ \\
\hline Dist. to primary school $(m)$ & 650 & $(330)$ & 652 & (336) & 683 & $(363)$ & 637 & (329) & 650 & $(316)$ \\
\hline Dist. to transportation hub $(m)$ & 1392 & $(1239)$ & 1730 & $(1630)$ & 1866 & $(1681)$ & 1723 & $(1652)$ & 1607 & $(1526)$ \\
\hline Minutes to center from hub & 26 & (8) & 26 & (8) & 26 & (8) & 26 & (8) & 27 & (9) \\
\hline Rail tracks $<200 m$ & 0.10 & $(0.31)$ & 0.12 & $(0.33)$ & 0.12 & $(0.32)$ & 0.12 & $(0.32)$ & 0.13 & $(0.34)$ \\
\hline Border $<200 m$ & 0.07 & $(0.25)$ & 0.07 & $(0.25)$ & 0.07 & $(0.26)$ & 0.06 & $(0.25)$ & 0.06 & $(0.24)$ \\
\hline D fully developed & 0.23 & $(0.42)$ & 0.26 & $(0.44)$ & 1 & (0) & 0 & $(0)$ & 0 & $(0)$ \\
\hline D high OV & 0.28 & $(0.45)$ & 0.26 & $(0.44)$ & 0 & (0) & 0 & (0) & 1 & (0) \\
\hline In(Development potential) & 0.38 & $(0.38)$ & 0.36 & $(0.37)$ & 0 & (0) & 0.27 & $(0.16)$ & 0.87 & $(0.25)$ \\
\hline $\mathrm{N}$ & \multicolumn{2}{|c|}{19825} & \multicolumn{2}{|c|}{6723} & \multicolumn{2}{|c|}{1767} & \multicolumn{2}{|c|}{3189} & \multicolumn{2}{|c|}{1767} \\
\hline
\end{tabular}

Notes: Means and standard deviations (in brackets). D high OV is defined I for all observations with development potential $>0.58$ and o otherwise.

index of Berlin. Before presenting the regression results of equation (2.6), we first provide this index.

\subsubsection{Berlin House Price Index}

Based on our data set of single-family homes we estimate a standard hedonic price index spanning the years 1978 through $2007 .^{29}$ We estimate time dummy coefficients for a standard hedonic functional form with no option value vari-

${ }^{29}$ Ours is the first West Berlin constant quality index based on a standard hedonic regression. Indeed, it is the first city-level transaction based hedonic index in Germany. The index is available at http: //www. lindenthal.eu. See Hoffmann and Lorenz (2006), The Committee for Land Price Valuation (Gutachterausschuss, 2008), and Schulz et al. (2003) for discussion of earlier estimates. 
ables and with constant coefficients on all property characteristics. We took the exponent of these coefficients and normalized to 100 in 1978 . The resulting price index is plotted in Figure 2.3.

The graph suggests that the Berlin housing market has experienced roughly three phases for the 30 years covered by the index. The first period, between 1978 and 1989, can be characterized by steady growth. The average nominal house price increase over this time period was 5 percent per annum. In real terms, the annual growth rate was I.9 percent.

The great expectations in the aftermath of the fall of the Wall fueled price increases, peaking in 1994 with nominal prices being 47 percent above I989 values. The average annual price increase for this period was 8.I percent in nominal terms, and 4.6percent in real terms.

In 1995, house prices decreased slightly followed by a much larger drop in 1996. In 2007, house prices were back at 1989 levels - in nominal terms. In real terms, however, prices had plummeted to 55 percent of their 1994 values, and 84 percent of their 1978 values. The average price fall between 1994 and 2007 was 2.3 percent per annum in nominal terms and 2.9 percent in real terms. The sluggish performance of the local economy, adverse demographic trends and the fading out of the Berlin subsidies, combined with low growth for German house prices in general (Lindenthal and Eichholtz, 20IO) are likely reasons for the disappointing price performance in the Berlin housing market after 1994.
Figure 2.3: West Berlin house price index

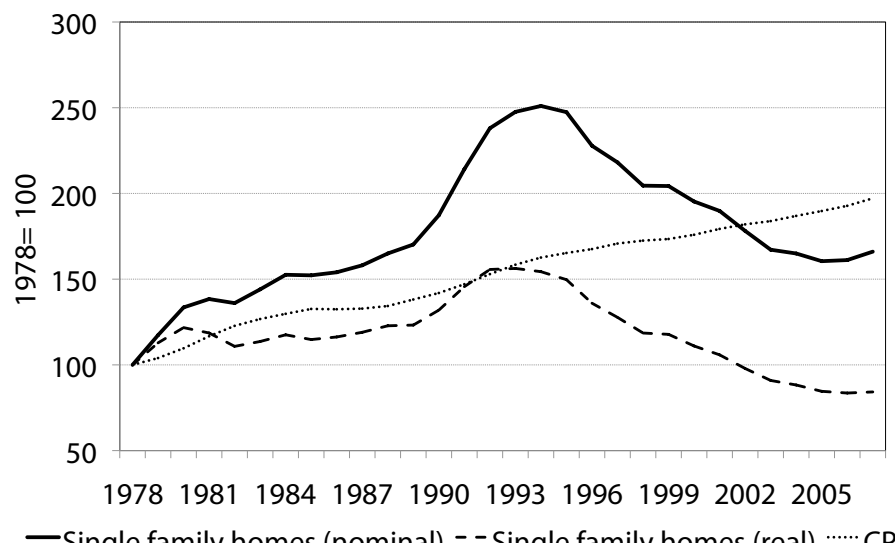

— Single family homes (nominal) - - Single family homes (real) ….. CPI

Notes: Hedonic indices for single-family homes were estimated based on a standard hedonic model with annual time dummies. The CPI index is provided by the German central bank (available online at Hedonic indices for single-family homes were estimated based on a standard hedonic model with annual time dummies. The CPI index is provided by the German central bank (available online at http://bundesbank.de/statistik/statistik_ zeitreihen.en.php?lang=en\&tr=UJFB99) 


\section{Testing the Static Option Value Model}

We first analyze redevelopment option value for the full sample period, using the regression model given by equation (2.6). Regressions Ia, $2 \mathrm{a}$ and 3 a exclude distance variables, relying on our matching of fully developed sales $\left(\ln D_{i}=0\right)$ with less developed $\left(\ln D_{i}>0\right)$ sales within half a mile to control for omitted location variables; moreover, we include 487 location dummies in all regressions. We also estimate every regression including further variables controlling for location based on geographic information systems (regressions $\mathrm{Ib}, 2 \mathrm{~b}$, and $3 \mathrm{~b}$ ).

The first two columns of Table 2.2 provide the regression results for the standard hedonic model - i.e., omitting option value variables. This model captures the cross sectional variation in Berlin house prices rather well, as the $\mathrm{R}$-squared is around 0.9. The results are robust to adding the distance variables as additional controls for location (regression Ib). Most of these variables are not statistically significant, suggesting that the 487 neighborhoods do a good job of controlling location. Within these neighborhoods, value is significantly reduced by increased distance to the nearest public transit station. Value increases with longer commuting time to the center of Berlin reflecting Berlin's industrial origins with factories and working class quarters in the center and higher quality buildings for the better off in the green belt around it.

Next, we introduce option value into the model by the log of the variable $D$ measuring development potential. Again, we use a specification with hedonics alone and one that also includes location effects. As before, time and spatial dummies are included in both setups. We have adequately captured option value only if estimates are non-negative (hypothesis $\mathrm{HI}$ ). The results presented in columns $2 \mathrm{a}$ and $2 \mathrm{~b}$ show that we cannot reject HI: the estimated elasticity of house value with respect to development potential is I6.o percent for the model with hedonics only, and I5.3 percent for the full hedonic model, both significant at the I percent level.

Moreover, the introduction of the redevelopment option into the model leads to an economically and statistically significant change in the coefficients for lot size and interior space. $^{30}$ The coefficient for lot size decreases by just over 25 percent, while that for interior space increases by about 50 percent. The effects of the other variables do not change markedly. The directions of these changes are predicted by standard omitted variables analysis: option value increases with lot size and decreases with interior space, and option value is necessarily non-negative. This implies the omission of option value from the standard hedonic will cause the co-

${ }^{30}$ Rosen's (1974) theory implies that hedonic coefficients represent implicit market prices. Our model separates option value from the present value of rent from existing characteristics. This implies that the coefficients for hedonic characteristics in our model measure the implicit value of the flow of rents, whereas those in the standard hedonic model (results in column Ia, Table 2.2) represent some combination of rental value and the value of the option. 
CHAPTER 2. REAL OPTIONS AND PRICE VOLATILITY

Table 2.2: Regression coefficients for static regressions

\begin{tabular}{|c|c|c|c|c|c|c|}
\hline \multirow[t]{2}{*}{ In(price) } & \multicolumn{6}{|c|}{ Model } \\
\hline & $1 a$ & $1 \mathrm{~b}$ & $2 a$ & $2 b$ & $3 a$ & $3 b$ \\
\hline In(lot size) & $0.474^{* * *}(0.011)$ & $0.477^{* * *}(0.012)$ & $0.361^{* * *}(0.017)$ & $0.368^{* * *}(0.018)$ & $0.399^{* * *}(0.019)$ & $0.406^{* * *}(0.020)$ \\
\hline In(interior space) & $0.243^{* * *}(0.016)$ & $0.238^{* * *}(0.017)$ & $0.368^{* * *}(0.021)$ & $0.360^{* * *}(0.022)$ & $0.344^{* * *}(0.023)$ & $0.335^{* * *}(0.024)$ \\
\hline In(replacement value) & $0.229^{* * *}(0.007)$ & $0.229^{* * *}(0.007)$ & $0.234^{* * *}(0.007)$ & $0.233^{* * *}(0.007)$ & $0.233^{* * *}(0.007)$ & $0.233^{* * *}(0.007)$ \\
\hline \multicolumn{7}{|c|}{ Logarithm of distance to ... } \\
\hline Green space & & $-0.009^{*} \quad(0.005)$ & & $-0.009^{*} \quad(0.005)$ & & $-0.009^{*} \quad(0.005)$ \\
\hline Water & & $-0.012 \quad(0.010)$ & & -0.011 & & $-0.009 \quad(0.010)$ \\
\hline Kindergarten & & -0.004 & & -0.001 & & -0.002 \\
\hline Primary school & & $-0.001 \quad(0.006)$ & & $0.001 \quad(0.006)$ & & $0.001 \quad(0.006)$ \\
\hline Publ. transport hub & & $-0.026^{* * *}(0.008)$ & & $-0.018^{* *}(0.008)$ & & $-0.020^{* *}(0.008)$ \\
\hline Minutes hub to center & & $0.092^{* * *}(0.024)$ & & $0.091^{* * *}(0.024)$ & & $0.087^{* * *}(0.024)$ \\
\hline \multirow{2}{*}{\multicolumn{2}{|c|}{$\begin{array}{l}\text { Border }<200 m \\
\text { Rail tracks }<200 m\end{array}$}} & -0.011 & & -0.012 & & -0.012 \\
\hline & & $(0.010)$ & & -0.005 & & -0.006 \\
\hline \multirow{4}{*}{\multicolumn{2}{|c|}{$\begin{array}{l}\text { In(dev. potential) } \\
\text { In(dev. pot.) D high dev. pot. } \\
\text { D fully developed } \\
\text { D high dev. pot. }\end{array}$}} & & \multirow[t]{4}{*}{$0.160^{* * *}(0.021)$} & \multirow[t]{4}{*}{$0.153^{* * *}(0.021)$} & $0.045^{*} \quad(0.026)$ & $0.038 \quad(0.027)$ \\
\hline & & & & & $0.190 * * *(0.045)$ & $0.188^{* * *}(0.045)$ \\
\hline & & & & & $0.028^{* * *}(0.008)$ & $0.028^{* * *}(0.008)$ \\
\hline & & & & & $-0.093^{* * *}(0.034)$ & $-0.091^{* * *}(0.034)$ \\
\hline Neighborhoods & \multirow{2}{*}{$\begin{array}{l}Y \\
Y\end{array}$} & $Y$ & $Y$ & $Y$ & $Y$ & $Y$ \\
\hline Time dummies & & $Y$ & $Y$ & $Y$ & $Y$ & $Y$ \\
\hline Constant & $-1.398^{* * *}(0.084)$ & $-1.328^{* * *}(0.156)$ & $-1.422^{* * *}(0.084)$ & $-1.435^{* * *}(0.152)$ & $-1.534^{* * *}(0.083)$ & $-1.537^{* * *}(0.151)$ \\
\hline R-squared & 0.903 & 0.904 & 0.905 & 0.906 & 0.907 & 0.908 \\
\hline
\end{tabular}

Notes: ${ }^{* * *} p<0.01,{ }^{* *} p<0.05,{ }^{*} p<0.1$. Robust standard errors (clustered for each of 487 neighborhoods) in parentheses, N=6688. Years covered: 1978-2007. The natural logarithm of sales prices (inflated to 2007 Euros) is regressed against a set of hedonics (lot size, interior floor space, replacement value of building) and variables describing the real option to extend the building. Development potential is defined as the ratio of maximum home size allowed under current zoning divided by current size. Time and neighborhood effects are controlled for by spatial (i.e. , neighborhood) and temporal dummies. Fully developed sales with lot size greater than the median (523 square meters) are matched with sales within half a mile to construct the 487 neighborhoods. 
efficient of lot size (interior area) to be biased upward (downward).

We subsequently investigate the effect of option value by introducing dummies for dwellings with high development potential $(\mathrm{HighOV})$ and with zero development potential (Fulldev), and by including an interaction term of the development potential with the dummy for high development potential. The coefficients for these variables allow for curvature of the option value with respect to the development potential illustrated by Figure 2.I. The results are provided in columns $3 \mathrm{a}$ and $3 \mathrm{~b}$ of Table 2.2. The curvature with respect to the development potential axis is as predicted by Figure 2.I and $\mathrm{H} 2$. The results show that the elasticity of house value with respect to development potential is about 23.5 percent $(=.045+.190)$ for the $\mathrm{I}, 767$ sales with the highest development potential. These are the smaller structures on large lots in neighborhoods where the option is likely to be in-themoney. The statistically significant 2.8 percent premium for fully developed properties controls for a residual location effect: better located properties are likely to be developed first.

The significant 9.4 percent discount on the high option value dummy does not mean that high option value homes carry a discount. This negative intercept is more than offset by the larger coefficient for ln(development potential). Multiply this coefficient estimate (0.19+0.045) with the minimum value for $\ln$ (development potential) for high option value sales (0.58) to get 0.1 I and add-0.093. In other words, the high option value properties start at a value of 4.4 percent in addi- tion to property value and increase to a mean $\left(75^{\text {th }}\right.$ percentile $)$ of I0.0 (I4.7) percent. The sale with the largest option value has 80.4 percent of property value in the redevelopment option.

\subsubsection{Option Value During the Boom and Bust Years}

The two pronounced phases of boom and bust evident in the graph of Berlin house prices depicted in Figure 2.2 provide for a natural experiment. We expect substantial option value to be created during the boom years, while much of this should dissipate during the subsequent bust.

To test whether option value does indeed go up in the boom and down in the bust, we estimate a hedonic model in which we approximate the boom period with a dummy variable for the six years from 1990 through 1995, and the bust with a dummy for the years from 1996 through 2007. The left out time period is the "quiet" period preceding the Big Bang events: the period from 1978 through 1989.

The basic setup of this model includes hedonic variables, dummies for the boom and bust years and spatial dummies. The results are presented in Table 2.3, model I. House value increases I0.4 percent during the boom, in real terms. During the bust house values average about $\mathrm{I} 7.4$ percent less than during the boom and 6 percent less than during the quiet period between 1978 and I989. The (average) decline from boom to bust of about 16 percent is statistically significant. 
CHAPTER 2. REAL OPTIONS AND PRICE VOLATILITY

Table 2.3: Regression coefficients for time-varying option value models

\begin{tabular}{|c|c|c|c|c|c|c|}
\hline Variable & 1 & 2 & 3 & 4 & 5 & \\
\hline In(lot size) & $0.480 * * \quad(0.01)$ & $0.364 * * \quad(0.02)$ & $0.399^{* *}(0.02)$ & $0.401^{* *}(0.02)$ & $0.399^{* *}$ & $(0.02)$ \\
\hline In(int. space) & $0.250 * * \quad(0.02)$ & $0.378^{* *}(0.02)$ & $0.355^{* *}(0.02)$ & $0.354^{* *}(0.02)$ & $0.356^{* *}$ & $(0.02)$ \\
\hline In(replacement value) & $0.228^{* *}(0.01)$ & $0.233^{* *}(0.01)$ & $0.232^{* *}(0.01)$ & $0.232^{* *}(0.01)$ & $0.232^{* *}$ & $(0.01)$ \\
\hline period = boom (1990-1995) & $0.099^{* *}(0.02)$ & $0.100^{* *}(0.02)$ & $0.101^{* *}(0.02)$ & $0.101^{* *}(0.02)$ & $0.101^{* *}$ & $(0.02)$ \\
\hline period = bust (1996-2007) & $-0.062^{* *}(0.01)$ & $-0.057^{* *}(0.01)$ & $-0.059^{* *}(0.01)$ & $-0.056^{* *}(0.01)$ & $-0.055^{* *}$ & $(0.01)$ \\
\hline In(dev. potential) & & & $0.060^{*} \quad(0.03)$ & & & \\
\hline $\mid$ quiet & & $0.220^{* *}(0.03)$ & & $0.130 * * \quad(0.05)$ & $0.127^{* *}$ & $(0.04)$ \\
\hline - boom & & $0.272^{* *}(0.03)$ & & $0.154^{* *}(0.04)$ & $0.144^{* *}$ & $(0.05)$ \\
\hline - bust & & $0.118^{* *}(0.03)$ & & $0 \quad(0.03)$ & 0.008 & $(0.03)$ \\
\hline \multicolumn{7}{|c|}{ In(dev. potential ratio) $\cdot$ D high dev. potential } \\
\hline |. quiet & & & $0.231^{* *}(0.05)$ & $0.178^{* *}(0.05)$ & $0.259^{* *}$ & $(0.07)$ \\
\hline - boom & & & $0.274^{* *}(0.04)$ & $0.200 * *(0.05)$ & $0.334^{* *}$ & $(0.07)$ \\
\hline - bust & & & $0.146^{* *}(0.05)$ & $0.196^{* *}(0.05)$ & $0.143^{*}$ & $(0.06)$ \\
\hline D high dev. potential & & & $-0.094^{* *}(0.03)$ & $-0.097^{* *}(0.03)$ & & \\
\hline | quiet & & & & & $-0.168^{* *}$ & $(0.05)$ \\
\hline - boom & & & & & $-0.217^{* *}$ & $(0.05)$ \\
\hline . bust & & & & & -0.051 & $(0.04)$ \\
\hline D fully developed & & & $0.029^{* *}(0.01)$ & $0.029^{* *}(0.01)$ & & \\
\hline | - quiet & & & & & 0.032 & $(0.02)$ \\
\hline - boom & & & & & $0.032^{*}$ & $(0.01)$ \\
\hline - bust & & & & & $0.027^{*}$ & $(0.01)$ \\
\hline Constant & $-1.052^{* *}(0.08)$ & $-1.077^{* *}(0.08)$ & $-1.187^{* *}(0.08)$ & $-1.196^{* *}(0.08)$ & $-1.194^{* *}$ & $(0.09)$ \\
\hline R-squared & 0.899 & 0.903 & 0.905 & 0.905 & 0.905 & \\
\hline
\end{tabular}

Notes: ${ }^{* *} p<0.01,{ }^{*} p<0.05,{ }^{\dagger} p<0.1$. Robust standard errors in parentheses. $\mathrm{N}=6688$. The natural logarithm of sales prices (inflated to 2007 Euros) is regressed against a set of hedonics and variables describing the real option to extend the building. Development potential is defined as the ratio of maximum home size allowed under current zoning divided by current size. Under model specifications 5-8, the option value coefficient is allowed to change across three time periods: build-up (1978-1989), boom (1990-1995) and bust (1996-2007). Neighborhood effects are controlled for by spatial dummies. 
To investigate the effect of option value on long-term house price movements - and to test $\mathrm{H}_{3}$ - model 2 includes development potential in the regression, and it is interacted with the market phase dummies. The results show that we cannot reject $\mathrm{H}_{3}$ : redevelopment potential has a significantly positive effect on value in the relatively quiet first period, and this effect goes up during the boom - but the difference is not significant. During the boom, the elasticity of house value with respect to development potential is 0.272 , even exceeding the elasticity on the high option value properties in the static regressions (Table 2.2, models $3 a$ and $3 b$ ). As predicted by the theoretical model, the redevelopment option elasticity shows a statistically significant decline of more than 0.15 in the subsequent bust. ${ }^{31}$ During the bust the elasticity was roughly half what it was during the quiet period, indicating a very substantial decline in option value over the market cycle.

To check for robustness of the results, we try a number of alternative specifications of the model with the timedependent redevelopment option. First, we investigate the effect of the redevelopment option by only letting the redevelopment option for dwellings with high redevelopment potential be time-dependent, keeping the other measures of option value constant. The results, model 3 of Table 2.3, do not materially differ from model 2.

Models 4 and 5 test hypotheses $\mathrm{H}_{2}$ and $\mathrm{H}_{3}$ simultaneously

${ }^{31}$ Note that the introduction of the redevelopment option has an effect on the coefficients for lot size and interior space similar to the static model. by shifting the elasticity with the dummy for high development potential and allowing all elasticity coefficients to shift over the three sub-periods. Again, $\mathrm{H}_{2}$ and $\mathrm{H}_{3}$ cannot be rejected: the coefficients on the interaction term in all three periods are significantly positive. In both specifications, the coefficient for option value in the boom is statistically and economically significant, but the difference with the coefficient for the quiet period is not statistically significant. For the bust, we do find a statistically significant negative difference with the preceding periods. For high option value properties, the elasticity is over .47 (.I4 plus .33) during the boom; it declines by two thirds, to .I5 during the bust; interestingly, high option value properties retain a significant positive elasticity even during the bust. For low option value properties the elasticity of .I4 goes to zero during the bust phase. ${ }^{32}$

Table 2.4 converts the elasticity estimates in Table 2.3 into the amount of option value over time for low and for high option value sales. ${ }^{33}$ Table 2.3 suggests that the share of

${ }^{32}$ Adding the high development potential dummy confirms Hi since the minimum $\left(25^{\text {th }}\right.$ percentile) of $\ln (D)$ for these properties is $.58(.68)$. This implies that option value as a percentage of property value is a minimum of 6 percent during quiet and boom periods and 3.7 percent during the bust. For the $25^{\text {th }}$ percentile property these numbers are about Io percent and 5 percent. Note that fully developed properties have a 3 percent premium during all phases of the cycle.

${ }^{33}$ This is done by multiplying the point estimates of elasticities by the appropriate mean values of the development potential variable (Table 2.I): 0.27 for the 3189 mid range sales and 0.87 for the 1767 high option value sales. Then the coefficient on the appropriate dummy for high development po- 
option value in transaction prices increased by between 15 and 20 percent during the boom for both low and high option value properties. During the bust, option value dropped to less than half of its pre-boom percentage for high option value properties, and the 4 percent option premium for properties with low development potential disappears. The relative magnitude of the change was uniform across the low and high option value segments, and it is robust across model specifications 3 through 5 .

Translating these relative numbers into Euro amounts visualizes the economic magnitude of the real option component in home values. Model specifications 3 through 5 imply that the option to add more space to the building is worth up to EUR 98,000 for high option value sales during the boom. Due to the high elasticity of property value with respect to development potential, and the increase in this elasticity during the boom, roughly 40 percent of the change in house value from the quiet period was due to change in option value. During the bust, about 50 percent of the decline in value was due to changes in option value. Turning to properties with low option value (nearly half of the sales we examined) option value also seems to contribute to the volatility of house prices. This is especially true during the bust, when about 12 percent of the decline in value is due to change in option value.

tential is added: the exponent of the result is option value as a percentage of property value.

\subsubsection{Generality of Results}

We control for location factors by pairing fully developed sales with nearby sales of those with some development potential. Specifically, we selected a sample of 6,723 sales from the full sample of 19,825 . This is the 35 percent of sales on lots above median for the full sample and with at least 9 sales within a half-mile ring of the fully developed sales. The resulting sample has sales in 35 of West Berlin's 47 neighborhoods as defined by the government. ${ }^{34}$ We calculate that 68 percent of all single-family homes in the full sample have at least io percent development potential. For homes with lot sizes bigger than the median, the share increases to 90 percent. With more than two thirds of all buildings sold being subject to changes in embedded real option value, our results can be generalized to Berlin's market for single family homes.

\subsection{Conclusions}

This paper investigates the effects of the redevelopment option on the value of existing dwellings, based on a theoretical model showing that option value is additive to the use value of the existing characteristic vector. In our hedonic model, implicit market prices measure the value of rents from existing property characteristics, while additionally, a market

34 The 47 government neighborhoods cover all of West Berlin; they are not overlapping. See Figure 2.2 for a map. 
CHAPTER 2. REAL OPTIONS AND PRICE VOLATILITY

Table 2.4: Share of option value in total home value in boom and bust period

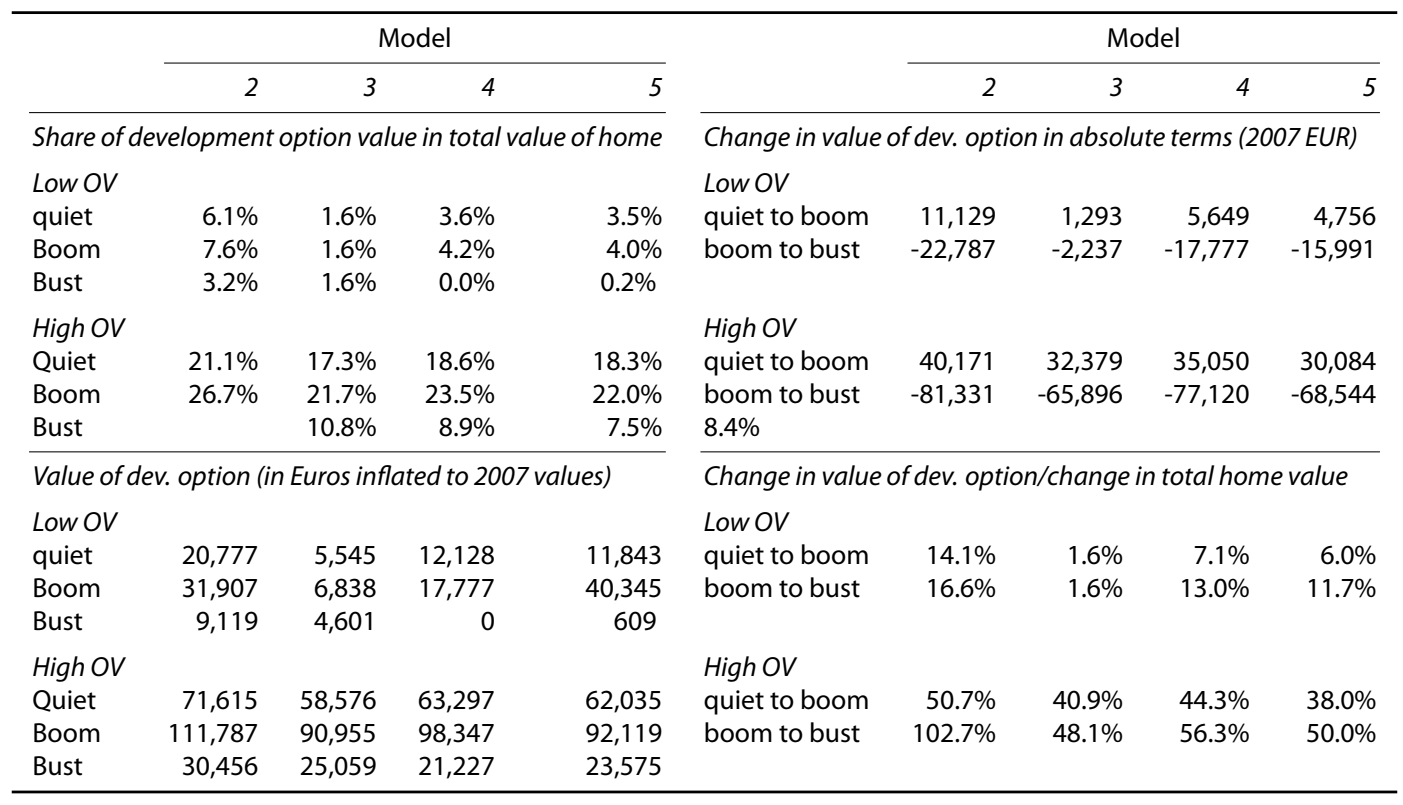

Notes: : All calculations are based on coefficients from Table 2.3. As an example of percentages consider high OV during the quiet period, I8.3 \% $=$ $\exp \left((.127+.259)^{*} 0.87-0.168\right)$, where 0.87 is the mean value for $\ln (D)$ from Table 2.I. To convert the percentages into Euros, we used the median transaction prices for each phase in our sample: For the build-up period, the median price was EUR 339,500, for the boom phase EUR 4I8,700 and for the bust phase EUR 28I,700. 
premium is paid for the option to tear down and replace, or substantially redevelop, the existing property. Theory implies that any redevelopment option value is a function of unrealized development potential for the dwelling. We propose to identify high option value properties by dividing the maximum structure allowed by zoning by the existing structure size. We identify neighborhoods with high option value by finding fully developed properties on lots above median size. The presence of neighboring properties with unrealized development potential establishes the possibility of inthe-money option value after controlling for location. The effect of option value on property value is expected to be highly nonlinear, to increase during periods of high volatility and/or rising house prices, and to decrease in periods with falling house prices.

A new database consisting of West Berlin house sales spanning the years 1978 through 2007 allows us to analyze the effects of the redevelopment option over different phases in the housing market cycle. The main prediction of theory is confirmed: the elasticity of house value with respect to development potential is 15 percent on average over our full sample period; for high development potential homes, the elasticity increases to 23 percent.

The time period covered in the dataset includes Berlin's Big Bang, which coincided with a boom in house prices, followed by a prolonged bust. The constant quality house price index presented in this paper shows that average house prices fell every year in the Io years after 1994, losing 45 per- cent in real terms from their peak. For high option value homes, about 40 percent of the price increase during the boom years can be explained by the change in the value of the redevelopment option, while about 50 percent of the of the subsequent fall in prices can be attributed to reduction in option value. For low option value homes, the effects on the real estate cycle are less pronounced but still economically significant. These results generalize to about 75 percent of West Berlin neighborhoods by geography and to 68 percent of all sales.

Our results support our re-interpretation of coefficients from standard hedonic models. When an appropriate option value variable is included in the regression, the coefficients on hedonic variables should be interpreted as the implicit market value of rental income. When the option value variable is excluded, these coefficients include the effects of additive option value. The difference is very large in our empirical findings: the coefficient on the log of lot size (log of interior area) is about 25 percent lower (50 percent higher) when the development potential variable is included in the regression. 


\section{Appendix A: Derivation of Hedonic Model with Option Value}

The model setup and definitions of terms are given by equation (2.I). Simplify by noting that the integrals from $T$ to infinity can be restated as the integrals from o to infinity discounted back to the present:

$$
\begin{array}{r}
P_{i}=\frac{r^{\prime} q_{i}^{0}}{(\rho+\delta-\mu)}+ \\
\max \left(e^{(\mu-\rho) T} \frac{r^{\prime} q_{i}^{n}}{(\rho+\delta-\mu}-e^{(\mu-\rho-\delta) T} \frac{r^{\prime} q_{i}^{0}}{(\rho-\mu)}-k e^{-\rho T}, 0\right)
\end{array}
$$

The scalars for values at time o, $v_{i}^{0}$ and $v_{i}^{n}$ further simplify notation. Moreover, assuming zero depreciation, $\delta=0$ gives the simplest possible closed form solution, as can be seen by examining equation (2.7). This case is particularly relevant in West Berlin, where our data do not contain property age or any other way to separately identify depreciation. The maximization problem then simplifies to:

$$
P_{i}=v_{i}^{0}+\max \left(e^{(\mu-\rho) T}\left(v_{i}^{n}-v_{i}^{0}\right)-k e^{-\rho T}, 0\right)+\epsilon_{i} .
$$

This is a special case of equation (2.3) in the text. The first order condition (FOC) for choosing $\mathrm{T}$ to maximize equation $(2.8)$ is: 35

$$
e^{(\mu-\rho) T^{*}}\left(v_{i}^{n}-v_{i}^{0}\right)=\frac{\rho}{\rho-\mu} k e^{-\rho T^{*}}
$$

At the time of redevelopment $T^{*}=0$, equation (2.9) implies that the net increase in value is a multiple of cost because the option to delay has value.

The second order condition evaluated at $T^{*}=0$ is $-(\rho-$ $\mu)\left(v_{i}^{n}-v_{i}^{0}\right)<\rho^{2} k$. This must hold given finite value, $\rho-\mu>$ 0 .

Define $X_{i}=\left(\frac{\rho}{\rho-\mu}\right)\left(\frac{k}{\left(v_{i}^{n}-v_{i}^{0}\right.}\right)$. The solution to the maximization problem in equation $(2.8)$ is now seen to depend on:

$$
e^{\mu T^{*}}=e^{\ln X_{i}}=X_{i} ; \quad e^{-\rho T^{*}}=e^{-\frac{\rho}{\mu} \ln X_{i}}=X_{i}^{-\frac{\rho}{\mu}}
$$

Substitute into equation (2.8) given $T=T^{*}$ to derive the solution given in the text as equation (2.5):

$$
P_{i}=v_{i}^{0}+\left(\frac{\mu}{\rho-\mu}\right) k\left[\left(\frac{k}{v_{i}^{n}-v_{i}^{0}}\right) \frac{\rho}{\rho-\mu}\right]^{-\frac{\rho}{\mu}}+\epsilon_{i}
$$

Generalization to a Wiener process for rents

The additive functional form given by equation (2.II) survives the introduction of a stochastic process for rents. Simplify by reducing the vector of hedonic characteristics to a

${ }^{35}$ In the following, we maximize under the assumption that $T^{*}>0$ : i.e at time $t=0$ parameters are such that the value gap $\left(v_{i}^{n}-v_{i}^{0}\right)$ is rising towards a trigger point where equation (2.9) holds. 
scalar, $s_{i}^{0}$, which implies that rent, $p$ is also a scalar. Consider an Ito process for the rent:

$$
\frac{d p}{p}=\mu d t+\sigma d W
$$

where the rate of drift per unit time, $t$ is $\mu$ and $\sigma$ scales the variance of a standard Wiener process, $d W$.

Given these simplifying assumptions and the stochastic process in equation (2.12), Clapp, Jou and Lee (2009) derive the following solution where the new aggregate level of the hedonic vector $s_{i}^{n}$, is chosen optimally:

$P_{i}=v s_{i}^{0}+B_{0}\left(s_{i}^{0}\right)^{B_{1}}+\epsilon_{i} \quad$ where $\quad B_{1}<0, \quad B_{0} \geq 0, v \geq 0$

The $B_{i}$ parameters are functions of the current level of price, the constant rate of interest $\rho$, the rate of depreciation $\delta$, the parameters of equation (2.12) and parameters of the cost function. 


\section{Chapter 3}

\section{Demographics, Human Capital, and the Demand for Housing}

This chapter is joint work with

Piet Eichholtz (Maastricht University).

The study received the AAREAL Best Research Paper Award, 2OIO, and the European Real Estate Society(ERES) Doctoral Prize, 2007.

\subsection{Introduction}

I8 years after Mankiw and Weil started a short-lived but intense debate on how demographics drive the demand for housing, empirical evidence is still not conclusive, especially in an international context. Demographic change, however, is one of the key challenges many industrialized countries will face in the future. To give a brief example, the United $\mathrm{Na}-$ tions Population Division (2007) estimates that Russia will lose 24 percent of its current population by the year 2050 . For Bulgaria, the expected decline in total population is 35 percent in the same period, while neighboring Turkey will experience an impressive population growth of 29 percent. On a regional level, population changes are even more pronounced. The German federal state of Thuringia, for example, is already losing I percent of its population annually (Thüringer Landesamt für Statistik, 2008). Beside the rapid changes in total populations numbers, societies will age dramatically. In South Korea, for instance, the median age is increasing three years every five years and the share of inhabitants older than 60 years will increase from i 4 percent now to 42 percent in 2050 . International demographic dynamics dwarf the so-called baby bust in the United States.

Given the fundamental demographic change currently underway, it is surprising how few studies have researched the 
effect of demographics on housing markets in Europe and Asia. For Japan, Ohtake and Shintani (1996) find that demographic change has a significant effect on housing prices through the short-run adjustment process in the housing market. Ermisch (1996) establishes a link between age (among other demographic variables) and the level of housing services demanded in six British agglomerations. Lindh and Malmberg (1999) show that the population's age structure is related to residential construction in Sweden and other OECD countries. Lee et al. (2OoI) find evidence that demographics do explain the amount of housing services demanded in Austria. Neuteboom and Brounen (2007) predict Dutch housing demand to increase with household age.

In their controversial work, Mankiw and Weil (1989) modeled the per-capita quantity of housing demanded as a function of age. Analyzing 1970 census data for the US, they found demand for housing to be very low for residents younger than 20 years, to shoot up for 20-35 years-olds, and to decline constantly thereafter. Furthermore, they created a time series of housing demand by combining the cross-sectional results on the age-specific quantity of housing demand with time series data on the age composition of the population. Regressing this demand time series against the aggregated housing quantity (represented by the net stock of residential capital) revealed no significant dependency. Real house prices, however, were found to depend on demand as defined by their model. Mankiw and Weil concluded that the ageing baby-boom generation's move out of the high-demand age- classes would drive total demand down and result in a sharp drop in house prices.

Criticism of this paper came from many directions: Peek and Wilcox (I99I) investigated the movements of house price indices and found that real after-tax interest rates and construction costs were the main determinants of price swings. Demographic variables like income and age were still significant but not as pronounced as suggested by Mankiw and Weil. Hendershott's (I99I) main point of criticism was the lack of predictive power of the Mankiw and Weil models for the I970s and I980s, making predictions for the I990s impossible. In addition, he criticized the negative time trend in their basic equation which accounts for most of the predicted decline Mankiw and Weil had explained by demographics.

Engelhardt and Poterba (199I) applied the Mankiw and Weil approach to new data. For Canada, they observed an age-housing demand relationship similar to the one Mankiw and Weil found for the US. Canadian house prices, however, were not determined by the derived demand variable.

Green and Hendershott's (1996) paper was the next cornerstone of the debate. They followed Mankiw and Weil in linking per capita housing expenditures and demographic information based on cross-sectional data from the 1980 census. The methodology, however, advanced in two aspects: first, they estimated the real contribution each hedonic characteristic of a dwelling makes to the household's housing expenditures. This made it possible to control for the quantity and quality of housing services consumed. Second, they re- 
gressed the marginal prices of each of these hedonic characteristics against the demographic variables of the household. These innovations allowed the quantity of housing services consumed (by defining a constant quality house) and all demographic characteristics but age to be kept constant. They found that demand for housing does not decline with age, but rather that education and income determine the quantity services of housing consumed. This implies that Mankiw and Weil underestimated the housing services the baby-boom generation would demand in the future by not controlling for the fact that younger generations enjoyed a better education than their predecessors.

This paper extends the work of Green and Hendershott (1996) in three directions: first, we refine the existing methodology and model the demographic dynamics more carefully. We separate life cycle variables, that change their values according to the household's state in the life cycle, from cohort variables, which do not change with age. Instead of allowing every demographic variable to vary (like Mankiw and Weil, I989), or keeping all demographics constant (like Green and Hendershott, 1996) we explicitly consider the change in the life cycle variables like income or household size over time. This leads to a more robust projection of housing demand.

Second, a very detailed micro-dataset provides information on the hedonic attributes of a representative share of English residential real estate in combination with extensive demographic information on the respective households.
The majority of earlier studies was based on publicly available census cross-sections. These are easy to analyze, allow for very large samples, and are very representative. On the downside, however, census data offers only very basic information on the physical attributes of the dwellings ${ }^{\mathrm{I}}$. Fortunately, our data set offers rich information on the physical characteristics of individual homes, their interior and exterior condition, energy efficiency, the local environment, and the attitudes of the inhabiting households towards their residence as well as similarly detailed information on the household's demographic profile. Overall, more than 900 variables are coded in the data set, of which approximately two thirds are relating to the dwelling, and one third to the household.

Third, using English data gives us the opportunity to analyze an environment different from the Unites States. This international perspective is crucial since demographic changes in the US are, although important, dwarfed by the developments in Europe and Asia. The United States are projected to experience further population growth (albeit at a lower rate than before) combined with a younger age distribution than most European countries.

Britain is not expected to have a demographic contraction like continental European countries, especially in Central and Eastern Europe, but the situation is very distinct from the US and Canada. The British population growth is

${ }^{\text {I}}$ Green and Hendershott (I996), for instance, had to restrict their analysis to I8 hedonic variables of housing quality, including 8 regional dummies. 
leveling off more rapidly and the population's age structure is already older than the American. Until 2050, the projected growth rate in British population numbers is less than half the American equivalent ${ }^{2}$. This makes the UK housing market a very interesting environment to investigate demographic implications.

The remainder of the study is organized as follows. In the first sections, we present the method and data we use. Section 4 discusses the results and establishes a link between demographics and housing demand. Continuing in Section 5, we combine our results with demographic projections, allowing for demand forecasts for the next 20 years. A summary and discussion of the main results finishes the paper.

\subsection{Method}

We follow the method first proposed by Rosen (1974) and subsequently refined by Green and Hendershott (1996). The first step is to estimate the relationship between the flow of housing services and the hedonic characteristics of the dwelling:

$$
q=f(Z),
$$

where $q$ is the flow of housing services from the dwelling (rent paid or user costs of housing - for a discussion see the next section), and $Z$ is a vector of the hedonic characteristics

${ }^{2}$ The United Nations project the population growth from 2010 to 2050 to be II \%, while the United States will enjoy a total population increase of $27 \%$. of the house. Then, we take the derivative of $f$ and obtain the real marginal contribution $q_{i}$ of each hedonic characteristic to housing demand:

$$
q_{i}=\frac{\partial f}{\partial z_{i}}(Z)
$$

In the last step, the marginal contributions obtained from (2) are regressed against the demographic characteristics of the household:

$$
q_{i}=g_{i}(Z, A, X, Y),
$$

where $X$ is a vector of the demographic characteristics of the household. The household's age $A$ and income $Y$ are excluded from $X$ and controlled for separately (Green and Hendershott, 1996).

Again following Green and Hendershott (1996) in selecting functional forms for (I) and (3), we use the translog function by Christensen et al. (I975) to estimate equation I:

$$
\ln (q)=\alpha_{0}+\sum_{i=1}^{n} \alpha_{i} \ln \left(z_{i}\right)+0.5 \sum_{i=1}^{n} \sum_{j=1}^{n} \beta_{i j} \ln \left(z_{i}\right) \ln \left(z_{j}\right)+\epsilon
$$

$\alpha_{0}$ being the intercept, $\alpha_{i}$ the coefficient of characteristic $i$, and $\beta_{i j}$ is the coefficient of the characteristics $i$ and $j$ interacting. $\epsilon$ is independently and normally distributed $\left(\mathrm{I}^{\prime}\right)$ and is estimated subject to the following restrictions:

$$
\sum_{i=1}^{n} \alpha_{i}=1
$$




$$
\begin{gathered}
\sum_{i=1}^{n} \beta_{i j}=0 \\
\beta_{i j}=\beta_{j i} .
\end{gathered}
$$

We restrict (I) to be homogeneous of degree one, therefore the aggregated housing service of a house can be computed (based on Euler's theorem) as:

$$
q=\sum_{i=1}^{n} q_{i} z_{i}
$$

where $z_{i}$ is the amount of characteristic $i$ included in the house. Taking partial derivatives of $\left(\mathrm{I}^{\prime}\right)$ with respect to $z_{i}$ gives us the hedonic prices $q_{i}$ :

$$
q_{i}=\frac{\partial q}{\partial z_{i}}=\left(\alpha_{i}+\sum_{j=1}^{n} \beta_{i j} \ln \left(z_{i}\right)\right) \frac{q}{z_{i}}
$$

Considering the case when markets are perfect and housing suppliers have identical cost functions, all variation in $q_{i}$ is caused by nonlinearities in the hedonic model (I). Residents, however, have heterogeneous utility functions depending on tastes and demographics. In the last step, we regress $q_{i}$ on the demographic variables and on the level of $z_{i}$ :

$$
q_{i}=\gamma_{0}+\gamma_{z} z_{i}+\sum_{a=1}^{14} \gamma_{a} A_{a}+\psi X+\gamma_{y} Y+\sum_{a=1}^{14} \gamma_{y a} Y A_{a}+\mu
$$

where the $\gamma$ 's are individual coefficients, $A_{a}$ are dummies for I4 five-year age cohorts (starting at age 15), and $\mu$ is independently and normally distributed. $Y$ is the household's income net of housing expenditures, while the vector $\psi$ contains the coefficients for the other demographic variables in $X$.

The service flow provided by the $i$ th hedonic characteristic varies with age-class $j$ :

$$
q_{i j}=\gamma_{0}+\gamma_{z} z_{i}+\sum_{a=1}^{14} \gamma_{a} A_{j a}+\psi X_{j}+\gamma_{y} Y+\sum_{a=1}^{14} \gamma_{y a} Y_{j} A_{j a}
$$

where $X_{j}$ and $Y_{j}$ contain the demographic profile of the household and its income.

Life-cycle variables like the household's size, employment status, physical fitness, and, most importantly, household income are unlikely to stay constant when households age. Cohort variables like educational level, gender, and ethnicity will not change in age. Instead of allowing every demographic variable to vary (like Mankiw and Weil, I989), or keeping all demographics constant (like Green and Hendershott, I996) we explicitly model the change in the life cycle variables like income ${ }^{3}$ over time, while keeping the cohort variables constant.

Like Campbell et al. (200I), we use income dynamics estimates derived from a household panel to calibrate the model.

${ }^{3}$ Hwang and Quigley (2006), in establishing a causality between income and housing services consumed, find that exogenous increases in aggregated income drive house prices up. 
For the I99I-200I waves from the British Household Panel Survey, we estimate a fixed effect model:

$$
\begin{array}{r}
\ln (\text { income })_{i, t}=\mu_{i}+\sum_{a=21}^{75} \delta_{a} D A_{a, i, t} \\
+\sum_{a=21}^{75} \sum_{e d u=1}^{3} \eta_{a, e d u} D A_{-} E d u c_{a, e d u, i, t}+\nu_{i, t}
\end{array}
$$

where $\mu_{i}$ is capturing household fixed effects, $D A_{a}$ is a dummy variable equal to I for households with a head aged $a$ (and o otherwise), DA_Educ are age-education interaction dummies, $\delta$ and $\eta$ are coefficients, and $\nu$ is independently and normally distributed.

Furthermore, we assume household size, employment, and physical fitness to change as people reach age 60 and above. Ermisch (1996) argues that household types change in the household life cycle, and we let this variable adjust to representative values for each age-class.

Finally, total demand for housing $q$ can be obtained by summing over the age classes and then the housing characteristics:

$$
q=\sum_{a=1}^{14} \sum_{i=1}^{n} w_{a} q_{i a}
$$

where $w_{a}$ is the share of households in age-class $a$.

\subsection{Data}

This paper builds on data collected for the English Housing Condition Survey (EHCS). The EHCS is a study undertaken by the Office of the Deputy Prime Minister to assess the condition of the English ${ }^{4}$ housing stock and to evaluate the effect of housing market policies. A representative cross-section of households is interviewed about their views on their home and neighbourhood, their income, and housing costs, and about demographic details of the household's members. Additional information on the interior and exterior condition of the dwelling, its energy efficiency, and the local environment is obtained by a subsequent professional inspection. Each dwelling's market value is estimated by two professional appraisors independently (Office of the Deputy Prime Minister, 2003). From I97I until 200I, the EHCS was conducted every five years. Since April 2002 the EHCS has been running on a continuous basis ${ }^{5}$.

For $\mathbf{1 7 , 5 0 0}$ dwellings a full interview, physical survey, and

${ }^{4}$ Similar studies have been undertaken for Wales and Scotland, but unfortunately these surveys are not entirely equivalent to the EHCS. We will therefore use English data only.

5The English Housing Condition Survey gradually evolved over time which makes it difficult to combine the data from different years in quasi-panels. Multiple demographic key variables like the education of the household's members or their attitudes towards the dwelling they live in were only introduced in 200I. Our later analysis shows that especially the educational achievement is crucial in explaining the willingness to pay for housing, thus we do not consider the pre-200I cross-sections, which lack this information. 
market valuation is obtained. Excluding vacant dwellings leaves us with a sample of 16,749 households covering all tenures and regions. The EHCS is based on a stratified sample with over-sampling of the rented tenures, which otherwise would be too small a sample to allow for reliable results. As a consequence of this sampling technique, each observation must later be weighted with a grossing factor when calculating aggregated national figures from this sample (ODPM, 2002).

The rental market for housing is subject to two strong sources of governmental intervention: first, Local Authorities (LA) and Registered Social Landlords (RSL) offer relatively inexpensive housing to low- and middle-income households. Affordability is important, since the median of the income ${ }^{6}$ of tenants from RSL or LA dwellings is only two

We have access to the continuous survey data for 2002, 2003, and 2004. Again, the number of variables is lower than in 200I. Pooling these years does not create additional information, since interesting details will be lost. In addition, the number of observations per year is roughly half the number of 200I, making an analysis based on single years with a large number of explanatory variables impossible.

Overall, demographic changes between 200I and 2004 are not very pronounced since the period is relatively short. Possible changes in demand patterns over time will be mainly caused by other factors like the expected changes in house prices, risk premia, or the cost of housing financing. In sum, we prefer the richness of the 200 I data set over the intersection of more years.

${ }^{6}$ Income is the annual net income of the household reference person and any partner from wages, pensions, savings and social benefits. It does not include housing related benefits such as council tax benefit, housing benefit, thirds of the median of income renters in the unregulated market. Second, a substantial share of low-income households are eligible for direct housing subsidies, especially the very young and the old households. Where housing benefits are paid, they amount to $85 \%$ of all rent paid on average.

For this study, both forms of state intervention cause severe distortions, since we assume that subsidies will shift demand upwards, and the choice of dwelling characteristics will no longer be solely determined by the household's housing preferences and budget. We therefore exclude all dwellings rented from Local Authorities and Registered Social Landlords, which further reduces our sample to 9,453 observations. After grossing the remaining observations still represent $80 \%$ of the English housing stock, according to the Office of the Deputy Prime Minister (ODPM, 2002).

Single cross-sections can obviously provide information for one moment in time only. Disentangling age effects common to all households from cohort effects is impossible. When one generation has a relatively strong willingness to pay for housing services (after controlling for income etc.), studies based on one cross-section necessarily have to assume that the following generations will have the same preference when reaching this age. Forecasts can be inaccurate in case there are inter-generational differences in tastes ( $\mathrm{My}-$ ers, 1999). The data this paper is based on allow us to analyze one cross-section only, thus our findings are subject to this

Income Support Mortgage Interest or any payments made under a Mortgage Payment Protection Insurance policy (ODPM, 2002). 
limitation.

The EHCS classifies dwellings into the following categories: small terraced houses, large terraced houses, (semi)detached houses, bungalows, and flats ${ }^{7}$. Dwelling types are relatively similarly distributed in 8 out of Io regions. (Semidetached houses and bungalows make up the largest share (54\%), followed by terraced houses (29\%) and flats (I8\%). Inner and Outer London, however, have a different structure, with less houses $(67 \% / 35 \%)$ and a higher share of apartments $(34 \% / 65 \%)^{8}$.

With respect to the year of construction, all dwellings are clustered into 9 cohorts $^{9}$. Large regional differences with respect to the construction time distribution can be observed. In general, the least attractive construction cohorts ranging from I850 until 1964 are more often observed in the northern regions and London. The South-West has the highest share of pre-I850 buildings. Our data suggest a natural selection

${ }^{7} \mathrm{~A}$ small terraced house is a house forming part of a block where at least one house is attached to two or more other houses. It has a floor space up to $70 \mathrm{~m}^{2}$, in contrast to the medium/large terraced house, which is bigger than $70 \mathrm{~m}^{2}$. Semi-detached houses are houses that are attached to one other house, whereas a for a detached house none of the habitable structure is joined to another residential building. Bungalows are houses with all of the habitable accommodation on one floor. We do not further classify flats into possible sub-categories like flats in high-rise vs. low-rise buildings or converted flats vs. purpose-built flats.

${ }^{8}$ Table 3.I provides additional summary statistics.

${ }^{9}$ The EHCS construction-classifications are: pre I850, I850-I899, I900-I9I8, the (inter-)war period I919-1944, I945-1964, I965-1974, I975-1980, I98II990, and I99I-200I. process in favor of quality: Buildings erected before 1850 are on average twice as valuable today as the average value of a house built after I850 (Table 3.2). High quality dwellings or houses at unique locations are more likely to survive, which will be reflected in relatively higher values for the very old cohorts.

A similar north-south difference can be observed in our sample with regard to age. Prices of dwellings in the northern regions are less than half the prices of those in the southern regions (not correcting for quality). London has a special role again, with private residential property values being twice as high as the national average (Table 3.2).

The northern regions display a lower share of owneroccupied dwellings and a higher share of residential property provided by Local Authorities when compared to the south of the country (London being an exception again).

$3.8 \%$ of all households in our sample live in dwellings that fail to meet minimal quality standards and are regarded 'unfit' for housing according to the $\mathrm{law}^{\mathrm{IO}}$. Again, Inner London has a special position with twice the national percentage of unfit dwellings, which might be caused by the relatively old housing stock and low home-ownership rates.

When analyzing the demographic characteristics of

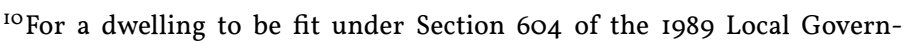
ment and Housing Act it must satisfy criteria related to: disrepair; structural stability; dampness; lighting, heating and ventilation; water supply; drainage; facilities for food preparation; and the presence, location and functioning of essential utilities (WC, bath/shower, and sink). 
CHAPTER 3. DEMOGRAPHICS AND HOUSING DEMAND

Table 3.1: Regional distributions of housing type and age of dwelling

\begin{tabular}{|c|c|c|c|c|c|c|c|c|c|c|c|c|c|c|}
\hline \multirow[b]{2}{*}{ region } & \multicolumn{5}{|c|}{ dwelling type (in \%) } & \multicolumn{8}{|c|}{ dwelling age cohort (in \%) } & \multirow[b]{2}{*}{$\begin{array}{l}\overline{8} \\
\text { ஸे } \\
\text { ஃे }\end{array}$} \\
\hline & 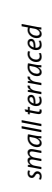 & 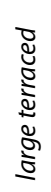 & 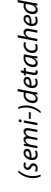 & $\begin{array}{l}3 \\
0 \\
5 \\
5 \\
5 \\
0\end{array}$ & $\tilde{t}$ & $\begin{array}{l}0 \\
\infty \\
\infty \\
\frac{0}{2}\end{array}$ & $\begin{array}{l}\text { న } \\
\infty \\
\text { ڤ } \\
\infty \\
\infty\end{array}$ & $\begin{array}{l}\frac{\infty}{a} \\
\frac{1}{8} \\
\frac{1}{2}\end{array}$ & 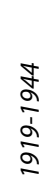 & 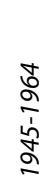 & 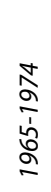 & 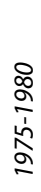 & 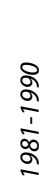 & \\
\hline North East & 12 & 17 & 47 & 10 & 13 & 1 & 4 & 10 & 18 & 26 & 17 & 6 & 11 & 7 \\
\hline Yorkshire \& Humber & 14 & 16 & 45 & 12 & 12 & 3 & 11 & 9 & 18 & 22 & 14 & 6 & 11 & 5 \\
\hline N. West \& Mersey & 16 & 18 & 45 & 8 & 13 & 2 & 11 & 12 & 20 & 20 & 13 & 5 & 11 & 6 \\
\hline E. Midlands & 10 & 12 & 55 & 14 & 8 & 4 & 7 & 7 & 14 & 22 & 16 & 8 & 13 & 8 \\
\hline W. Midlands & 15 & 16 & 49 & 7 & 14 & 2 & 7 & 8 & 19 & 25 & 16 & 6 & 11 & 6 \\
\hline South West & 12 & 15 & 45 & 14 & 13 & 7 & 8 & 7 & 12 & 20 & 15 & 8 & 15 & 7 \\
\hline Eastern & 12 & 12 & 46 & 15 & 15 & 4 & 5 & 5 & 12 & 22 & 19 & 9 & 14 & 9 \\
\hline South East & 10 & 14 & 48 & 10 & 18 & 3 & 8 & 7 & 13 & 23 & 17 & 8 & 14 & 7 \\
\hline Outer London & 13 & 20 & 32 & 2 & 34 & 0 & 8 & 10 & 39 & 15 & 11 & 4 & 7 & 5 \\
\hline Inner London & 7 & 22 & 5 & 1 & 65 & 1 & 21 & 14 & 15 & 17 & 12 & 5 & 9 & 6 \\
\hline England total & 13 & 16 & 44 & 10 & 18 & 3 & 9 & 9 & 17 & 22 & 15 & 7 & 12 & 7 \\
\hline
\end{tabular}

Note: Dwelling types are relatively similarly distributed in 8 out of io regions. (Semi-)detached houses and bungalows make up the largest share, followed by terraced houses and flats. Inner and Outer London, however, have a different structure, with less houses and a higher share of apartments.

Large regional differences with respect to the age structure of houses can be observed. In general, the least attractive age cohorts ranging from I850 until I964 are more often observed in the northern regions and London. The South-West has the highest share of pre-I850 buildings.

Source: own calculations based on EHCS data. 
CHAPTER 3. DEMOGRAPHICS AND HOUSING DEMAND

Table 3.2: Total number of dwellings, tenure, average dwelling price

\begin{tabular}{|c|c|c|c|c|c|c|c|c|c|}
\hline & \multirow[b]{2}{*}{$\begin{array}{l}\stackrel{\widehat{\varrho}}{\mathrm{g}} \\
\stackrel{\Xi}{\Xi}\end{array}$} & \multicolumn{4}{|c|}{ Tenure (in \%) } & \multicolumn{4}{|c|}{ avg. price (in $£$ ) } \\
\hline & & 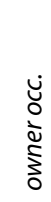 & $\begin{array}{l}\stackrel{+}{\varrho} \\
\stackrel{े}{\mathbf{d}}\end{array}$ & 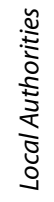 & 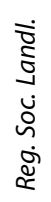 & 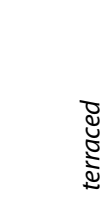 & 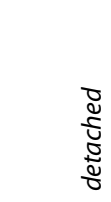 & $\begin{array}{l}3 \\
\frac{3}{5} \\
0 \\
5 \\
5 \\
0\end{array}$ & $\tilde{t}$ \\
\hline North East & 1.04 & 67 & 7 & 21 & 5 & 42,774 & 75,285 & 79,332 & 40,079 \\
\hline Yorkshire \& H. & 2.11 & 68 & 10 & 18 & 4 & 48,417 & 85,245 & 76,334 & 58,836 \\
\hline N. West \& Mersey & 2.79 & 70 & 9 & 14 & 8 & 43,952 & 94,270 & 84,649 & 53,722 \\
\hline E. Midlands & 1.78 & 74 & 9 & 14 & 4 & 52,883 & 102,856 & 93,336 & 38,154 \\
\hline W. Midlands & 2.08 & 71 & 6 & 14 & 8 & 54,454 & 105,750 & 111,789 & 56,894 \\
\hline South West & 2.07 & 76 & 10 & 7 & 7 & 84,107 & 145,635 & 125,584 & 72,046 \\
\hline Eastern & 2.28 & 74 & 9 & 12 & 5 & 96,356 & 153,136 & 117,680 & 76,201 \\
\hline South East & 3.33 & 76 & 11 & 7 & 7 & 111,728 & 215,237 & 159,019 & 83,024 \\
\hline Outer London & 1.83 & 70 & 12 & 11 & 7 & 152,590 & 242,808 & 211,440 & 112,374 \\
\hline Inner London & 1.15 & 43 & 17 & 28 & 13 & 295,674 & 491,748 & 217,515 & 173,685 \\
\hline England (total) & 20.46 & 71 & 10 & 13 & 6 & 90,996 & 161,360 & 125,771 & 73,640 \\
\hline
\end{tabular}

Notes: The northern regions display a lower share of owner-occupied dwellings and a higher share of residential property provided by Local Authorities when compared to the south of the country (London being an exception).

With regard to value, a similar north-south difference can be observed. Prices of dwellings in the northern regions are less than half the prices of those in the southern regions (not correcting for quality). London has a special role again, with private residential property values being twice as high as the national average.

Source: EHCS 
households in our sample, we follow the EHCS definition for Household Reference Persons (HRP), representing the household's social and economic position. The HRP is the person in whose name the dwelling is owned or rented or who is otherwise responsible for the accommodation. When two or more people jointly own or rent the dwelling, the person with the highest income is taken as HRP (ODPM, 2002).

Educational levels differ significantly across age groups in the sample. More than $50 \%$ of all residents aged 65 and above do not reach the GCSE-level (or comparable), as opposed to merely $12 \%$ for the 25 -29-year-olds. Of the $25-29-$ year-olds $38 \%$ are holding a university degree, as compared to less than $15 \%$ for people older than 65 . Since education is the most prominent determinant of human capital, one obviously needs to control for it.

We regard tenure as a typical example of a life cycle driven variable. Our data suggests that tenure is determined by the household's current position in the life cycle. The largest share of students and young professionals heading a household first lives in privately let dwellings. The share of privately rented houses decreases by half between age 20 and 30, as people leave school or university and start working, start families, and buy their own homes. From age 30 until 40, the share drops again by half and stays low thereafter. The very low home-ownership rate among residents aged 70 and older, however, could be caused by a negative cohort effect for this generation.

\subsection{Results}

The user cost of housing $q$ for renters is the sum of rent, energy, and service costs (if not included in the rent already), and the local council tax ${ }^{\mathrm{II}}$, if applicable. For owner-occupied housing, the cost of housing $q_{\text {owner }}$ can be understood as the opportunity cost of not investing in an asset class similar to residential real estate:

$$
q_{\text {owner }}=V \cdot\left(r_{f}+\rho-g\right)+K,
$$

where $V$ is the value of the dwelling, $r_{f}$ the risk-free interest rate in 200I, $\rho$ a risk premium for residential real estate, $g$ the expected capital gain, and $K$ is the sum of all direct costs for maintenance, energy, and council tax. We set $r_{f}$ to $4.78 \%$ which is the yield for 20-year British government bonds in 200I. $g$ is set to $2.5 \%$, which is the average real annual growth rate of the Halifax housing index for 1983-200I. For the risk premium $\rho$ we take one half of the UK equity premium of $4.2 \%$, as estimated by Dimson et al. (2003). Figures for the direct costs are provided in the EHCS data set. We subsequently try a number of specifications for the interest rate, the equity premium and the expected price appreciation, which scales the vector of marginal prices. The relative magnitude of the marginal prices compared to each other is

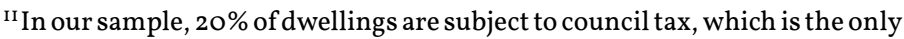
residential property tax in the UK. Council tax is paid by the resident and not necessarily by the owner. We account for council tax support granted to economically weak households. 
CHAPTER 3. DEMOGRAPHICS AND HOUSING DEMAND

Table 3.3: Education and income by birth cohort

\begin{tabular}{|c|c|c|c|c|c|c|c|c|c|c|c|}
\hline \multirow[t]{2}{*}{ Age } & \multicolumn{5}{|c|}{ Education (\%) } & \multicolumn{6}{|c|}{ Median income $(£)$} \\
\hline & $\stackrel{\stackrel{\varrho}{\check{~}}}{\check{c}}$ & Ч્ّ & $\frac{\frac{n}{d}}{\frac{d}{d}}$ & 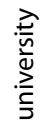 & $\frac{\bar{d}}{\frac{\mathfrak{O}}{\varrho}}$ & $\overline{\bar{\sigma}}$ & $\stackrel{\text { ֻ }}{\stackrel{0}{\varrho}}$ & 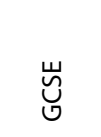 & $\frac{\frac{u}{d}}{\frac{d}{d}}$ & 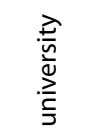 & $\frac{\bar{d}}{\frac{\bar{g}}{\varrho}}$ \\
\hline $20-24$ & 5 & 25 & 37 & 24 & 9 & 10,658 & 6,165 & 13,693 & 10,687 & 11,443 & 13,985 \\
\hline $25-29$ & 14 & 30 & 18 & 26 & 12 & 19,102 & 13,966 & 18,104 & 20,692 & 23,299 & 23,145 \\
\hline $30-34$ & 14 & 34 & 20 & 19 & 13 & 22,733 & 15,365 & 21,014 & 21,736 & 29,203 & 30,391 \\
\hline $35-39$ & 15 & 34 & 20 & 19 & 12 & 24,136 & 17,780 & 21,545 & 25,117 & 29,789 & 30,831 \\
\hline $40-44$ & 22 & 28 & 17 & 20 & 13 & 24,229 & 18,726 & 20,648 & 24,664 & 30,819 & 34,761 \\
\hline $45-49$ & 30 & 25 & 16 & 19 & 10 & 22,892 & 18,400 & 22,379 & 24,340 & 28,303 & 35,739 \\
\hline $50-54$ & 36 & 20 & 14 & 18 & 12 & 22,635 & 18,038 & 20,694 & 26,330 & 29,263 & 36,002 \\
\hline $55-59$ & 43 & 20 & 13 & 14 & 10 & 18,748 & 15,424 & 17,220 & 21,067 & 25,197 & 31,205 \\
\hline $60-64$ & 48 & 18 & 9 & 16 & 9 & 14,488 & 12,690 & 15,194 & 16,315 & 20,086 & 20,429 \\
\hline $65-69$ & 58 & 18 & 7 & 13 & 4 & 11,649 & 9,528 & 12,353 & 12,733 & 17,687 & 18,955 \\
\hline $70-74$ & 63 & 13 & 8 & 11 & 5 & 9,860 & 7,941 & 11,482 & 13,129 & 14,089 & 17,666 \\
\hline $75-79$ & 68 & 11 & 10 & 8 & 3 & 8,648 & 7,223 & 9,587 & 13,160 & 13,008 & 17,296 \\
\hline $80+$ & 71 & 9 & 9 & 7 & 4 & 7,581 & 6,688 & 8,890 & 9,413 & 11,885 & 16,754 \\
\hline
\end{tabular}

Notes: Income is the median annual net income at the household level, including income from savings, pensions and housing benefits.

Source: EHCS, 2001 cross-section. 
stable, however.

We estimate $\left(\mathrm{I}^{\prime}\right)$ by ordinary least squares, subject to constraints (4)-(6). Table 3.4 presents the coefficients and the partial derivatives $q_{i}$ for each of the 47 hedonics, which can be understood as the premium (or discount) households are willing to pay for one more unit of this characteristic. The signs of the partial derivatives are all as expected: positive for normal goods and negative for inferior goods. As an example, residents are willing to pay an additional $£$ I,793 a year for living in a detached house, when compared to an apartment, which is the reference house type. Not surprisingly, a residence in London comes at a hefty premium when compared to the North East.

Houses constructed in the I9th century are preferred over more recently erected structures. Houses built before 1850 are most attractive, while the least attractive construction periods are 1945-1974 and I99I-200I. Older houses apparently have features like architecture or neighborhood attractiveness that are not captured in our control variables but accounted for in the time dummy.

Other normal goods like parking space or a garage, a second living room or bathroom, central heating, more floor space, or a larger plot size all have positive derivatives.

Living in a city center (as opposed to a rural environment) is attractive when compared to a suburban residential or an urban area. Neighbors are not valued much: isolated locations or places with only a few dwellings are more expensive than places with many houses surrounding. As expected, areas experiencing high demand are more expensive; areas with many vacancies, on the other hand, come at a discount. The EHCS provides two measures of the level of crime in an area. In the interviews, respondents are asked about their perceptions with regard to crime. We find a positive coefficient for the dummy indicating that no crime is perceived. Second, we interpret the presences of secured windows and doors as an indicator for a threat of burglary, and we find negative coefficients for it. Links to public transport close to the house make a place more attractive $\mathrm{I}^{\mathrm{I} 2}$.

Having established hedonic prices, we link the prices to the demographic characteristics of the inhabitants by equation $\left(3^{\prime}\right)$. We use 52 variables $^{13}$ to estimate how the portfolio of housing services demanded varies with age, house-

${ }^{12}$ The explanatory power of the regression improves quite substantially when estimating $\left(\mathrm{I}^{\prime}\right)$ including dwellings rented out by social landlords and local authorities into the sample as well, with the $R^{2}$ nearing 0.76. Apparently, rents are easier to explain by the underlying hedonics, since they are heavily regulated. In many cases regulation prescribes a clear relation between hedonics like floor space or number of rooms and the rent asked. In addition, buildings in the social housing sector are more standardized than owner-occupied houses, which makes them easier to model in a linear way.

I3 We regress the marginal prices $q_{i}$ against the following demographic variables: age-group dummies ( $15-19,20-24,25-29,30-34,35-39,40-44,45^{-}$ $49,55-59,60-64,65-69,70-74,75-79,80+$ ), education dummies (up to GCSE/O level/CSE Equivalent; up to A level or equivalent; up to degree, or degree equivalent; higher degree/postgraduate qualification), employment status dummies (full time work, part-time work, retired, unemployed, full time education), gender, dummy for persons with long-term illness in household, ethnicity dummies (black, Asian, other non-white), 
CHAPTER 3. DEMOGRAPHICS AND HOUSING DEMAND

Table 3.4: Marginal prices $q_{i}$ for hedonic characteristics

\begin{tabular}{|c|c|c|c|c|c|c|c|}
\hline \multicolumn{4}{|c|}{ Variables describing dwelling } & \multicolumn{4}{|c|}{ Variables describing location } \\
\hline Variable & Mean & $S D$ & $N$ & Variable & Mean & $S D$ & $N$ \\
\hline \multicolumn{4}{|c|}{ Dwelling type (vs. apartment) } & \multicolumn{4}{|l|}{ Region (vs. North East) } \\
\hline Terraced small & 296 & 714 & 1213 & Yorkshire and Humber & 109 & 640 & 970 \\
\hline Terraced large & 433 & 1026 & 1798 & North West and Mersey & 619 & 1156 & 1057 \\
\hline Detached & 1793 & 1577 & 4617 & E Midlands & 729 & 994 & 1044 \\
\hline Bungalow & 1956 & 1650 & 882 & W Midlands & 888 & 998 & 905 \\
\hline tenure (vs. renting) & & & & S West & 2326 & 1734 & 1138 \\
\hline Owner Occupied & 1421 & 2890 & 8225 & Eastern & 2269 & 1559 & 994 \\
\hline \multicolumn{4}{|c|}{ Year of construction (vs. 1991-2001) } & S East & 3237 & 2057 & 1010 \\
\hline pre 1850 & 1724 & 2214 & 387 & O/London & 7929 & 3579 & 779 \\
\hline $1850-1899$ & 1240 & 2437 & 1046 & I/London & 10422 & 6040 & 549 \\
\hline $1900-1918$ & 1039 & 1583 & 1127 & \multicolumn{4}{|c|}{ Neighborhood type (vs. rural) } \\
\hline 1919-1944 & 807 & 1272 & 1982 & City centre & 197 & 3586 & 248 \\
\hline $1945-1964$ & 288 & 952 & 1811 & Urban & -924 & 2383 & 2026 \\
\hline $1965-1974$ & 285 & 880 & 1329 & Suburban residential & -399 & 1910 & 5152 \\
\hline $1975-1980$ & 429 & 1184 & 545 & Rural residential & -263 & 1890 & 1301 \\
\hline $1981-1990$ & 444 & 1111 & 781 & Village centre & -348 & 1881 & 392 \\
\hline Misc. & & & & \multicolumn{4}{|c|}{ \# houses in community (vs. 500+) } \\
\hline Parking lot & 722 & 740 & 6412 & isolated & 1599 & 2478 & 190 \\
\hline 2nd living room & 427 & 787 & 4439 & Under 100 & 781 & 1256 & 1329 \\
\hline 2nd bathroom & 818 & 1432 & 1001 & $100-299$ & 364 & 670 & 2413 \\
\hline 2nd WC & 536 & 899 & 3592 & $300-499$ & 224 & 647 & 1491 \\
\hline In(bedrooms) & 1223 & 1315 & 9014 & Demand & & & \\
\hline $\ln ($ plot $)$ & 11 & 20 & 7585 & High demand area & 1918 & 1585 & 2349 \\
\hline \multirow[t]{4}{*}{ In(floorspace) } & 536 & 411 & 9453 & $\begin{array}{l}\text { No vacancies around } \\
\text { Misc. }\end{array}$ & 771 & 1171 & 8175 \\
\hline & & & & No crime perceived & 287 & 688 & 936 \\
\hline & & & & Good public transport & 173 & 644 & 1061 \\
\hline & & & & No secure windows & 72 & 383 & 4404 \\
\hline
\end{tabular}

Notes: Mean and standard deviation in $£$ /year. The average values of $q_{i}$ can be interpreted as the average annual premium (or discount) residents pay for an additional unit of $i$. For example, living in a detached house (in contrast to a apartment) is worth on average $£$ I,793, after controlling for size etc. A second bathroom's price is $£ 818$. 
hold composition, household type, economic situation of the household, income, employment status, educational level, ethnicity, and attitudes of the inhabitants regarding the dwelling they live in.

Equation $\left(2^{\prime}\right)$ states that imputed prices for each hedonic characteristic are in fact marginal prices: the level of the hedonic characteristic $z_{i}$ influences the marginal price $q_{i}$. For example, the willingness to pay for one additional bedroom depends on the number of bedrooms already present in the house. A household's unobservable taste will impact both the price and the quantity - someone with a strong preference for a garden will not only be willing to pay more for the garden but is more likely to have a large garden as well. In order to avoid the error term $\mu$ being correlated to the lefthand side $q_{i}$, we use two-stage least squares (2SLS), as suggested by Bartik (1987). In contrast to Green and Hendershott (1996), however, we employ 2 SLS for the logarithmic variables only (floor space, plot size, \# bedrooms). Income net of housing, regional dummies, dummies on the tenure, and dwelling type are used as instruments. Prices for characteristics measured by dummy variables are estimated by OLS omitting $z_{i}$, since the values of the respective dummies are difficult to be replaced by instruments not already included

dummy for disabled person living in the household, dummy for households with children, dummies for personal motives of the residents (always lived in the dwelling, have familiy and friends close by, live close to work, regard the dwelling as the "right kind of property", affordability, wishing to move), the usage (weekend and evenings only), the household's income, the interactions of income with age, and the household's size. in our direct regressors.

The demand for most housing components increases with household size. Especially detached houses and bungalows are more in demand. As expected, the demand for more (bath) rooms is positively related to the number of people living in the dwelling. Singles do not have demand patterns very different from multi-person households after controlling for household size.

Higher levels of income shift the reservation prices for almost all housing components upwards (or downwards for inferior housing services). As an example, we estimate the premium a household is willing to pay for living in a detached house (vs. living in a small terraced house) to increase by $3.3 \%$ when income doubles.

Beside this direct income effect, we believe that a household's human capital is driving its current housing consumption decision. The optimal level of housing consumption does not depend on current income solely, but to a large extent on the present value of future streams of income. The more income a household can expect, the more housing services it can (and wishes to) consume over its lifetime. Borrowing on mortgage allows young households to smooth their consumption inter-temporally, as higher levels of housing consumption are possible in earlier years already. Assuming a concave housing utility curve, the smoothing of housing consumption increases a household's lifetime utility. In addition, transaction costs are reduced, as the level of housing services does not necessarily need to be readjusted 
each time current income changes. The household will only move to a larger (smaller) home in case the expected value of human capital changes significantly.

Unfortunately, human capital is not easily measurable. We therefore have to rely upon education as a proxy for human capital, assuming higher levels of education to be related to higher future income. As an illustration, a well-educated young professional can expect that her income will increase more in subsequent years than the income of a less educated household with the same level of current income. Our results show that, after controlling for income, households headed by university graduates are willing to pay more (less) for all normal (inferior) goods when compared to households with lower educational achievements. This holds true for less advanced educational levels as well: having passed GCSE lets the household demand more housing than households without any conventional education (our reference group) ${ }^{\mathrm{I}}$.

Similarly, health plays an important role in housing demand. In our sample, households with members suffering from long-term illnesses or including people with disabilities consume less housing services. This does not imply that housing has a lower priority for the ill or disabled. Health problems, however, impair human wealth as future incomes are expected to be lower, which in turn depresses overall housing consumption.

${ }^{\mathrm{I}}$ Relaxed borrowing constraints could be an alternative explanation, since banks could be more willing to provide mortgages to better educated customers.
We do not find a direct impact of age on housing demand. Most coefficients for the cohort dummies are insignificant. Still, older households are more willing to pay for housing than younger households. The higher incomeage interaction coefficients for older age groups do not indicate that older people spend more on housing in absolute terms. Given the lower income for retirees, it is rather the relative share of the income devoted to housing that drives up the coefficients. People simply stay in their houses after retiring, consuming the same amount of housing as before. This inter-temporal smoothing of housing consumption makes sense from an investor's life cycle perspective as well: owner-occupiers build up housing wealth during their working years and consume more than otherwise possible when retiring. For aging owner-occupiers, housing services are often as big as income. People apparently do not account for the opportunity costs of not renting out or selling the paid-off house they are living in. However, this line of reasoning cannot explain why elderly renters pay relatively more as well, since they have to make rent payments in cash. We believe that moving is costly for older people, both financially, since they have to rely on professional help more than younger households, and emotionally and socially, since they are leaving a place they lived in for years. In the same line of reasoning, it is not surprising that most of the coefficients for the variable indicating retirement are positive and significant, indicating a constant willingness to pay for housing even when income decreases. 
Only few black and Asian households are included in the sample, and they are not evenly distributed geographically. After controlling for age, income, education, household type and size, we find Asian and black households to attach a discount on being owner, having a parking lot, or a suburban residential location. Dwellings constructed between I85O and I9I 4 or located in highly demanded neighborhoods carry a premium. These results do not necessarily imply different tastes with regard to these characteristics directly, but we interpret them as a preference for traditional migrant neighborhoods in the historic city centers.

Households that are at home on weekends and in evenings only are less inclined to spend on housing services than households that use the space during workdays as well. The premium for owning the property, for instance, is decreased by $£ 250$ a year.

Those households that indicated that the place they live in is "the right kind of property" for them are willing to pay more for many housing services. Households that are intending to move soon, on the other hand, consume less housing than expected, given their level of income, education, and other demographic factors. We read this as another indicator for transaction costs letting households wait until the desired and the current level of housing strongly deviate before upgrading to a better home.

Having established the link between demographics and the determinants of a house, we can now asses how demand for a constant-quality house will change in age. National av- erages are taken to define a representative constant quality dwelling. We calculate the demand for this dwelling in three alternative ways:

First, we calculate a total age derivative, in which all demographic characteristics of an age-group are changing in age (life cycle variables). Age groups are assumed to have the same demographic characteristics their predecessors had earlier. This is, roughly, the Mankiw and Weil (1989) approach.

Second, we calculate a partial age derivative based on cohorts, keeping all demographics beside age constant, which is in line with the approach used by Green and Hendershott (1996). For variables like the highest educational achievement or attitudes of the residents, this assumption is reasonable. But for variables like income, it certainly is not.

Third, the results from the demographic regression (Table 3.5) suggest that changes in household size, income, employment status, and health significantly influence housing demand. We therefore define life cycle variables ${ }^{15}$, which change with age, and estimate demand taking account of likely changes in these life cycle variables.

Changes in income are estimated using (8). In general, a household's income first increases with age, peaks around age 52 , declines until age 65 and stabilizes subsequently. The better a household is educated, the more pronounced dynamics can be observed. For instance, income first quadru-

${ }^{15}$ Life-cycle variables are income, household size, household type, health of household members, or employment status. 
Figure 3.1: Income dynamics for British households

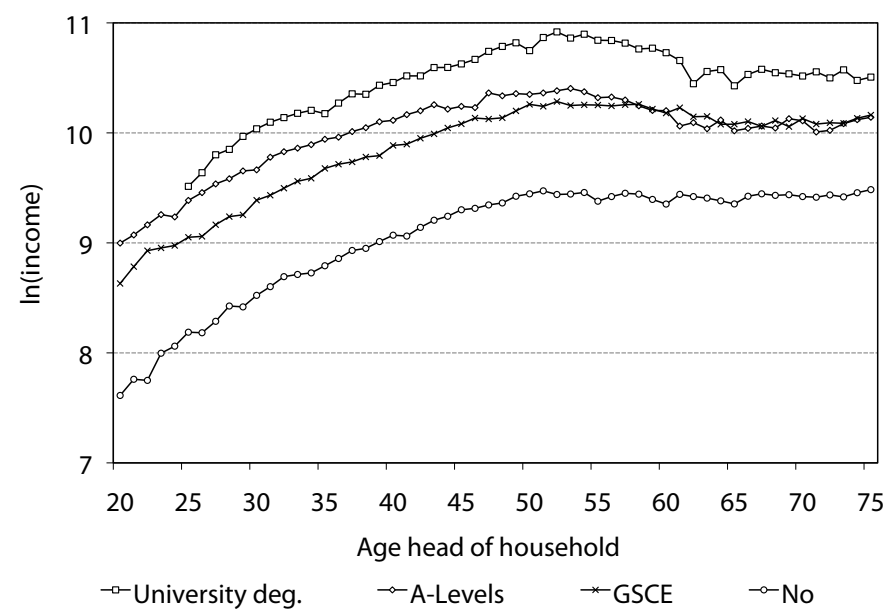

All values in $£ /$ year. A household's income first increases with age, peaks around age 52, declines until age 65 and stabilizes subsequently. The better a household is educated, the more pronounced dynamics can be observed. For instance, income quadruples for households headed by university graduates from age $25-52$, and decreases again by one third as the members of the household retire, before it stabilizes. For lower educational levels, both the increase and the decline are less steep. Households who's head has enjoyed no formal education start at very low income levels, experience robust income growth until age 55, but do not suffer from income losses as they reach retirement.

Data: British Household Panel Survey, 199I-200I. ples for households headed by university graduates from age $25-52$, and decreases again by one third as the members of the household retire, before it stabilizes. For lower educational levels, both the increase and the decline are less steep. Households who's head has enjoyed no formal education start at very low income levels, experience robust income growth until age 55, but do not suffer from income losses as they reach retirement. This surprising result could be linked to state transfers to the elderly and, more likely, to cohort effects in disguise: $62 \%$ of all household heads born between 1925 and 1930 received basic schooling only, while for the cohort born between 1975 and 1980 , the share drops to as low as II\% (please see Table 3.3).

After age 65, we assume all households to retire, the household size to go down to an average of I.5, the share of households with at least one disabled member to rise to $15 \%$, and the share of households with long-term ill persons to rise to $35 \%^{16}$, and calculate an adjusted partial derivative. We acknowledge that this is still a rough way of modelling which could be refined in the future. The age group of 50-54 is our reference group for both partial derivatives.

Figure 3.2 shows that demand for housing increases from age 20-24 until age 50-54 for all three derivatives by ca $50 \%$. The total age derivative increases faster than the par-

${ }^{16}$ These assumptions are based on the averages for older age groups in our sample (controlled for income and education). We run robustness tests, using different parameters for income dynamics, health and household size. We do not observe qualitative changes in the results. 
Figure 3.2: Demand for an average dwelling as a function of age

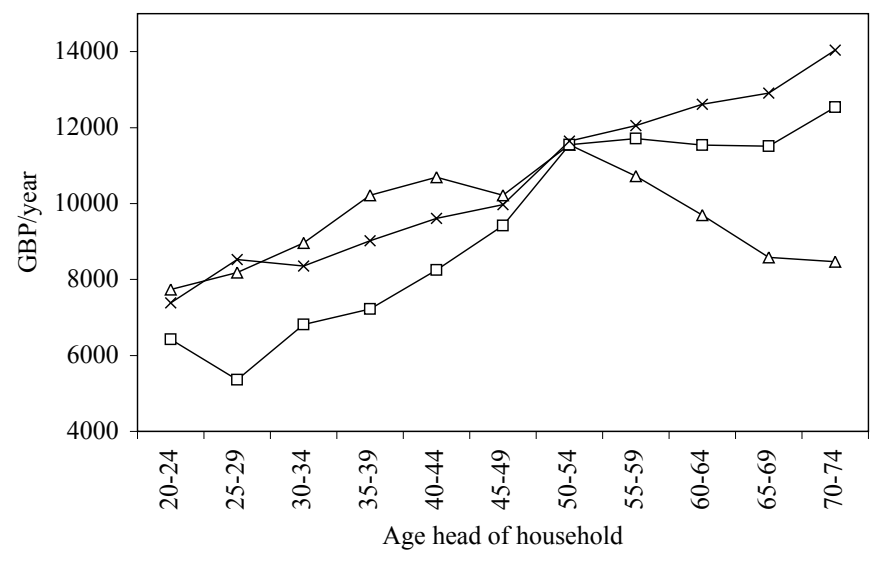

$\triangle-$ total age derivative $-\square$ - part. age deriv. with adj. $*$ part. age deriv. w/o adj.

Notes: We define a constant quality house based on national averages and calculate the age-cohort specific demand for this house in three alternative ways:

I) Total age derivative, where all demographic characteristics vary with age 2) Partial age derivative, where the demographic profile is kept constant over all age-groups

3) Partial age derivatives with adjustments, which allows for changes in the selected demographic characteristics of a cohort - relative income or household size are expected to change as a household moves through the housing life cycle. tial derivatives, which can be explained by younger cohorts having enjoyed a better education, earning more and having overall a higher expected worth of human capital. After $50-54^{17}$, the total age derivative declines again, indicating that older households were consuming less housing services than younger ones. The partial derivatives, however, do not decrease, indicating that today's 50-year-olds will not reduce housing consumption - on the contrary, housing will be a more important part of their overall consumption. After age 55 , the adjusted demand stabilizes, although the household's disposable income decreases. The unadjusted partial age derivative keeps increasing in age, even for the very old.

The total age derivative can be regarded as the lower bound of future housing demand for aging households, whereas the unadjusted partial age derivative is the higher bound. Or put differently: Mankiw and Weil were too pessimistic, while Hendershott and Green probably overestimated future demand. The adjusted partial age derivative's demand projections will be located in between the two extreme positions.

The pattern of the graph is very robust. Using different reference groups, alternative regression models, or different assumptions for the user-cost of housing $q$ does not alter the overall shape qualitatively. Choosing younger reference groups makes the difference between the total age

${ }^{17}$ Please note that the age indicated in the graph is the age of the household reference person. By definition, this is not the average age of the household members, which is usually lower. Thus, the demand graphs for individuals instead of households is shifted to the left. 
derivative and the partial age derivatives more pronounced as younger age cohorts are better educated and demand more housing. Using a semi-logarithmic functional form for $\left(\mathrm{I}^{\prime}\right)$ does not change the results significantly. The level of the total demand, however, is quite sensitive to higher (lower) user cost of housing assumed, which will shift all three graphs upwards (downwards) in comparable ways.

The relative change of demand for housing services in age is similar for all dwelling types, as Figure 3.3 shows. Only the levels differ: the willingness to pay is highest for detached houses followed by terraced houses, bungalows and apartments. Demand for bungalows and detached houses rises faster in age than demand for apartments and terraced houses.

\subsection{Future Demand for Housing}

Our results allow for a discussion of the future development of housing demand in England with regard to changing demographics. We will focus on the two determinants of housing demand: the number of households and the level of housing services demanded per household.

The number of households in England is expected to grow further. The Government Actuary's Department (GAD) projects England's population to increase by Io percent to 56 million in the period between 2007 and 2027 (GAD, 2007). In addition, household size is expected to decrease, lead-
Figure 3.3: Demand disaggregated for dwelling types

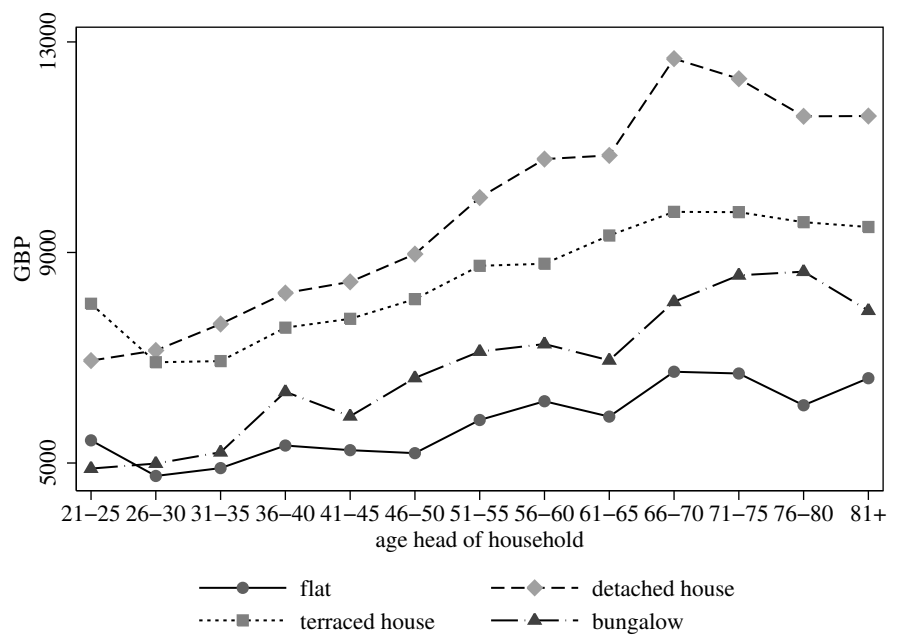

Notes: The relative change of demand for housing services in age is similar for all dwelling types. Only the levels differ: the willingness to pay is highest for detached houses followed by terraced houses, bungalows and apartments. Demand for bungalows and detached houses rises faster in age than demand for apartments and terraced houses. 
ing to even more growth in household numbers suggesting higher future demand for housing. This robust future outlook is very different from the projections for many other European countries. Especially in many Central and Southern European countries, population growth has already turned into shrinkage and the population structure is older already (United Nations Population Division, 2007).

Combining projections for the population numbers and the age structure with the earlier established willingness to pay for a constant-quality house, gives a forecast for aggregate housing demand. Assuming the average household size to stay constant, we derive the number of households per age group and calculate aggregated demand based on Equation (9) for each year until 2027

Our calculations suggest that housing demand will continue to grow, with an average growth of 0.9 percent in the next 20 years. Demand growth will peak in the period from 2012 until 2017 and slow down afterwards.

Based on alternative assumptions regarding fertility rates and migration dynamics, the GAD offers so-called 'variant scenarios' in addition to the most likely scenario. Assuming higher fertility rates and higher net-migration into the UK leads to a scenario with a younger population, while lower fertility rates and low influx of (mostly) young immigrants results in projections of a relatively old population.

The graphs in Figure 3.4 show that the overall housing demand development is very similar across the three scenarios. Again, annual demand growth is positive for all years in all scenarios with a peak in 2012-2017. For the younger population scenario, changes are mainly driven by shifts in the total number of households. In the case of an older population, however, almost the entire growth can be attributed to higher per-household demand. Due to the robust outlook under all scenarios covered, we expect English housing demand to increase in the next years ${ }^{18}$.

\subsection{Conclusion}

This paper aims to investigate how demographics determine the amount and the quality of housing services demanded. It contributes to the current debate in three ways: First, based on a very detailed 200 I cross-section of English households, we find that human capital is a key driver for housing demand. Variables that are positively related to human capital increase the demand for housing. For instance, each additional level of education a household has achieved, drives up its reservation prices for the housing services consumed. On the other hand, factors like chronic illnesses that impair hu-

${ }^{18}$ To convert our demand forecasts into house price predictions, we need information on supply elasticities in England. Malpezzi and Maclennan (2OOI) investigate the supply elasticity for residential property in the US and the UK. First, they find that the supply elasticity is lower in the UK than in the US. Second, for the post-war UK they estimate supply elasticities between $O$ and I, depending on the parameter values chosen in the models. This suggests that increased demand will further drive up house prices. 
Figure 3.4: Aggregate housing demand growth projections, England 2005-2030

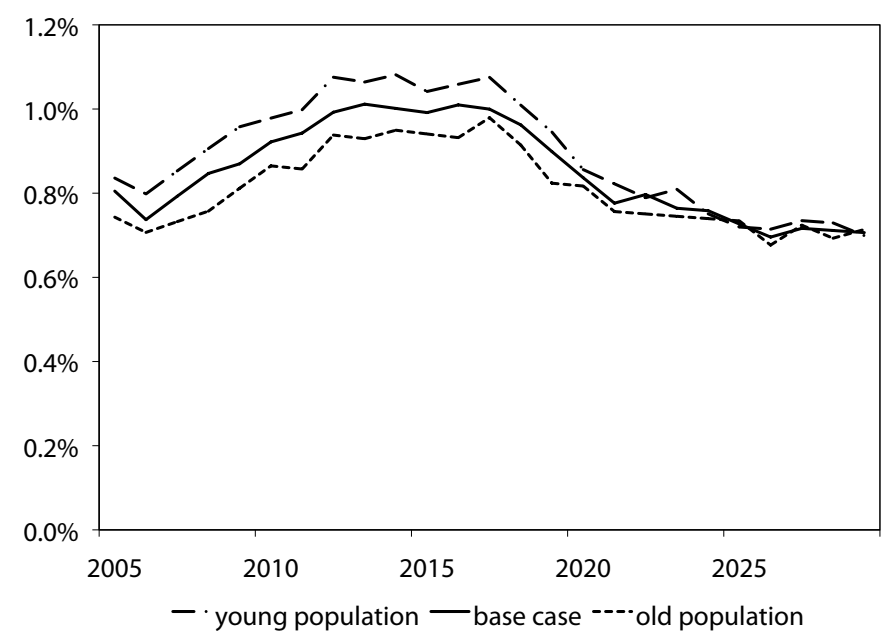

Notes: The Government Actuary's Department offers two alternative population scenarios in addition to the base case: Assuming higher fertility rates and higher net-migration into the UK leads to a scenario with a younger population, while lower fertility rates and low migration results in projections of a relatively old population.

Combining projections for the population numbers and the age structure with the earlier established willingness to pay for housing services, gives a forecast for aggregated housing demand. man capital have a negative impact on housing consumption. Since each generation is better educated than the generations before, an aging society will demand more housing on an aggregated level, even if the total number of households stops growing. A scenario analysis with different population projections shows that the upward sloping partial age derivative is supporting demand in an aging society.

Second, we refine the existing methodology by distinguishing between life cycle variables that are expected to change with age for each household, and cohort variables, that are determined by the household's birth-cohort and not by age. Earlier studies either let all demographics change with age, or kept all variables constant during the entire household life cycle.

Third, we believe that our findings are very relevant for other European countries beside England. Despite the cultural and economic heterogeneity within Europe, the upward-sloping age-demand-relationship observed in England should be a reasonable proxy for other European nations, even in case of different demographic profiles. Today, Europe is facing an unprecedented demographic change: The entire area reaching from Germany in the west, to Russia in the east, and to the Balkans in the south is losing population already today - and this development is expected to gain momentum in the next decades (United Nations Population Division, 2007).

A regional housing market with unattractive economic perspectives and living conditions faces a double challenge: 
CHAPTER 3. DEMOGRAPHICS AND HOUSING DEMAND

not only does the total number of households decline, but households having enjoyed a better education are more likely than the less educated to move away to more prosperous regions. Without the younger generation being better educated and more wealthy than the generations before, the pressure on housing demand caused by population shrinkage cannot be off-set. 
CHAPTER 3. DEMOGRAPHICS AND HOUSING DEMAND

Table 3.5: Demographic regression - selected results

\begin{tabular}{|c|c|c|c|c|c|c|c|c|c|c|c|c|c|c|c|c|c|c|}
\hline \multirow[t]{2}{*}{ price of } & \multicolumn{2}{|c|}{ Household } & \multicolumn{2}{|c|}{ Income } & \multicolumn{4}{|c|}{ Education } & \multicolumn{2}{|c|}{ Health } & \multirow[b]{2}{*}{ retired } & \multicolumn{2}{|c|}{ Ethnicity } & \multicolumn{2}{|c|}{ Perceptions } & \multirow{2}{*}{$\frac{\text { Usage }}{\text { WE \& ev. }}$} & \multirow[b]{2}{*}{$z_{i}$} & \multirow[b]{2}{*}{$R^{2}$} \\
\hline & size & income & $20-24$ & $60-64$ & GCSE & A-lev. & Univ. & higher & It ill & disab. & & black & Asian & right kind & want move & & & \\
\hline Terraced small & 87 & & & 0.028 & & 167 & & 262 & & & 229 & & & & & & & 0.14 \\
\hline Terraced large & & 0.013 & -0.039 & & & & 215 & 392 & & & & 278 & 167 & & & & & 0.09 \\
\hline Detached & 147 & 0.033 & & & 148 & 376 & 661 & 894 & & -235 & 235 & & & 279 & -241 & -122 & & 0.21 \\
\hline Bungalow & 223 & 0.045 & & & & & 306 & 492 & & -371 & 476 & & -1427 & & & & & 0.16 \\
\hline Yorkshire \& H. & & -0.018 & & & -101 & & -196 & -250 & & & & & & & & & & 0.11 \\
\hline N West \& Mersey & 135 & & & 0.032 & & 254 & 501 & 905 & & & & & -570 & & & & & 0.17 \\
\hline E Midlands & 80 & 0.021 & & & & & 298 & 333 & & & 307 & & & & & & & 0.15 \\
\hline W Midlands & 122 & 0.027 & & & & & 343 & 828 & & & & & & & & -178 & & 0.20 \\
\hline SWest & 210 & 0.053 & -0.107 & -0.046 & & & 378 & 555 & & & 626 & & & 604 & & & & 0.15 \\
\hline Eastern & 174 & 0.049 & & & & 386 & 385 & 416 & & & 667 & & & & -311 & & & 0.24 \\
\hline S East & 409 & 0.048 & -0.079 & & & 332 & 985 & 1060 & & & & & -973 & & -503 & -260 & & 0.23 \\
\hline O/London & 777 & & & & & 1184 & 1118 & 2183 & & -1586 & & -1644 & -934 & & -757 & & & 0.27 \\
\hline 1/London & 734 & & & & & 1597 & 2654 & 3362 & & -3369 & 4119 & -1643 & & 3770 & -1040 & & & 0.24 \\
\hline Owner occupied & 130 & 0.053 & & 0.043 & 278 & 544 & 1016 & 1240 & -230 & -360 & & -1055 & -887 & 368 & -575 & -254 & & 0.16 \\
\hline pre 1850 & & 0.047 & & & & 858 & & & & & & & & & 648 & & & 0.16 \\
\hline 1850-1899 & & 0.081 & & -0.087 & & 519 & 806 & 906 & -403 & & 1358 & 1229 & 862 & 491 & -329 & & & 0.17 \\
\hline 1900-1918 & 114 & & & & & 524 & 568 & 877 & & & & 597 & 388 & 624 & & & & 0.19 \\
\hline 1919-1944 & & & & 0.023 & & 316 & 534 & 1112 & & & & 402 & & & & -112 & & 0.13 \\
\hline 1945-1964 & & & -0.066 & & & & 320 & 457 & & & & & & & & & & 0.10 \\
\hline $1965-1974$ & 75 & 0.012 & & -0.021 & & & 200 & 238 & & -252 & & & & & -158 & & & 0.09 \\
\hline $1975-1980$ & & & & & & & 294 & & -284 & & 837 & & & & & & & 0.22 \\
\hline $1981-1990$ & 129 & & & & & & & 386 & & & & & & -262 & & 226 & & 0.09 \\
\hline City centre & & & & & & & & & & & & & & & & & & 0.21 \\
\hline Urban & -328 & -0.053 & 0.125 & & & -359 & -434 & -775 & & & -941 & & & -1404 & & & & 0.17 \\
\hline Suburban res. & -251 & -0.018 & & 0.022 & & & & -431 & & & & -415 & -531 & -226 & & & & 0.07 \\
\hline Rural residential & & -0.050 & & & & & & -358 & -329 & & & & & -486 & & & & 0.09 \\
\hline Village centre & & & & & & & & & & & & & & -964 & & & & 0.10 \\
\hline Under 100 & & 0.028 & & -0.033 & 206 & 216 & 408 & 774 & & & & & & 904 & & & & 0.13 \\
\hline $100-299$ & & 0.020 & & 0.017 & 133 & 164 & 233 & 300 & & & & & & & & & & 0.05 \\
\hline $300-499$ & 50 & & 0.019 & & & & & 287 & -108 & & & & & & & & & 0.09 \\
\hline isolated & & & & & & & & & & & & & & & & & & 0.26 \\
\hline Prking lot & & 0.013 & & & & 53 & 117 & 104 & & -88 & 178 & -292 & -245 & 81 & -99 & -66 & & 0.09 \\
\hline 2nd liv. & & 0.015 & -0.034 & & 97 & 125 & 242 & 379 & & & 204 & & & 141 & -69 & -83 & & 0.18 \\
\hline 2nd bath & 302 & & 0.247 & & & & & 236 & & & & 668 & -821 & & 271 & 164 & & 0.31 \\
\hline 2nd WC & 39 & 0.026 & -0.034 & & 145 & 189 & 312 & 378 & & -138 & 205 & & & 280 & -96 & -78 & & 0.20 \\
\hline No crime & & & & & & & 140 & 161 & & & & & 219 & & & & & 0.06 \\
\hline Good pub. trans. & 108 & & 0.041 & 0.019 & -86 & & & & & & & & & & & & & 0.33 \\
\hline No sec. windows & -23 & 0.007 & & -0.007 & & & & & -41 & & & 179 & 100 & 86 & & & & 0.03 \\
\hline High demand area & 75 & 0.025 & -0.071 & 0.026 & & & 369 & 686 & & & 380 & 466 & 338 & 410 & & & & 0.17 \\
\hline No vacancies & & & -0.025 & & & & 152 & 306 & -73 & & & 244 & & & -69 & & & 0.02 \\
\hline In(bedrooms) & & 0.014 & 0.020 & 0.036 & & 157 & 234 & 440 & -76 & -141 & -255 & 640 & 216 & & & & 344 & 0.10 \\
\hline In(plot size) & & 0.000 & & 0.000 & 2 & 4 & 2 & 2 & & & 3 & -3 & & & & -1 & -7 & 0.03 \\
\hline In(area) & -17 & 0.008 & & 0.005 & 33 & 69 & 62 & 83 & & & 59 & & & & -29 & -16 & 562 & 0.32 \\
\hline
\end{tabular}

Notes: Only significant coefficients (p-value < o.I) are displayed. All others are omitted for the sake of readability. Due to space constraints, results for only selected regressors are presented above. Prices for plot size, floor space, number of bedrooms, and repaircosts (all in logs) are estimated in a 2 SLS, following Bartik (1987). We use income net of housing, regional dummies, tenure dummies and house type dummies as instruments. $R^{2}$ for 2 SLS have no statistical meaning and are therefore not stated. All other equations are estimated by ordinary least squares. 


\section{Chapter 4}

\section{The topography of growth and decline: Local price dynamics within cities}

\subsection{Introduction}

Cities are highly dynamic organisms. They emerge, prosper, decline, and perish in reaction to changing populations, economic trends, political, social, and technological advances. Urban economists like Krugman (Krugman, I99I, I993; Fujita et al. , 2000) explain why people crowd together and found cities in the first place. Others investigate the relative competitiveness of cities (e.g. Ellison and Glaeser, I999; Porter, 1996), carving out the causes for cross-sectional variation and time-trends. Yet another discourse focuses on cities' ability to adapt to changing environments, or, as Glaeser (2005) called it, to "re-invent" themselves.

This paper researches within-city dynamics. It builds on a broad strand of literature addressing the urban layout of cities, which extends the mono-centric Alonso-Mills-Muth model (Alonso, I964; Mills, I972; Muth, 1969) to a variety of poly-centric specifications. By now we understand how economic factors influence the formation of subcenters (Fujita and Ogawa, 1982; McMillen and Smith, 2003). Price differentials across residential neighborhoods are exogenous, as they are reflecting differences in employment opportunities or amenities in general.

Guerrieri et al. (2010) carry the debate to the next level by explicitly modeling endogeneities in neighborhood home price levels. They assume that wealthy households obtain a higher utility from being close to other wealthy neighbors than less wealthy households do. Ultimately, this leads to a 
sorting of households within a city based on home values. In a self-enforcing process, the rich and the less wealthy huddle in separate parts of town.

Previous studies analyzed subcenters of huge metropolitan areas that remained relatively large entities, comparable to mid-size cities. Redfearn (2007), for instance, identifies only 4I subcenters for the Los Angeles metropolitan area based on a non-parametric identification methodology. Guerrieri et al. (2010) manage to zoom in a bit further when analyzing 77 community districts for the city of Chicago, each consisting out of several census tracts. Nothing is known about endogenous price dynamics in smaller towns or at more fine-grained levels of observations.

Endogeneous effects, however, are likely to be the strongest at very local levels. When choosing a location to live, the relative magnitude of the endogenous forces increases in the proximity of evaluated alternatives. Simply speaking, when deciding to move to one block or to an adjacent block, the usual determinants like proximity to work or distance to city-wide amenities are less important since they are very similar. Instead, local factors gain in relative importance. Pushing it to the extreme: The only spatial difference across two neighboring houses are the non-mutual neighbors.

House prices were at the forefront of the latest financial cycle. Seemingly constant real growth rates in home values first fueled the financial system and the real economy during the too-nice-to-be-true upswing in the mid 200o's. The subsequent downswing was again caused by (and left a deep impact on) the housing sector. Home values in the United States as estimated by the Case-Shiller Composite 20 house price index lost 31.6 percent in the 3 years following their peak in April 2006 (Case and Shiller, 2010). In the same period foreclosures sky-rocketed, pushing the highly leveraged financial system over the edge.

This paper analyzes how changes in price trends translate into changes in the spatial distribution of prices within cities. Were certain quarters, for instance, more sensitive to the the price bubble? Do prices converge across neighborhoods when home values are decreasing in a metropolitan region, leveling out the differences between the prosperous areas and the unpopular ones? Or does a decline in home values increase the polarization in rich and poor quarters? Does an extended period of falling prices create pockets of relative poverty within the tissue of a city?

Another set of questions is motivated by changing demographics. Over the last fifty years, at least 370 cities worldwide with populations over I0O,OOo have shrunk by more than Io percent (Oswalt and Rieniets, 2006). Classic examples of cities facing demographic challenges are Pittsburgh, Detroit, or New Orleans. In Europe, more than one-third of European cities lost population in the period from 1996 to 200I (European Commission, 2007). The unprecedented rates at which Central and Eastern European countries are 
currently losing population give a new urgency to the questions of how demographic contraction affects not only the total wealth of regions, but also the relative distribution of housing wealth within these regions. For instance, all but two Eastern German cities ${ }^{\mathrm{I}}$ have suffered from falling population numbers and depressed home values in the last two decades. I am not aware of any study that researches the impact of demographic decline on the wealth distribution within such cities.

The Netherlands are an ideal test environment for studying housing markets due to a national peculiarity: Housing supply is to a large extend exogenous. Vermeulen and Rouwendal (2007) estimate the housing supply elasticity for The Netherlands to be negligibly small. Dutch municipalities release land for new residential construction only in homeopathic doses. In addition, zoning rules are extremely tight and red tape around construction is dense. The average time between the decision to start a building project and the beginning of actual construction is estimated to be on average 90 months (Eichholtz and Lindenthal, 2008). Thus, any responses to demand shocks will be very delayed, if there is a response at all. The market for existing homes, however is entirely free and comparable to the United States or other Western countries.

The paper is structured as follows: First, three ideas on changing within-city price differentials are introduced. The second section suggests empirical strategies to test these the-

${ }^{\mathrm{I}}$ Dresden and Leipzig ories while the data used in this paper are described in section three. The fourth part presents the empirical results, followed by an overall discussion.

\subsection{Research question}

Figure 4.I simplifies the relative price paths of buildings with comparable quality characteristics across two neighborhoods within the same metropolitan area. Neighborhood $\mathrm{A}$ is a more attractive quarter enjoying relative housing wealth, while neighborhood B has lower home values. Line $G_{0}$ represents the original price gradient.

The relative price differences are not fixed but evolve in time. A negative shock to house prices at metropolitan level, for instance, leads to lower home values in both neighborhoods. In case the general decline improved the relative attractiveness of neighborhood A versus $\mathrm{B}$, the stronger differences in home values across neighborhoods $\left(D_{1}\right)$ lead to a steeper price gradient $G_{1}$. Alternatively, a shock could level out the differences $\left(D_{2}\right)$, causing the inter-neighborhood price gradient to flatten $\left(G_{2}\right)$.

Why would a general swing in home values impact relative price differentials at local levels? First, Guerrieri et al. (2010) reason that being in the proximity of rich neighbors improves the general level of amenities like the quality of schools or lower crime levels. Under the assumption that richer households derive a higher utility from such amenities 
Figure 4.1: Decreasing home values and relative prices levels across neighborhoods

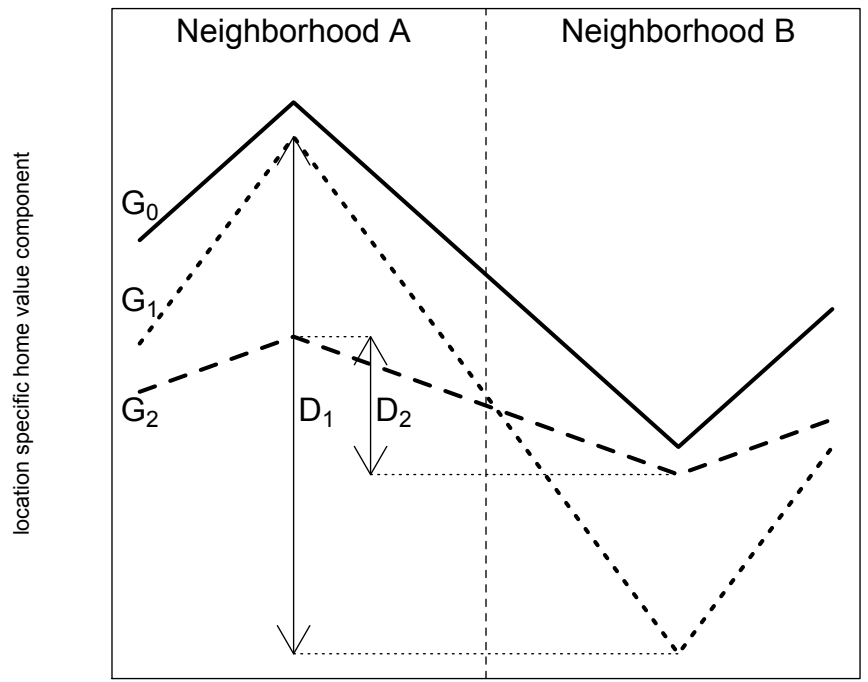

Note: This figure depicts the relative price paths of buildings with comparable quality characteristics across two neighborhoods within the same metropolitan area. Neighborhood $\mathrm{A}$ is a more attractive quarter enjoying relative housing wealth, while neighborhood B has lower home values. Line $G_{0}$ represents the original price gradient.

A negative shock to house prices at metropolitan level leads to lower home values in both neighborhoods. In case the general decline enforced the relative attractiveness of neighborhood $\mathrm{A}$ versus $\mathrm{B}$, the stronger differences in home values across neighborhoods $\left(D_{1}\right)$ lead to a steeper price gradient $G_{1}$. Alternatively, a shock could level out the differences $\left(D_{2}\right)$, causing the interneighborhood price gradient to flatten $\left(G_{2}\right)$ than poorer families can, an endogenous price dynamic sets in: the rich concentrate in (and further improve) amenity rich areas while the poor favor cheap housing in low-amenity parts of town. When testing whether the predictions derived from this model can be confirmed empirically, Guerrieri et al. (2010) find affordable neighborhoods bordering already expensive quarters to be the most sensitive to this circle of endogenous gentrification. In boom years they will gain more in value than other neighborhoods and, symmetrically, they will lose more in city-wide down swings. The first two hypotheses of this paper test whether these findings can be confirmed with more detailed data.

Houses located in areas close to relatively high-value neighborhoods will ...

$H_{1}$ : ...experience higher price growth than homes in areas bordering comparable or low-price neighborhoods when prices rise at city-level.

\section{$\mathrm{H}_{2}$ : ...lose more value than homes in areas bordering com-} parable or low-price neighborhoods when prices fall at city level.

The alternative hypotheses state that there is no (or an offsetting) price growth effect for proximity to more expensive areas.

Household mobility is a necessary condition for any endogenous sorting of households in wealthy and poor neighborhoods. Without people moving, the virtuous circle of 
endogenous wealth accumulation in distinct quarters cannot set in. The most mobile group of people are those that just move into the city. If a city has a sizable influx of new residents, not only demand for housing in general is supported but also the speed of gentrification will accelerate. I do not know of any paper investigating such a moderating role of population growth on endogenous home price dynamics. This paper will therefore test the following hypothesis:

\section{$H_{3}$ : Endogenous gentrification effects increase in the city's population growth rate.}

Second, sticky housing supply in combination with shrinking household numbers potentially shifts and tilts the price gradient. Aggregate housing demand is a product of the number of households and the demand for housing services per household. A lower number of households causes a lower level of aggregate demand (keeping everything else constant) and pushes prices down as supply cannot adjust quickly enough due to the durable nature of the structures in place. If income, availability of financing, and consumption preferences of the remaining households are not affected by the decline in home values, ${ }^{2}$ these households can consume

${ }^{2}$ This sounds like a bold assumption since Glaeser and Gyourko (2005) find cities with falling home values to attract low human capital households. For The Netherlands in general, however, income per households was not at least the same amount of non-housing goods while simultaneously increase the consumption of housing services without paying more for it. As a result, they will chose to increase housing consumption, at least partially. Overall, households will move from weak areas with less attractive structures and amenities in place to stronger quarters, 'filling up' vacant higher quality apartments that used to be out of reach. This population and human capital transfer aggravates disparities within cities. Alternatively, if house prices increase while population numbers drop, the relative differentials will not change since poor households cannot move 'up'. In sum, changes in the within-city house price gradients are expected to differ depending on the the cities' population growth rates.

More formally speaking, the relative price difference between low price areas and neighboring high-price areas will $\cdots$

$H_{4}$ : ...stay equal or become smaller for areas with rising city-wide home prices, regardless of changing population numbers.

$H_{5}$ : ...become more pronounced for areas with falling citywide home prices when population numbers decline.

$H_{6}:$...stay equal or become smaller for areas with falling city-wide home prices when population numbers decline.

depressed by falling home values and the global financial crisis. On average households gross income decreases by just -0.28 percent in real terms in 2009 (CBS, 2010) 
Finally, one can think of an investment-driven reason for changes in the inner-city price differentials. Above average price growth rates for selected quarters in town during boom periods and subsequent higher losses in busts indicate local price speculation and overshooting. Investors chase after good investment opportunities in those areas where prices have been going up, further fueling the price rally. Once locally overheated markets dip into decline, prices in these 'fast rise' areas will melt down quicker than in surrounding areas. A vast literature on home price bubbles emerged in the last decade (for instance Himmelberg et al. , 2005; Brunnermeier and Julliard, 2008; Case and Shiller, 2003). Only few papers, however, explicitly address the spatial diffusion of speculative processes. Roehner (1999), as an exception, analyzes the price path of twenty districts in central Paris during the price bubble in the late 1980 . He finds home prices in mundane quarters to rise faster, reach the peak earlier, and to decline more rapidly than house prices in less wealthy areas. Roehner's findings warrant a last hypothesis:

$H_{7}$ : House prices in areas that have risen more than average in price upswings will decline more than average in subsequent price downswings, regardless of the relative position of the area on the within-city price gradient.

Although $H_{7}$ falls short of a rigorous test for local price bubbles, controlling for speculation in even a naïve manner strengthens the findings from $H_{1}$ through $H_{6}$.

\subsection{Methodology}

This paper suggests two empirical approaches to estimate the within-city price dynamics. The first models neighborhood effects by including spatial dummies based on the neighborhood classification offered by the Dutch Central Bureau of Statistics (CBS) into a hedonic regression. Subsequently it analyzes endogenous changes in the neighborhood coefficients for several periods in time, both in booming and declining market regimes.

The second approach estimates continuous surfaces of home values in metropolitan areas. House price index surfaces are like topographic maps of a landscape: neighborhoods carrying a location premium translate into 'hills' or 'peaks' in the surface, while less attractive areas form 'troughs' or 'valleys'. This approach does not rely on any formal neighborhood classification and uses the information more efficiently, allowing for a more detailed analysis.

The following sub-sections lay out the empirical estimation techniques in more detail.

\subsubsection{Spatial dummy approach}

Using spatial dummies is probably the most straight forward way of including location into a hedonic regression analysis. The CBS subdivides The Netherlands into 2542 neighborhoods, distributed across 44I municipalities (Central Bureau of Statistics, 20IOa). We only include neighborhoods 
with sufficient numbers of observations across time. For each neighborhood, we define a variable as I for all sales located within this neighborhood and o otherwise. The following ordinary least squares (OLS) equation is estimated for several subperiods:

$$
\ln \left(P_{i}\right)=\alpha+\mathbf{B} X_{i}+\mathbf{G N}_{\mathbf{i}}+\epsilon_{i},
$$

where the natural logarithm of the sales price $P$ of house $i$ is regressed against a vector of hedonic variables $\mathbf{X}_{\mathbf{i}}$ describing the physical characteristics of the house ${ }^{3}$ and a vector $\mathbf{N}_{\mathbf{i}}$ containing the spatial dummies. $\alpha_{t}$ is the regression intercept, $\mathbf{B}$ and $\mathbf{G}$ are vectors of regression coefficients and $\epsilon_{i}$ is the error term, which is expected to be normally and independently distributed (IID).

The vector of neighborhood coefficients $\mathbf{G}$ represents the relative attractiveness of each neighborhood, which can be understood as the value of a featureless home in a certain location - the house-specific characteristics are already captured in the hedonic coefficients $\mathbf{B}$. The second step explains changes in these location coefficients across the four periods by estimating the following equation with OLS:

$$
\begin{aligned}
\Delta_{t, t-1} \operatorname{Coeff}_{n}= & \alpha+\beta_{1} D_{\text {bust }, n}+\beta_{2} \Delta_{t-1, t-2} \operatorname{Coeff}_{n} \\
& +\beta_{2} D_{\text {bust }, n} \Delta_{n, \text { max }, t-1} \operatorname{Coeff}_{n}+\epsilon_{n}
\end{aligned}
$$

${ }^{3}$ The following hedonic variables are included: interior floor space, lot size, construction period, house type, number of rooms, number of floors, presence of balcony or terrace, monument status of building.
The change in the coefficient for neighborhood $n$ from period $t-1$ to $t$ is regressed against an intercept $\alpha$ and a period time dummy $D_{\text {bust }}$. The neighborhood coefficients are mean reverting in case $\beta_{2}$ on the lagged change in coefficients is estimated to be smaller than -I. In case $\beta_{2}$ is positive, coefficients are estimated to follow multi-period trends. $\Delta_{n, \max }$ measures the difference in coefficients of neighborhood $n$ and its most expensive neighbor in the preceding period. The variable is not defined in case all neighbors have lower coefficients. $\beta_{3}$ captures potential spillover effects from highprice neighborhoods to more affordable areas $\left(H_{1}\right.$ and $\left.H_{2}\right)$. The interaction terms $D_{\text {bust }}$ allows for different elasticities across boom and bust market regimes. $\epsilon_{n}$ is the IID error term.

\subsubsection{Neighborhood analysis based on Kriging}

This approach comprises of three steps. The house-specific price component is first explained in a standard hedonic model, which is a reduced version of (4.I):

$$
\ln \left(P_{i}\right)=\alpha+\mathbf{B} X_{i}+\lambda_{i}+\epsilon_{i},
$$

At this stage we do not directly control for any locationrelated differences in home prices - all spatial dependencies are captured in the error term $\lambda_{i} . \epsilon_{i}$ encompasses the remaining estimation error, which is independently and identically distributed (IID) around o. 
When estimating (4.3) by ordinary least squares the residuals will contain both $\lambda$ and $\epsilon$. Obviously, the spatial correlation in the residuals will render the OLS estimates to be inefficient, the standard errors biased, and the predicted values to be potentially incorrect (i. a. Dubin 1988). Efficiency and standard error bias, however, are not a major concern in the following step in which we carve out the spatial correlations from the residuals of (4.3). Since $\epsilon$ is IID, it will drop out subsequently.

In the second step, we estimate an index surface of housing values by means of ordinary kriging. Kriging is a minimum mean squared error technique to interpolate the value of a variable at unobserved geographic locations based on observed values close by. Originating from geology and mining science, this procedure found several applications in the domain of real estate research. Basu and Thibodeau (1998), find kriged predictions to be more precise than OLS-based predictions in case spatial dependencies are contained in the residuals. For an introduction to kriging in real estate research see Pace et al. (1998b); a more elaborated foundation is provided by Cressie (1993).

Kriging is still not a standard estimation technique, so a more elaborated motivation might be warranted that discusses the advantages of kriging versus controlling for space through dummies. Simple spatial modeling by means of e. g. space dummies estimate an index value for predefined spatial entities like provinces, counties, municipalities, neighborhoods, and, in rare cases, residential blocks. This ap- proach bears several problems. First, one needs (to define) an adequate classification into spatial units. Often, a classification at the desired level of aggregation is not available. And, in case it is, the segmentation will follow possibly arbitrary administrative boundaries that are only partially relevant for demarcating submarkets. Clapp and Wang (2006) show that U.S. census tracts are not ideal for analyzing local housing markets. Instead, they suggest a classification and regression tree technique to determine relevant boundaries directly from the data. Second, sparse data prohibit very detailed local index estimations based on fine-grained spatial entities since a minimum number of observations within an entity is needed for achieving reliable results - a 'natural maximum' in local detailedness cannot be surpassed. Third, when relying on any kind of boundary-based segmentation, the index will be discontinuous at spatial boundaries.

An index surface does not rely on any boundary classifications. It estimates an index value for any point on a plain and is therefore continuous. Naturally, the precision of the surface increases in the density of observations. Explicitly modeling the spatial correlation across observations allows for a more fine-grained estimation as information from neighboring observations support the otherwise too sparse data in the researched area - one can 'zoom in' more. Clapp and Wang (2006), however, argue that including more neighbors is not automatically better. They present a trade-off between more smoothness of the surface over space (when many neighbors are included) versus lower location-specific 
bias: with fewer neighbors included, the surface will match local differences more closely.

We estimate the outreach and functional form of the spatial correlation based on fitted exponential semi-variograms (Cressie, 1993). The variograms are used to compute the weights $w$ for the basic ordinary kriging equation

$$
F(x, y)=\sum_{i=1}^{i=N} w_{i} \lambda_{i}
$$

where the interpolated value at a point with location $(x, y)$ is the weighted sum of the measured values at surrounding points, subject to the unbiasedness constraint

$$
\sum_{i=1}^{i=N} w_{i}=1
$$

The index surface evolves in time as it is re-estimated for every of the four periods in the sample. ${ }^{4}$ In a last step, we explain differences in the interpolated values $E$ for a point $i$ across time:

${ }^{4}$ Pace et al. (1998a) model the spatial and the temporal dependencies more directly by estimating an equation containing simultaneously spatial and temporal lags.

$$
\begin{array}{r}
\Delta_{t, t-1} E_{i}=\alpha_{t}+\beta_{1} D_{\text {bust }, i}+\beta_{2} \Delta_{t-1, t-2} E_{i} D_{\text {bust }, i} \\
+\beta_{3} \text { Slope }_{i, t-1} D_{\text {bust }, i}+\beta_{4} \Delta_{\text {max }} E_{i, t-1} D_{\text {bust }, i} \\
+\beta_{5} \Delta \text { Pop }_{i} D_{\text {bust }, i} \\
+\beta_{6} \Delta \text { Pop }_{i} \Delta_{\text {max }} E_{i, t-1} D_{\text {bust }, i} \\
+\beta_{7} \Delta_{t-1, t-2} E_{\text {exc }, i} D_{\text {bust }, i}+\epsilon_{i}
\end{array}
$$

In this regression equation, the change in fitted values in the index surface $E_{t}-E_{t-1}$ is regressed against a bust period dummy variable that is defined I for changes after Q2 2008 (and o otherwise) and a set of variables characterizing the location of point $i$. $\alpha_{t}$ is the regression intercept while the coefficient $\beta_{1}$ captures the general price decline in the bust period. Including the lagged change in fitted values $\left(\Delta_{t-1, t-2} E\right)$ controls for potential mean reversion in the surface estimates. ${ }^{5}$

The absolute position of a given point in a cities price gradient is cancelled out by analyzing the differences in $E$ instead of their levels. Calculating both the spherical distance and the difference in estimated values to the closest local price maximum and minimum controls for the relative position of a location on the local price gradient. A point on a fitted surface is considered to be a maximum (minimum) if no other

${ }^{5}$ Mean reversion in the surface estimates could be caused by market participants correcting deviations from the local mean in subsequent time periods. Alternatively, it could have a purely estimation technique reason in case surface estimates are randomly distributed around a true mean to which they move back in subsequent periods. 
point in a radius of $750 \mathrm{~m}$ has a higher (lower) point estimate. A positive (negative) coefficient $\beta_{4}$ on the difference in fitted values ('vertical distance') to the nearest local maximum $\Delta_{\text {max }} E_{t-1}$ means that prices for locations far away from a peak grow at a faster (slower) rate than the peak areas.

The 'slope' $\left(E_{\max }-E_{t-1}\right) /$ distance $_{\max }$ to the nearest local maximum relates the 'vertical' distance to the 'horizontal' spherical distance. The bigger the value on the slope variable is, the bigger is the relative price difference to close neighbors. A positive coefficient $\beta_{3}$ on this proxy variable supports the endogeneity theory by Guerrieri et al. (2010).

$\triangle P o p$ measures the resident population's growth rate of the year preceding each of the four periods. Interacting the population growth rates with the price difference to the closest maximum disentangles endogenous price dynamics from relative changes in the gradient due to sticky housing supply. A positive coefficient on this variable indicates that lowprice areas are more sensitive to changes in population than high price neighborhoods.

Finally, the impact of local speculative dynamics is controlled for by $E_{e x c}$, which is defined as the difference between the index estimate $E_{i}$ and the mean of all index estimates for points located within a circle with a radius of $1000 \mathrm{~m}$ around $i$. If $E_{e x c, t-1}$ is bigger than $E_{e x c, t-2}$, the location $i$ has appreciated relative to its close peers. Changes in this relative price premia or discounts can be read as a naïve proxy for local price speculation.

All variables are interacted with the bust-period dummy to allow for changes in the coefficients across boom and bust periods. ${ }^{6}$

In (4.6) both the dependent variable and the independent variables are (partially) based on estimates from the same index surface. The slope variable, for instance, contains $E_{t-1}$ which is a component of the dependent variable as well. This violation of the underlying regression assumptions potentially leads to wrong standard error estimates. The magnitude of the errors is probably small, since the independent variables contain 'non-toxic' components that are not based on the kriged index estimates. Nevertheless, an alternative cross-sectional specification (4.7) circumvents the problem since the dependent variable and the independent regressors rely on different index surface estimations:

$$
\begin{array}{r}
E_{\text {exc }, i, t}=\alpha_{t}+\beta_{1} D_{\text {bust }, i, t}+\beta_{2} E_{\text {exc }, i, t-1} \\
+\beta_{3} \text { Slope }_{i, t-1} D_{\text {bust }, i, t}+\beta_{4} \Delta_{\text {max }, t-1} E_{i} D_{\text {bust }, i, t} \\
+\beta_{5} \Delta \text { Pop }_{i} D_{\text {bust }, i, t}+\beta_{6} \Delta \text { Pop }_{i} \Delta_{\text {max }} E_{i, t-1} D_{\text {bust }, i, t} \\
+\beta_{7} \Delta_{t-1, t-2} E+\epsilon_{i, t}
\end{array}
$$

All variables are defined as in (4.6). The relative over- or underpricing of location $i$ versus the average index surface figures in the proximity is regressed against a set of location characteristics.

${ }^{6}$ Due to space constraints, the non-iteracted 'base' variables are not explicitly mentioned in (4.6) but enter the estimation as well. 


\subsection{Data}

This paper relies on a database on all housing transactions that were facilitated by the association of Dutch realtors (NVM). ${ }^{7}$ The data cover about 2.6 million observations from the years 1985-2009. The sample can be split into 0.8 million apartments and I.8 million single-family homes. About 50 variables describe the hedonics of each building (house size, housing type, year of construction, number of bedrooms, number of bathrooms/WC, basement, attic, parking), its location (location within communitiy, distance to amenities), and details of the transaction itself (e. g. initial asking price, final transaction price, date of first offer, transaction date). The NVM database provides the exact street address of each transaction, which allows for geocoding each observation through the Google Maps application programming interface (Google, 2010).

In the last 25 years, Dutch home prices knew only one direction: up. The Dutch Realtor Association's price index for existing residential real estate (Nederlandse Vereniging voor Makelaars, 20IO) grew by I30 percent since 1985 (270 percent in nominal terms). Only for the last 5 quarters of the sample (2008Q3-2009Q3), one can observe a substantial price decline. This paper focuses on transactions in this unique bust period and compares them to sales in the preceding peak pe-

${ }^{7}$ The NVM dataset is already used in multiple studies; i. a. De Wit, Englund and Francke (2009), Brounen and Kok(20IO), Brounen, Neuteboom, and Xu (2008).
Figure 4.2: Four phases in the latest Dutch house price cycle

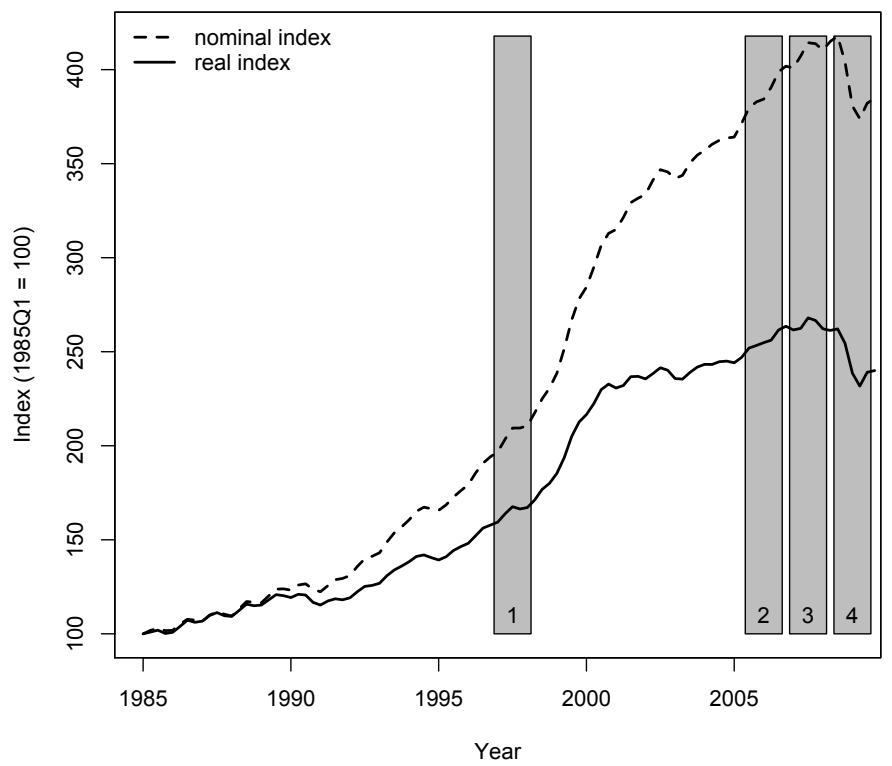

Notes: The solid line depicts the development of prices for Dutch detached homes adjusted for inflation, while the dashed line shows prices in nominal terms. The four grey bars visualize the periods of investigation in this study. Phase I (1997QI-I998QI) provides for a snapshot in the middle of a period of price increases, with the most rapid price gains still to come where markets turn from 'warm' to 'hot'. Phase $2(2005 \mathrm{Q} 3-2006 \mathrm{Q} 3)$ covers the the last quarters of the boom phase, while Phase 3 (2007QI-2008QI) includes the tipping point where prices peak, before entering a phase of price losses. Phase $4(2008 \mathrm{Q} 3-2009 \mathrm{Q} 3)$ is the only period in the sample where prices fall.

Sources: Price index by NVM (2010), deflator from Central Bureau of Statistics (2010). 
riod and two boom intervals. Phase I (I997QI-I998QI) provides for a snapshot in the middle of price increases, with the most rapid price gains still to come - where markets turn from 'warm' to 'hot'. Phase 2 (2005Q3-2006Q3) covers the the last quarters of the boom phase, while Phase 3 (2007QI-2008QI) includes the tipping point where prices peak, before entering a period of price losses.

Subsampling the same amount of transactions per neighborhood in each phase keeps the spatial distribution across CBS neighborhoods constant in time. This ensures that differences in estimates are not caused by different sample sizes or changes in liquidity across time. ${ }^{8}$ Summary statistics for the samples can be found in Table 4.I.

The index surfaces based on (4.4) are estimated for areas only that are actually used for residential construction according to the nationwide zoning information for The Netherlands (Central Bureau of Statistics, 2007). In these areas, home values are interpolated along a $200 \mathrm{~m}$ regular grid.

Population numbers for each Dutch municipality, quarter, and neighborhood are obtained from the Central Bureau of Statistics (2OIOc). Figure 4.3 visualizes the geographic classification of Dutch municipalities at the example of the city of Maastricht. Each municipality is subdivided into quarters represented by bold lines and neighborhoods, depicted in thin lines. In 2009, The Netherlands were structured in 44I municipalities, 2,542 quarters and II,574 neighborhoods. The average headcount per municipality, quarter,

${ }^{8}$ Only quarters that have at least Io observation in each phase are included. and neighborhood is 37383,6486 , and 1425 inhabitants respectively. These areas are not regularly shaped as they follow natural features of the environment, demographic characteristics of the population and the physical characteristics of the housing stock. Their sizes range from below $500 \mathrm{~m}$ in diameter for neighborhoods in city centers to several kilometers in rural areas.

\subsection{Results}

\subsubsection{Hedonic regression}

The starting point of both approaches is the estimation of the hedonic regression equation (4.I) and (4.3), respectively. Table 4.2 presents the estimated coefficients for both equations in all 4 sub-periods. Most coefficients are significant at the one percent significance level, which is not surprising given the high number of observations and the parsimonious model specification. The signs and magnitude of the regression coefficients are as expected. The regression estimates suggest positive elasticities on interior floor space, lot size, number of rooms, monument status, presence of a balcony or terrace and younger building vintage years. Semi-detached homes are valued less then detached buildings. Overall, the coefficients are stable in time - with one exception: the coefficients on the number of floors change signs across timeperiods.

The overall explanatory power of the spatial dummy model 
CHAPTER 4. LOCAL PRICE DYNAMICS WITHIN CITIES

Table 4.1: Summary statistics for subsamples

\begin{tabular}{|c|c|c|c|c|c|}
\hline Phase & & 1 & 2 & 3 & 4 \\
\hline $\mathrm{N}$ & & 13,853 & 13,853 & 13,853 & 13,853 \\
\hline \multirow[t]{4}{*}{ Price (Euros, in thousands) } & 1st Q. & 118 & 221 & 233 & 220 \\
\hline & Median & 153 & 292 & 310 & 293 \\
\hline & Mean & 175 & 325 & 342 & 328 \\
\hline & 3rd Q. & 209 & 395 & 423 & 400 \\
\hline \multirow[t]{4}{*}{ Interior floor space $\left(\mathrm{m}^{2}\right)$} & 1st $Q$. & 120 & 120 & 120 & 120 \\
\hline & Median & 137 & 145 & 145 & 140 \\
\hline & Mean & 149 & 153 & 154 & 151 \\
\hline & 3rd Q. & 166 & 175 & 175 & 171 \\
\hline \multirow[t]{4}{*}{ lotsize $\left(m^{2}\right)$} & 1st Q. & 251 & 255 & 257 & 253 \\
\hline & Median & 341 & 349 & 353 & 345 \\
\hline & Mean & 594 & 611 & 625 & 630 \\
\hline & 3rd Q. & 580 & 580 & 593 & 575 \\
\hline \multirow[t]{9}{*}{ Year of construction (in \%) } & $1500-1905$ & 4.2 & 4.3 & 4.6 & 4.5 \\
\hline & $1906-1930$ & 14.2 & 12.6 & 12.6 & 13.1 \\
\hline & 1931-1944 & 10.3 & 9.2 & 8.5 & 9.0 \\
\hline & $1945-1959$ & 8.0 & 7.3 & 8.0 & 8.5 \\
\hline & $1960-1970$ & 13.1 & 11.5 & 11.1 & 12.1 \\
\hline & $1971-1980$ & 17.0 & 14.1 & 13.5 & 13.1 \\
\hline & 1981-1990 & 18.2 & 13.6 & 13.3 & 12.8 \\
\hline & $1991-2000$ & 15.0 & 20.8 & 20.2 & 17.8 \\
\hline & 2000 & n.a. & 6.6 & 8.1 & 9.1 \\
\hline \multirow[t]{3}{*}{ Number of rooms (in \%) } & $1-2$ & 0.7 & 2.3 & 1.3 & 0.9 \\
\hline & $2-4$ & 43.3 & 32.9 & 29.4 & 29.2 \\
\hline & $5-7$ & 53.8 & 59.5 & 63.5 & 63.6 \\
\hline \multirow[t]{3}{*}{ Number of floors (in \%) } & 1 & 2.2 & 3.2 & 3.6 & 3.7 \\
\hline & 2 & 66.0 & 69.0 & 70.2 & 69.8 \\
\hline & $3+$ & 31.8 & 27.7 & 26.2 & 26.6 \\
\hline \multirow[t]{3}{*}{ Other characteristics (in \%) } & detached & 43.6 & 45.2 & 46.2 & 42.6 \\
\hline & monument status & 0.4 & 0.7 & 0.6 & 0.5 \\
\hline & balcony/terrace & 15.9 & 19.6 & 17.8 & 18.1 \\
\hline
\end{tabular}

Notes: Phase demarcations are I997QI-I998QI, 2005Q3-2006Q3, 2007QI-2008QI, 2008Q3-2009Q3. Identical distribution of observations across neighborhoods in time is achieved by stratified sampling. 
CHAPTER 4. LOCAL PRICE DYNAMICS WITHIN CITIES

Table 4.2: Hedonic regression coefficients from (4.I) and (4.3)

\begin{tabular}{|c|c|c|c|c|c|c|c|c|c|}
\hline \multicolumn{2}{|l|}{ Variable } & \multicolumn{2}{|c|}{ 1997Q1-1998Q1 } & \multicolumn{2}{|c|}{ 2005Q3-2006Q3 } & \multicolumn{2}{|c|}{ 2007Q1-2008Q1 } & \multicolumn{2}{|c|}{ 2008Q3-2009Q3 } \\
\hline \multirow{2}{*}{\multicolumn{2}{|c|}{$\begin{array}{l}\text { Intercept } \\
\text { In(int space) }\end{array}$}} & $7.515^{* * *}$ & $7.045^{* * *}$ & $7.963^{* * *}$ & $7.611^{* * *}$ & $7.856^{* * *}$ & $7.616^{* * *}$ & $7.810^{* * *}$ & $7.460^{* * *}$ \\
\hline & & $0.528^{* * *}$ & $0.791^{* * *}$ & $0.560^{* * *}$ & $0.793^{* * *}$ & $0.585^{* * *}$ & $0.831^{* * *}$ & $0.602^{* * *}$ & $0.849^{* * *}$ \\
\hline \multicolumn{2}{|l|}{ In(lot size) } & $0.202^{* * *}$ & $0.162^{* * *}$ & $0.211^{* * *}$ & $0.153^{* * *}$ & $0.214^{* * *}$ & $0.148^{* * *}$ & $0.207^{* * *}$ & $0.145^{* * *}$ \\
\hline \multicolumn{2}{|c|}{ Neighborhood dummies } & $Y$ & $N$ & $Y$ & $N$ & $Y$ & $N$ & $Y$ & $N$ \\
\hline \multirow{8}{*}{$\begin{array}{l}\text { Year of construction } \\
\text { (vs. 1500-1905) }\end{array}$} & 1906-1930 & $0.026^{* *}$ & $0.059^{* * *}$ & $0.029^{* *}$ & $0.049^{* * *}$ & -0.012 & 0.019 & $0.022^{*}$ & $0.067^{* * *}$ \\
\hline & 1931-1944 & $0.096^{* * *}$ & $0.088^{* * *}$ & $0.083^{* * *}$ & $0.033^{*}$ & $0.039^{* * *}$ & 0.025 & $0.091^{* * *}$ & $0.097^{* * *}$ \\
\hline & 1945-1959 & $0.109^{* * *}$ & $0.149^{* * *}$ & $0.063^{* * *}$ & $0.053^{* * *}$ & $0.026^{* *}$ & $0.043^{* *}$ & $0.064^{* * *}$ & $0.083^{* * *}$ \\
\hline & $1960-1970$ & $0.143^{* * *}$ & $0.108^{* * *}$ & $0.076^{* * *}$ & $0.025^{\dagger}$ & $0.038^{* * *}$ & 0.012 & $0.063^{* * *}$ & $0.051^{* * *}$ \\
\hline & 1971-1980 & $0.196^{* * *}$ & $0.078^{* * *}$ & $0.091^{* * *}$ & $-0.036^{*}$ & $0.054^{* * *}$ & $-0.044^{* *}$ & $0.092^{* * *}$ & 0.007 \\
\hline & 1981-1990 & $0.260^{* * *}$ & $0.173^{* * *}$ & $0.148^{* * *}$ & $0.045^{* *}$ & $0.107^{* * *}$ & $0.026^{\dagger}$ & $0.150^{* * *}$ & $0.088^{* * *}$ \\
\hline & 1991-2000 & $0.321^{* * *}$ & $0.218^{* * *}$ & $0.212^{* * *}$ & $0.087^{* * *}$ & $0.169^{* * *}$ & $0.058^{* * *}$ & $0.194^{* * *}$ & $0.100^{* * *}$ \\
\hline & post 2000 & - & - & $0.224^{* * *}$ & $0.079^{* * *}$ & $0.205^{* * *}$ & $0.090^{* * *}$ & $0.246^{* * *}$ & $0.156^{* * *}$ \\
\hline \multicolumn{2}{|c|}{ Semidetached (vs. detached) } & $-0.127^{* * *}$ & $-0.071^{* * *}$ & $-0.101^{* * *}$ & $-0.053^{* * *}$ & $-0.100^{* * *}$ & $-0.049^{* * *}$ & $-0.092^{* * *}$ & $-0.048^{* * *}$ \\
\hline \multirow{3}{*}{$\begin{array}{l}\text { Number of rooms: } \\
\text { (vs. 1-2) }\end{array}$} & $3-4$ & $0.116^{* * *}$ & 0.047 & $0.022^{\dagger}$ & $0.044^{*}$ & 0.005 & 0.003 & 0.005 & -0.025 \\
\hline & $5-7$ & $0.139^{* * *}$ & $0.076^{*}$ & $0.054^{* * *}$ & $0.082^{* * *}$ & $0.034^{*}$ & 0.029 & $0.036^{\dagger}$ & 0.004 \\
\hline & $8+$ & $0.148^{* * *}$ & $0.112^{* *}$ & $0.045^{* *}$ & $0.047^{*}$ & 0.019 & -0.030 & 0.030 & $-0.056^{\dagger}$ \\
\hline \multirow{2}{*}{$\begin{array}{l}\text { Number of floors: } \\
\text { (vs. 1) }\end{array}$} & 2 & $-0.041^{* * *}$ & $-0.176^{* * *}$ & $0.119^{* * *}$ & 0.010 & $0.078^{* * *}$ & $-0.045^{* *}$ & $0.105^{* * *}$ & 0.007 \\
\hline & $3+$ & $-0.017^{\dagger}$ & $-0.122^{* * *}$ & $0.144^{* * *}$ & $0.044^{* *}$ & $0.101^{* * *}$ & -0.020 & $0.126^{* * *}$ & 0.019 \\
\hline \multirow{2}{*}{\multicolumn{2}{|c|}{$\begin{array}{l}\text { monument } \\
\text { terrace or balcony }\end{array}$}} & $0.120^{* * *}$ & $0.203^{* * *}$ & $0.064^{* *}$ & 0.033 & $0.075^{* *}$ & 0.039 & $0.128^{* * *}$ & $0.226^{* * *}$ \\
\hline & & $0.036^{* * *}$ & $0.138^{* * *}$ & $0.039^{* * *}$ & $0.133^{* * *}$ & $0.043^{* * *}$ & $0.144^{* * *}$ & $0.035^{* * *}$ & $0.126^{* * *}$ \\
\hline \multicolumn{2}{|l|}{ adj. $R^{2}$} & 0.877 & 0.569 & 0.824 & 0.554 & 0.833 & 0.544 & 0.820 & 0.533 \\
\hline
\end{tabular}

Notes: ${ }^{\dagger}$ significant at $p<.10 ;{ }^{*} p<.05 ;{ }^{* *} p<.01 ;{ }^{* * *} p<.001$. Most coefficients are significant at the one percent significance level, which is not surprising given the high number of observations and the parsimonious model specification. Signs and magnitude of the regression coefficients are as expected. The regression estimates suggest positive elasticities on int. floor space, lot size, \# of rooms, monument status, presence of a balcony or terrace and younger building vintage. Semi-detached homes are valued less then detached buildings. All but one coefficient are stable in time. 
Figure 4.3: Spatial segmentation in Dutch municipalities

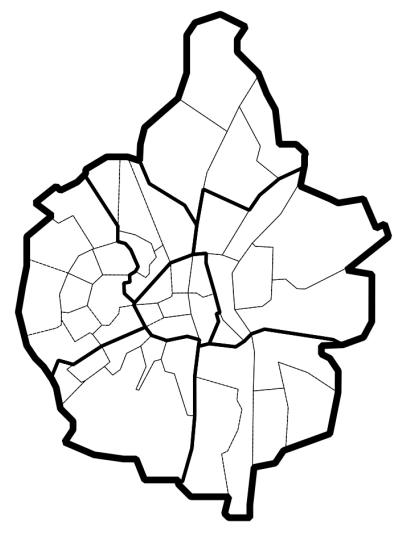

$2000 \quad 4000 \mathrm{~m}$
Notes: Using Maastricht as an example the map visualizes the geographic segmentation system of Dutch municipalities. Each municipality is subdivided into quarters (wijk) represented by bold lines and neighborhoods (buurt), depicted in thin lines. In 2009, The Netherlands were structured in 44

municipalities, 2,542 quarters and II,574 neighborhoods. The average headcount per municipality, quarter, and neighborhood is 37383,6486 , and 1425 inhabitants

respectively. These areas are not regularly shaped as they follow natural features of the environment, demographic characteristics of the population and the physical characteristics of the housing stock. Their sizes range from below $500 \mathrm{~m}$ in diameter for neighborhoods in city centers to several kilometers in rural areas.

Data: Central Bureau of Statistics (20IO). is very high with adjusted $R^{2}$-values ranging from 0.82 to 0.87.9 ${ }^{9}$ Omitting the spatial dummies causes an overall lower model fit (adj. $R^{2}$ from 0.53 to 0.57). Obviously, the residuals contain a substantial amount of spatial correlations, which violates OLS' assumption of independent error terms. Furthermore, the coefficients are estimated to be bigger for interior floorspace and to be smaller for lot size when not controlling for location, indicating that expensive homes, on average, carry bigger homes on relatively small lots.

Table 4.3 presents summary statistics for the spatial dummies instead of individual coefficients due to the high number of neighborhoods. The coefficients are re-centered around zero to achieve better comparability across time. The values for the $25^{t h}$ percentile, median and $75^{\text {th }}$ percentile are robust in time (only slightly increasing for the later periods), suggesting a stable general distribution of neighborhood level housing wealth across The Netherlands. More formally testing, we find the neighborhood coefficients to be highly correlated across time, suggesting a good model specification and little variation in the relative position of neighborhoods in the city-wide price gradients.

Still, there is variation in the coefficients that can be further explained by (4.2). The average change in the coefficients $\left(\Delta_{t, t-1}\right.$ Coeff $)$ is about 0.130 to 0.152 for the boom period and -0.129 to -0.131 in the bust period (adding up the coefficients $0.152-0.281$ for column I). The direction and

${ }^{9}$ Brounen et al. (2009) run a GLS on similar NVM data and achieve comparable higher adj. $R^{2}$ of 0.83 . 
Table 4.3: Summary statistics of coefficients for spatial dummies

\begin{tabular}{|c|c|c|c|c|}
\hline & \multicolumn{4}{|c|}{ Phase } \\
\hline & 1 & 2 & 3 & 4 \\
\hline Min & -0.941 & -0.694 & -0.754 & -0.760 \\
\hline 1st Q. & -0.171 & -0.174 & -0.188 & -0.192 \\
\hline Median & -0.003 & 0.008 & -0.003 & 0.003 \\
\hline Mean & 0.000 & 0.000 & 0.000 & 0.000 \\
\hline 3rd Q. & 0.161 & 0.167 & 0.171 & 0.170 \\
\hline Max & 1.131 & 0.727 & 0.805 & 0.849 \\
\hline \multicolumn{5}{|c|}{ Correlations } \\
\hline Phase & 1 & 2 & 3 & 4 \\
\hline 1 & 1 & & & \\
\hline 2 & 0.95 & 1 & & \\
\hline 3 & 0.94 & 0.96 & 1 & \\
\hline 4 & 0.94 & 0.95 & 0.97 & 1 \\
\hline
\end{tabular}

Notes: 592 neighborhoods dummy coefficients were estimated for each of the 4 phases. The upper panel provides summary statistics for the coefficients, normalized to a mean of 0 . The lower panel shows correlation estimates for the coefficients across time. The high correlation numbers of 0.94 and higher suggest inter-temporal stability of the regression coefficients. magnitude of these price developments are in line with the NVM index trends. Changes in the coefficients are negatively autocorrelated. If prices in an area increase by Io percent, for instance, they will decrease by an additional 3.I4 percent to -3.77 percent. This mean reversion effect has the same magnitude in boom and bust period as the coefficients for the interaction with the bust dummy is not significantly different from zero.

Areas bordering richer neighborhoods (column2 in Table 4.4) experience a stronger price growth. For each percentage point difference in home values, the lower area will rise additional $\mathrm{I} 2$ basis points in the next period. This result supports $H_{1}$ and is in line with earlier studies. No significant change in this effect is found for the bust period, which speaks against $\mathrm{H}_{2}$. It is interesting to note that the spillover effect is one-sided: Being close to low value areas does not have a statistically significant effect on a neighborhood's home price growth rate. The coefficient on the price difference to the most affordable neighbor is not significantly different from zero (column 3).

The low number of observations does not allow for tests of $H_{3}$ through $H_{7}$, which will be addressed in the next section.

\subsubsection{Kriging results}

The functional form for the spatial correlations in the residuals from (4.3) is obtained by fitting a spherical semivariogram (Cressie, I993). Figure 4.4 shows the variogram 
CHAPTER 4. LOCAL PRICE DYNAMICS WITHIN CITIES

Table 4.4: Regression coefficients for neighborhood analysis (4.2)

\begin{tabular}{|c|c|c|c|}
\hline$\Delta_{t, t-1}$ Coeff & 1 & 2 & 3 \\
\hline Intercept & $\begin{array}{l}0.152^{* * *} \\
(0.013)\end{array}$ & $\begin{array}{l}0.138^{* * *} \\
(0.018)\end{array}$ & $\begin{array}{l}0.130^{* *} \\
(0.019)\end{array}$ \\
\hline$D_{\text {bust }}$ & $\begin{array}{c}-0.281^{* * *} \\
(0.013)\end{array}$ & $\begin{array}{l}-0.269^{* * *} \\
(0.019)\end{array}$ & $\begin{array}{l}-0.262^{* *} \\
(0.020)\end{array}$ \\
\hline$\Delta_{t-1, t-2}$ Coeff & \multirow{2}{*}{\multicolumn{3}{|c|}{$\begin{array}{ccc}-0.377^{* * *}-0.363^{* * *}-0.314^{* *} \\
(0.033) & (0.042) & (0.048) \\
0.005 & 0.014 & -0.061 \\
(0.049) & (0.060) & (0.069)\end{array}$}} \\
\hline $\mid \cdot D_{\text {bust }}$ & & & \\
\hline$\Delta_{n, \max , t-1}$ Coeff & \multirow{2}{*}{\multicolumn{3}{|c|}{$\begin{array}{l}0.119^{* *} \\
(0.038) \\
-0.052 \\
(0.056)\end{array}$}} \\
\hline $\mid \cdot D_{\text {bust }}$ & & & \\
\hline$\Delta_{n, \min , t-1}$ Coeff & & & $\begin{array}{c}-0.060 \\
(0.037)\end{array}$ \\
\hline $\mid \cdot D_{b u s t}$ & & & $\begin{array}{c}0.068 \\
(0.054)\end{array}$ \\
\hline$N$ & 1180 & 726 & 712 \\
\hline adj. $R^{2}$ & 0.540 & 0.561 & 0.536 \\
\hline
\end{tabular}

$\overline{\text { Notes: Standard errors in parentheses. }{ }^{*} \text { significant at }} p<.05 ;{ }^{* *} p<.01$; *** $p<.001$ (black dots) individually estimated for each period and the fitted models (solid lines). All variograms show strong spatial correlation, especially for distances smaller than $2 \mathrm{~km}$.

Formal testing for time varying spatial correlations opens up another research direction, but simple eyeballing of the variograms suggest an increase in the nugget size (the "intercept') in the bust period, indicating an increased heterogeneity in the house-specific error-term component. The spatial dependencies become less strong after $2 \mathrm{~km}$, which suggests a relatively fine-grained neighborhood structure. Nevertheless, the variograms keep a slightly positive slope even for distances exceeding $50 \mathrm{~km}$ due to region-wide correlations. Since the focus of this study is on neighborhood-level differences, these far reaching dependencies are disregarded and a range of $\mathrm{Io} \mathrm{km}$ is chosen when fitting the variograms.

For each sub-period, I estimate an index surface based on a universal kriging estimation provided by the gstat library (Pebesma, 2004) in the $R$ software environment for statistical computing. Figure 4.5 displays the index surface in the peak period as an example. Relative housing wealth is visualized by a continous color scheme ranging from white (lowest values) to black (highes values).

The average distance from surface I to 2 , I to 3 , and I to 4 is $0.57,0.6$, and 0.58 (Table 4.5), which is in line with the national price changes found in the NVM index. For each period, about 4,700 points are classified as local maxima or minima. ${ }^{\text {IO }}$ The average distance of a point to a maximum or

${ }^{\text {Io }} \mathrm{A}$ point is defined to be a local maximum (minimum) if no other point 
Figure 4.4: Variograms for Dutch detached homes through time

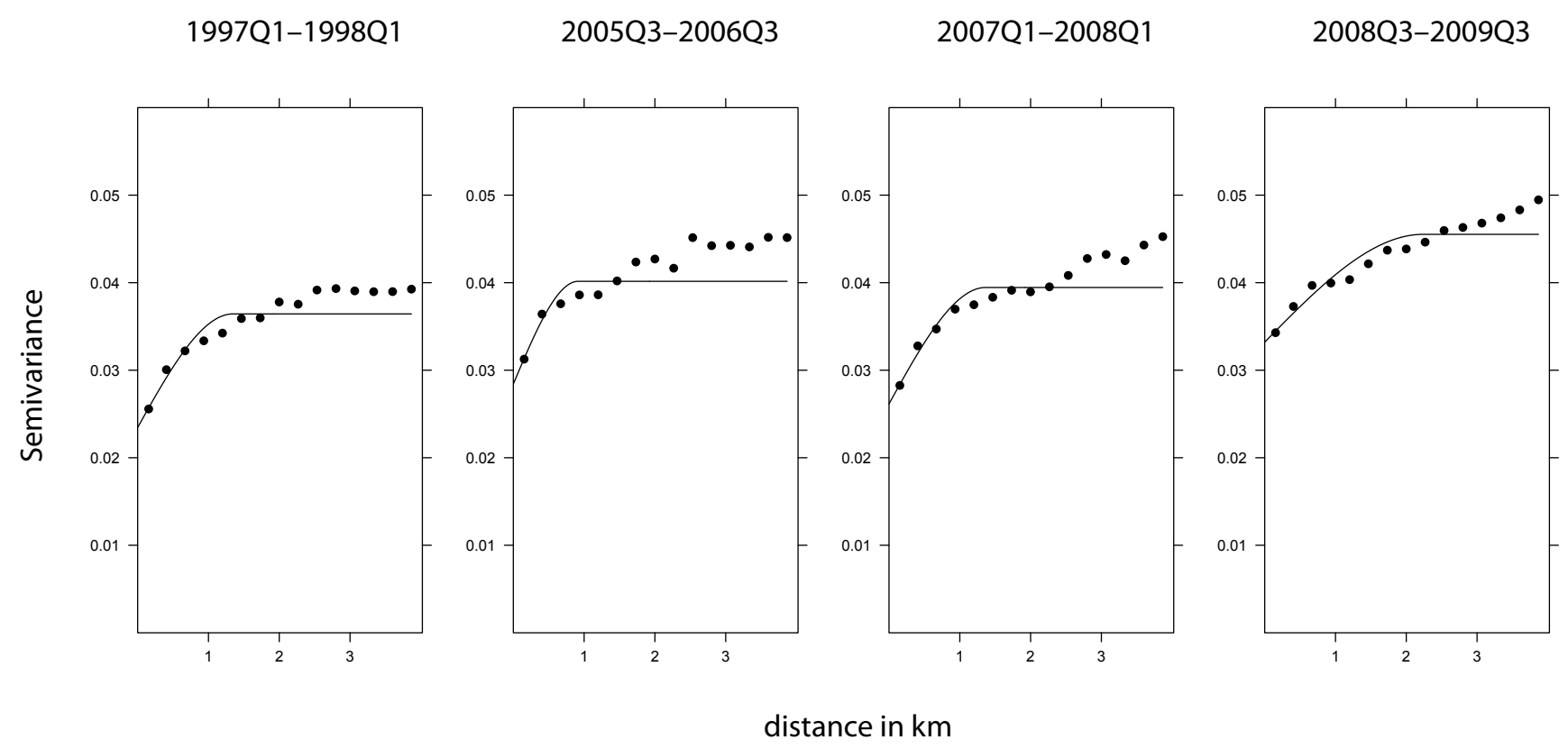

Note: The variograms (Cressie, 1993) are calculated based on the error terms from (4.3) with gstat library in R (Pebesma, 2004). 
Figure 4.5: Index surface for detached home prices, The Netherlands, 2007Q1-2008Q1

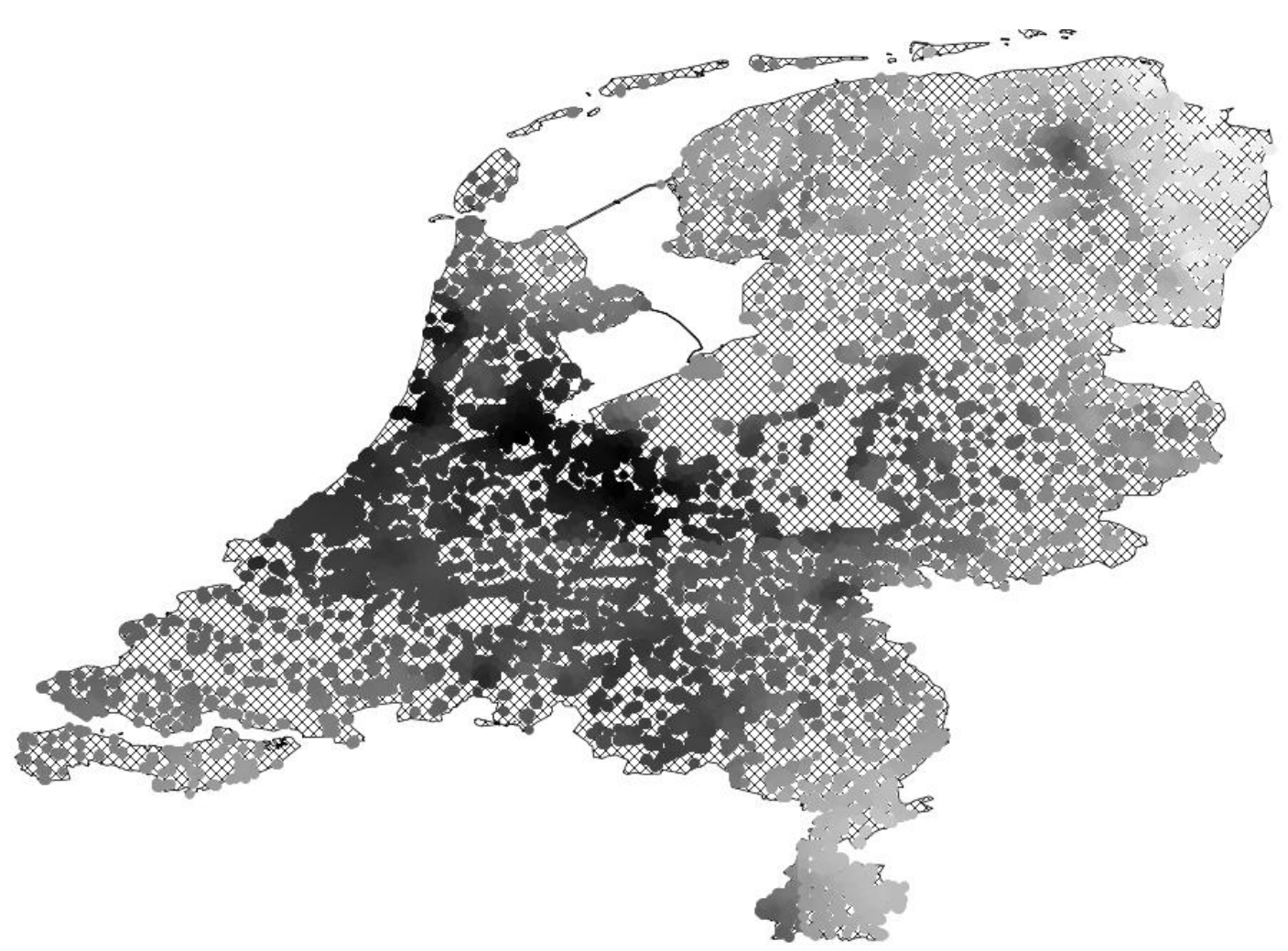

Note: Index surface estimated on residuals from (4.3) by ordinary kriging. Dark areas indicate high location-specific prices, while lighter areas visualize more affordable neighborhoods. 
minimum is about $1.25 \mathrm{~km}$ and home values at the maxima are on average 3.5 percent higher, while the minimum areas carry a discount of similar magnitude. This documents substantial price variation within small distances. Within a circle of about two kilometers, the range in price differences is on average 7 percent.

How did prices change within the cities? Figure 4.6 presents price gradients for parts of Amsterdam, Breda, Groningen and Maastricht. Each panel shows the price estimates for the boom, the peak and the bust period along selected circles of latitude. The examples give a mixed picture: For Breda, Groningen, and Maastricht, the slope of the gradient becomes flatter during the bust period, indicating bigger relative losses in home values in expensive quarters. For central Amsterdam, however, the price gradient becomes steeper. The following part investigates these shifts formally.

Tables 4.6 and 4.7 present the regression coefficients and standard errors for in total six regression equations derived from (4.6) and (4.7). With four cross-sectional surfaces initially estimated, only three periods remain after differencing the index estimates once. Since (4.6) and (4.7) include lagged variables, only two periods in time will be compared finally: The boom period just before the house prices reach their peak, and the subsequent bust. As expected, the coef-

within $750 \mathrm{~m}$ has a higher (lower) index value. Reducing (increasing) the range around each point will lead to more (fewer) local extrema classifications. ficient for the bust period dummy variable is significant and negative in all model specifications.

The coefficient on $\Delta_{t-1, t-2} E$ in Table 4.6 is negative and significant, suggesting that growth rates fade out. Still, index levels (not growth rates) will only revert to their means when this coefficient is equal to or smaller than -I. During the bust period, the coefficients fall to values of -0.35 , which suggests that only a third of the growth rate experienced in boom phases fade away in subsequent periods. This persistence in home value growth is in line with the momentum found by Case and Shiller (2003) for the American housing market in the I970s and 1980s. ${ }^{\mathrm{II}}$

Mean reversion occurs in relative terms, however. The coefficients estimates for $\Delta_{t-1, t-2} E_{e x c}$ in (4.6) are significantly negative (-0.I3 to -0.I45). Locations that have enjoyed home value growth larger (smaller) than the average value of locations close by will therefore experience lower (higher) growth rates in the next periods. The effect becomes stronger in the bust period, with interaction coefficients of -0.072 to $0.08 \mathrm{I}$. If a location 'sticked out' in one period, the differences to its close surroundings will not vanish entirely, but slowly fade. In the alternative specification (4.7), a price elevation above local averages will melt down to $0.4 \mathrm{I}$ or 0.42 percent in the next period. In the bust period, the reversion to the mean is slightly quicker (by -0.027 to -0.036).

Locations close to a local maximum and with a large price

${ }^{\text {II }} \mathrm{A}$ multi-period mean reversion, however, is still possible but is not tested for in this empirical setup. 
CHAPTER 4. LOCAL PRICE DYNAMICS WITHIN CITIES

Table 4.5: Summary statistics of index surface estimates for four sub-periods

\begin{tabular}{lrrrr}
\hline Phase & 1997Q1-1998Q1 & 2005Q3-2006Q3 & 2007Q1-2008Q1 & 2008Q3-2009Q3 \\
\hline Predictions & & & & \\
Min & -0.86 & -0.45 & -0.43 & -0.39 \\
1st Qu. & -0.56 & 0.02 & 0.04 & 0.01 \\
Median & -0.4 & 0.19 & 0.24 & 0.21 \\
Mean & -0.4 & 0.17 & 0.20 & 0.18 \\
3rd Qu. & -0.25 & 0.32 & 0.36 & 0.34 \\
Max & 0.11 & 0.59 & 0.60 & 0.57 \\
\hline Descriptives & & & & \\
\# minima & 2344 & 2341 & 2339 & 2361 \\
\# maxima & 2490 & 2269 & 2279 & 1302 \\
distance to min (m) & 1262 & 1276 & 1319 & 1307 \\
distance to max (m) & 1191 & 1294 & 1303 & 0.036 \\
$E_{t}-E_{\text {min }, t}$ & 0.040 & 0.035 & 0.036 & 0.037 \\
$E_{\text {max }, t}-E_{t}$ & 0.043 & 0.036 & 0.037 & -0.020 \\
$E_{t}-E_{t-1}$ & $\mathrm{n} / \mathrm{a}$ & 0.572 & 0.040 & \\
\hline
\end{tabular}

Note: All residential area as defined by Dutch zoning points are added to a regular $200 \mathrm{~m}$-by-200 $\mathrm{m}$ grid for which point estimates in the four phases are calculated by ordinary kriging. Number of points in grid: 56,332 .

The relative attractiveness of neighborhoods is described by their distance to local extreme values in the index surface. A point is defined to be a local maximum (minimum) if no other point within $750 \mathrm{~m}$ has a higher (lower) index value. Isolated settlements covering only small areas $\left(<0.1 \mathrm{~km}^{2}\right)$ are excluded. 
Figure 4.6: Estimated price gradients for selected cities

Amsterdam (at latitude 52.36576)

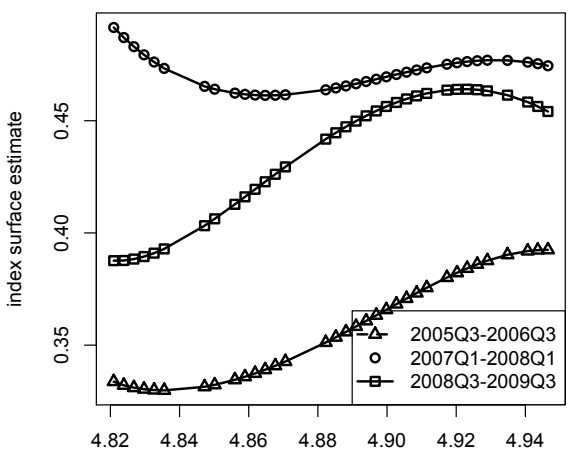

degrees longitude

Groningen (at latitude 53.2309)

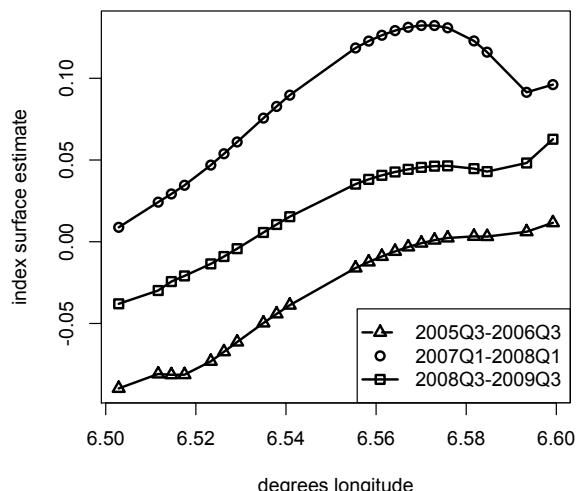

118
Breda (at latitude 51.5742)

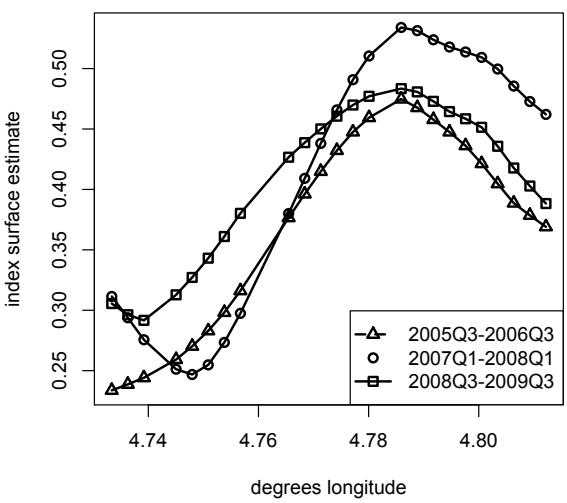

Maastricht (at latitude 50.8472)

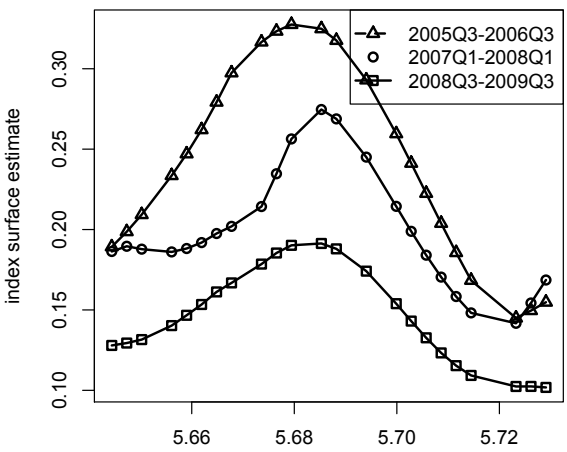

degrees longitude
Notes: The figures show price gradients for cuts along the circles of latitude through the index surfaces estimated for the cities of Amsterdam, Breda,

Groningen and Maastricht. The boom phase gradient is marked by pyramids, the peak gradient by circles, and the bust period by boxes. For Breda, Groningen, and Maastricht, the slope of the gradient becomes flatter during the bust period, indicating bigger relative losses in home values in expensive quarters. For central Amsterdam, however, the price gradient becomes steeper. 
Table 4.6: Regression results on changes in index surface during boom and bust (4.6)

\begin{tabular}{|c|c|c|c|}
\hline$\Delta E_{t, t-1}$ & 1 & 2 & 3 \\
\hline Intercept & $(0.002)$ & $0.118^{* * *}(0.002)$ & $0.119^{* * *}(0.002)$ \\
\hline$D_{\text {bust }}$ & $-0.133^{* * *}(0.002)$ & $-0.130^{* * *}(0.002)$ & $-0.130^{* * *}(0.002)$ \\
\hline$\Delta E_{t-}$ & $(0.003)$ & $*(0.003)$ & -0.143 \\
\hline $\mid \cdot D_{\text {bust }}$ & $*(0.005)$ & $-0.210^{* * *}(0.005)$ & $-0.210^{* * *}(0.005)$ \\
\hline \multicolumn{2}{|c|}{$\Delta_{t-1, t-2} E_{e x c}-0.145^{* * *}(0.017)$} & $-0.130^{* * *}(0.017)$ & $-0.132^{* * *}(0.018)$ \\
\hline $\mid \cdot D_{\text {bust }}$ & $-0.072^{* *}(0.026)$ & $-0.081^{* *}(0.027)$ & $-0.080^{* *}(0.027)$ \\
\hline$\triangle P o p$ & $-0.139^{* * *}(0.018)$ & $0.001 \quad(0.007)$ & -0.006 \\
\hline $\mid \cdot D_{\text {bust }}$ & $0.332^{* * *}(0.027)$ & $(0.012)$ & $(0.013)$ \\
\hline Slope & $0.142^{* * *}(0.011)$ & & -0.024 \\
\hline $\mid \cdot D_{\text {bust }}$ & $-0.061^{* * *}(0.015)$ & & -0.006 \\
\hline$\cdot \Delta P o p$ & $10.058^{* * *}(0.495)$ & & $(0.325)$ \\
\hline$\cdot D_{\text {bust }} \Delta P$ Pop & $-7.548^{* * *}(0.735)$ & & $(0.481)$ \\
\hline$\Delta_{\max } E_{t-1}$ & & $0.159^{* * *}(0.007)$ & $0.170^{* * *}(0.010)$ \\
\hline - D bust & & $-0.033^{* * *}(0.010)$ & $-0.031^{*} \quad(0.014)$ \\
\hline$\cdot \Delta P o p$ & & $0.163 \quad(0.132)$ & -0.031 \\
\hline$\cdot D_{\text {bust }} \Delta P$ Pop & & $0.673^{* * *}(0.200)$ & $0.627^{*} \quad(0.286)$ \\
\hline adj. $R^{2}$ & 0.316 & 0.308 & 0.308 \\
\hline
\end{tabular}

Notes: Standard errors in parentheses. $\mathrm{N}=98,47 \mathrm{I} .{ }^{\dagger}$ significant at $p<.10$; ${ }^{*} p<.05 ;{ }^{* *} p<.01 ;{ }^{* * *} p<.001$. This set of regression is based on (4.6). The change in fitted values in the index surface $E_{t}-E_{t-1}$ is regressed against the change one period before $\left(E_{t-1}-E_{t-2}\right)$, the difference in fitted values ('vertical distance') to the nearest local maximum $\left(E_{\max }-E_{t-1}\right)$, and the 'slope' $\left(E_{\max }-E_{t-1}\right) /$ distance $_{\max }$ to the nearest local maximum. $\Delta_{t-1, t-2} E_{\text {exc }}$ is the change in the difference between the index estimate of point $i$ and the average index value within a circle of $1000 \mathrm{~m} . \Delta P o p$ are annual changes in the resident population at municipality level. All variables are interacted with the bust-period dummy to allow for changes in the coefficients across boom and bust periods.
Table 4.7: Regression results on changes in index surface during boom and bust, alternative specification (4.7)

\begin{tabular}{|c|c|c|c|c|c|c|}
\hline$E_{e x c, i, t}$ & 1 & & 2 & & 3 & \\
\hline Intercept & $-0.000^{*}$ & $(0.000)$ & -0.000 & $(0.000)$ & $0.002^{* * *}$ & $(0.000)$ \\
\hline$D_{\text {bust }}$ & $-0.000^{*}$ & $(0.000)$ & $-0.000^{* *}$ & $(0.000)$ & $-0.002^{* * *}$ & $(0.000)$ \\
\hline$E_{e x c, i, t-1}$ & $0.420^{* * *}$ & $(0.005)$ & $0.410^{* * *}$ & $(0.005)$ & $0.416^{* * *}$ & $(0.005)$ \\
\hline $\mid \cdot D_{\text {bust }}$ & $-0.036^{* * *}$ & $(0.007)$ & $-0.032^{* * *}$ & $(0.007)$ & $-0.027^{* * *}$ & $(0.007)$ \\
\hline$\triangle P$ op & -0.001 & $(0.002)$ & -0.000 & $(0.002)$ & -0.000 & $(0.002)$ \\
\hline $\mid \cdot D_{\text {bust }}$ & $-0.011^{* * *}$ & $(0.002)$ & $-0.011^{* * *}$ & $(0.002)$ & $-0.011^{* * *}$ & $(0.002)$ \\
\hline Slope & $0.008^{* * *}$ & $(0.002)$ & $0.028^{* * *}$ & $(0.003)$ & $0.029^{* * *}$ & $(0.003)$ \\
\hline $\mid \cdot D_{\text {bust }}$ & $0.005^{\dagger}$ & $(0.003)$ & -0.004 & $(0.004)$ & -0.004 & $(0.004)$ \\
\hline$\cdot \Delta P o p$ & -0.049 & $(0.042)$ & 0.045 & $(0.060)$ & 0.043 & $(0.060)$ \\
\hline$\cdot D_{\text {bust }} \Delta P o p$ & $0.389^{* * *}$ & $(0.062)$ & $0.251^{* *}$ & $(0.088)$ & $0.232^{* *}$ & $(0.088)$ \\
\hline \multirow{4}{*}{\multicolumn{3}{|c|}{$\begin{array}{l}\Delta_{\max } E_{t-1} \\
\mid \cdot D_{\text {bust }} \\
\mid \cdot \Delta \text { Pop } \\
\mid \cdot D_{\text {bust }} \Delta \text { Pop }\end{array}$}} & $-0.018^{* * *}$ & $(0.002)$ & $-0.017^{* * *}$ & $(0.002)$ \\
\hline & & & $0.008^{* *}$ & $(0.003)$ & $0.006^{*}$ & $(0.003)$ \\
\hline & & & $-0.088^{*}$ & $(0.035)$ & $-0.086^{*}$ & $(0.034)$ \\
\hline & & & $0.133^{*}$ & $(0.053)$ & $0.141^{* *}$ & $(0.052)$ \\
\hline \multirow{2}{*}{\multicolumn{3}{|c|}{$\begin{array}{l}E_{t-1}-E_{t-2} \\
\mid \cdot D_{\text {bust }}\end{array}$}} & & & $-0.005^{* * *}$ & $(0.001)$ \\
\hline & & & & & $-0.007^{* * *}$ & $(0.001)$ \\
\hline adj. $R^{2}$ & 0.147 & & 0.149 & & 0.151 & \\
\hline
\end{tabular}

Notes: Standard errors in parentheses. $\mathrm{N}=88,849$.

${ }^{\dagger}$ significant at $p<.10 ;{ }^{*} p<.05 ;{ }^{* *} p<.01 ;{ }^{* *} p<.001$ 
differential to this maximum (high values for Slope) have higher price appreciation in the boom phase (coefficient of 0.I42 for Slope) than points where price differences are less pronounced. During the bust, these gentrifying neighborhoods still perform better than peers bordering lower-price areas (the sum of the coefficients is still positive). The effect is confirmed in (4.7). These findings support hypothesis $H_{1}$ and are in line with the results from Guerrieri et al. (2010). $\mathrm{H}_{2}$ cannot be confirmed, though.

The moderating effect of population growth is confirmed by the positive coefficient of 10.058 for the interaction term Slope $\triangle$ Pop in (4.6). The effect persists during the bust phase, but only at a quarter of the boom's rate (I0.058-7.548 $=2.5 \mathrm{I}$ ). For (4.7) the moderating role is prominent in the bust phase only (coefficients of 0.232 to 0.389 ). Overall, these results support $H_{3}$.

Prices in already expensive neighborhoods underperform more affordable locations during boom times. The coefficient estimate on the position relative to the closest local maximum $\Delta_{\max , t-1} E$ is significant and positive (0.159 and O.I70): the bigger the vertical distance of a location to a local peak, the bigger the gain in the boom period. The coefficient for population-growth interaction term is not significant. Thus, $H_{4}$ cannot be rejected.

Statistically, the convergence effect is weakened in the bust phase as the coefficient for the interaction term is o.o33. Economically, this drop is only 2I percent. Demographic trends again interfere: When population growth rates turn negative and home values decline, the 0.627 or 0.673 coefficient will turn negative. Economically, this effect is non-negligible, as a quick back-of-an-envelope calculation reveals. The first quartile in the latest three-year population growth distribution of Dutch municipalities is -0.4 percent. Multiplying the coefficient and this number gives growth rates for local minima that are 25 basis points below the corresponding rates of maxima, which are just a few hundred meters away. For minima that are located in the 25 percent of municipalities whose population grew with at least I.5 percent, the price gap to maxima will narrow down due to a I percent higher growth rate. $H_{5}$ and $H_{6}$ cannot be rejected.

\subsection{Discussion}

This paper researches within-city home price dynamics in bullish and bearish residential real estate markets. It contributes to the literature addressing the urban layout of cities by formulating and empirically testing hypotheses on changes in the price gradients across neighborhoods under different market regimes and demographic conditions.

First, the existing concept on endogenous house price dynamics is extended by the notion of the moderating role of demographics. New residents flocking into the city will speed up the sorting process as the wealthy settle close to each other and the poor prefer the affordable homes in poorer quarters. Indeed, the empirics show that higher in- 
tensities of endogenous gentrification can be found in areas with robust population growth.

Second, this paper discusses how a decline in a city's population and a simultaneous negative shock to home values lead to a home value polarization within cities. Under such a scenario, the price gap between wealthy and poor areas increases. Falling prices allow households to move up in the housing ladder since they receive 'more house' for the same money. This effect is estimated to be economically significant for Dutch neighborhoods.

Third, evidence for momentum in house prices at the neighborhood-level is presented. A cross-sectional analysis of growth rates suggests a mild mean reversion in the trend. Changes to levels, however, are sticky. The magnitude in the mean reversion in the trends depends on the market regime, so in case one tries to exploit this potential market inefficiency, a good understanding of market trends is warranted.

Fourth, a new level of spatial detailedness is achieved by analyzing a high-quality data-set for The Netherlands. The data comprise of I.8 million single family home transactions and 0.8 million apartments sold by members of the Dutch Realtor Association (NVM). Previous studies have worked with American data, so this paper offers an international perspective. These data are geocoded and matched with demographic information through means of GIS analysis.

Fifth, to fully exploit this finely-grained data, a spatial estimation technique is borrowed from the geoscience domain. This gives results that were out of reach when relying on tra- ditional hedonic regressions. This is the first paper that estimates home price index surfaces for an entire country based on a spatial error model (SER).

The results of this study are not only relevant from a real estate finance point of view. Case et al. (200I) and others (Carroll et al. , 2006; Bostic et al. , 2009) link housing wealth to consumption. They find that households' consumption is more sensitive to changes in housing wealth than to changes in wealth from holding stocks - at the aggregate level. If these findings hold at the neighborhood level as well, a relative shift in the housing wealth within a city will change nonhousing consumption levels across neighborhoods. 


\section{Chapter 5}

\section{Conclusion}

Housing markets are like the weather, sports, or politics: They are one of the truly big topics almost everybody has an opinion about. Often, when being introduced at a party with "This is Thies. He is currently writing a dissertation in finance..." the first reaction was an unconvincing "Oh really? How interesting - ", followed by awkward silence and an uneasy search for excuses to leave. A quickly uttered "My research is on house prices..." usually saved the moment. Smooth and pleasant small-talk directly evolved, fuelled by an endless supply of housing-related anecdotes and personal experiences shared by my newly-found friends.

Leaving behind party chit-chat, serious discussions soon sprung up. People were looking for answers to questions they were facing: Should they buy that house down the road now or would it be better to wait one more year? Where are prices in this city heading to? Will they be able to sell their home once they retire? Is this a stable neighborhood? Is it a good idea to buy a second home and to rent it out? The magnitude of a household's investment in housing and the direct impact of housing choices on the every-day quality of life forbade answers that were too easy.

This dissertation researches four aspects of housing markets. First, it examines the long run relation between prices and rents for houses in Amsterdam from I650 through 2005. Spanning 355 years, this study probably holds the world record for analyzing the longest time series in the asset pricing literature in general, not to speak of residential real estate research in particular. Chapter I shows that, in the long run, house prices can be explained by a theoretical fundamental value calculated from rents and interest rates. The rent-price ratio not only displays an impressive persistence throughout the centuries (Figure I.5) but also reverts back to this theoret- 
ical basis (Figure I.6)

If houses are over- or undervalued compared to the rental streams they produce, will either prices adjust or rents? Table I.4 presents the results from an error correction model which indicates that the 'balance' is achieved mainly through price changes. Rents are more sticky and respond to a smaller extend.

Based on these results, can an investor make money by betting on corrections? In principle, yes. Such an investor, however, needs deep pockets and a long life as the correction back to equilibrium can take decades. Throughout the second half of the $19^{\text {th }}$ century, for instance prices of Amsterdam's houses remained overvalued for more than 50 years. This result is a warning for those who read the massive decline of Berlin's single family homes during the last 15 years (Figure 2.3) as a soon-reverting deviation from the long run mean. Berlin's homes seem to be affordable right now. Still, they are a risky bet, since there is no guarantee that prices will move up again in the near future.

Second, the dissertation is the first to estimate how house prices volatility is affected by so-called real options. An example of a real option is the possibility to extend the size of an existing home by adding more rooms or by taking down the existing structure and building a bigger new house. Real options carry value since they give the owners of a building flexibility. When markets develop favorably and the value for additional space increases, the owner can 'execute' the option and start building. In case additional space is not in demand, he/she can just postpone any new development. Chapter 2 measures the value of the option to extend in different market climates. It incorporates this real option in a standard hedonic regression model and shows how neighborhoods and houses with unrealized renovation potential can be identified.

The study uses an unexplored dataset of housing transactions in West Berlin, covering thirty years between 1978 and 2007. West Berlin is an ideal test environment for this type of study because it offers detailed data on the maximum size allowed under current zoning for each building sold. In addition, the fall of the Berlin Wall in 1989 stirred-up housing markets. A clear division in a tranquil 'walled-in' phase (1978-I989), a 'big bang' period with high house price growth directly after the wall came down (1990-1995) and a long 'cool down' phase (1996-2007) gives the opportunity to compare the value of this real option in different market regimes.

The empirical results show that house value has an elasticity of about 0.15 with respect to development potential, measured by the ratio between the maximum square meters allowed by zoning and the existing house size. For high option value properties the elasticity increases to 0.23 (Table 2.4). The evidence presented suggests that the 'big bang' boom period between 1989 and 1994 was associated with a significant increase in option value for the properties with substantial redevelopment potential; about 40 percent of the boom was due to increase in option value. During the Io year bust after 1994 , about 50 percent of the decline was due to change in 
option value. Volatility of this magnitude applies to about IO percent of all properties sold during the sample period. More than 68 percent of all sales have increased volatility over the cycle due to unrealized option value.

The history of home values in Amsterdam also motivated research on a third aspect of housing markets in this dissertation. The crisis years of I78I-I8I4 were the only time in Amsterdam's history when the city's population numbers declined substantially. In these 22 years, home values fell by on average 3 percent annually. This massive loss in housing wealth indicates a strong link between demographics and housing markets (and the general economy, of course). Chapter 3 aims to investigate how demographics determine the amount and the quality of housing services demanded.

Based on a very detailed 200I cross-section of English households, it finds that human capital is a key driver for housing demand. Variables that are positively related to human capital increase the demand for housing. For instance, each additional level of education a household has achieved, drives up its reservation prices for the housing services consumed. On the other hand, factors like chronic illnesses that impair human capital have a negative impact on housing consumption. Since each generation is better educated than the generations before, an aging society will demand more housing on an aggregated level, even if the total number of households stops growing. A scenario analysis with different population forecasts shows that the upward sloping partial age derivative is supporting demand in an ageing society

\section{(Figure 3.4).}

These findings are very relevant for other European countries beside England. Despite the cultural and economic heterogeneity within Europe, the upward-sloping age-demandrelationship observed in England should be a reasonable proxy for other European nations, even in case of different demographic profiles. Today, Europe is facing an unprecedented demographic change: The entire area reaching from Germany in the west, to Russia in the east, and to the Balkans in the south is losing population already today - and this development is expected to gain momentum in the next decades (United Nations Population Division, 2007).

A last point to take-away from this study is that regional housing markets with unattractive economic perspectives and living conditions face a double challenge: not only does the total number of households decline, but households having enjoyed a better education are more likely to leave for more prosperous regions than lower educated households. Without the younger generation being better educated and more wealthy than the generations before, the pressure on housing demand caused by population shrinkage cannot be off-set.

The fourth chapter researches how the distribution of housing wealth within a city is changing once average prices change for the city in general. This study was motivated by the observation that some neighborhoods in Berlin like Prenzlauer Berg, Friedrichshain or Mitte flourished in the last years while Berlin as a city experienced strong losses in 
housing wealth. Data availability let me conduct this study on all of The Netherlands instead of the city of Berlin, ${ }^{\mathrm{I}}$ but the question remained the same: How do within-city home price dynamics change in bullish and bearish residential real estate markets? What is the role of demographics in this process? It contributes to the literature addressing the urban layout of cities by formulating and empirically testing hypotheses on changes in the price gradients across neighborhoods under different market regimes and demographic conditions.

This study finds that a decline in a city's population and a simultaneous negative shock to home values lead to a home value polarization within cities. Under such a scenario, the price gap between wealthy and poor areas increases. Falling prices allow households to move up in the housing ladder since they receive 'more house' for the same money. This effect is estimated to be economically significant for Dutch neighborhoods.

Furthermore, evidence for momentum in house prices at

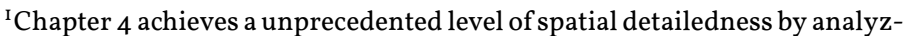
ing a high-quality data-set for The Netherlands. The data comprise of $\mathrm{I} .8$ million single family home transactions and 0.8 million apartments sold by members of the Dutch Realtor Association (NVM). These data are geocoded and matched with demographic information through means of GIS analysis. To fully exploit this finely-grained data, a spatial estimation technique is borrowed from the geoscience domain. This gives results that were out of reach when relying on traditional hedonic regressions. This is the first paper that estimates home price index surfaces for an entire country based on a spatial error model (SER) the neighborhood-level is presented. A cross-sectional analysis of growth rates suggests a mild mean reversion in the trend. Changes to levels, however, are sticky. The magnitude in the mean reversion in the trends depends on the market regime, so in case an investor tries to exploit this potential market inefficiency, a good understanding of market trends is warranted.

Earlier papers have developed a closed form model that predicts endogenous home price dynamics. Very casually speaking, they predict that rich households benefit from and prefer to have other well-off people as neighbors. This preference leads to a segmentation of cities in rich and poor neighborhoods, endogenously linked to home values in these areas. Chapter 4 extends this literature by the notion of the moderating role of demographics. New residents flocking into the city will speed up the sorting process as the wealthy settle close to each other and the poor prefer the affordable homes in poorer quarters. Indeed, the empirics show that higher intensities of endogenous gentrification can be found in areas with robust population growth.

The essence of this dissertation is that housing markets are more risky than they appear to be. When I started my research in 2007 , residential real estate seemed to be a safe asset class, characterized by steady positive returns and low risk. The following years proved this perception to be wrong - and so does my research. Mispricings occur often and persist for long periods of time. Real options amplify these deviations from fundamentals and thereby increase house price 
volatility. Demographics ultimately determine the demand for housing services. Against common belief, an aging society does not necessarily demand less housing. Human capital is the key demand factor, not age. Finally, drops in aggregate house prices increase the inequalities within cities with falling population numbers, which is a discomforting result, given Europe's challenging demographic outlook. 


\section{Nederlandse Samenvatting (Summary in Dutch)}

Housing matters. Voor geïndustrialiseerde landen zijn woningen het grootste onderdeel van de private consumptie. Het Amerikaanse Bureau of Labor Statistics schat dat woningbezitters in de Verenigde Staten ongeveer 24 procent van hun totale bestedingen in 2010 aan wonen uitgaven. Het kopen van een woning is voor de meeste huishoudens de grootste investering van hun leven. In Nederland zit voor de gemiddelde woningbezitter ruim 60 procent van zijn totale kapitaal vast in de woning. En woningen domineren niet alleen de bezittingen, maar ook de schulden van huishoudens: voor het gemiddelde Nederlandse huishouden vertegenwoordigt de woninghypotheek zo'n 33 procent van het totale kapitaal. De woningmarkt is groot genoeg om een indrukwekkende invloed op de algemene economie te hebben. De waarde van het Nederlandse eigen-woningbezit (dus exclusief huurwoningen) wordt geschat op $€$ I.7 biljoen (!) in 2009. Dit is meer dan twee keer ons nationale Bruto Nationaal Product en overstijgt ruimschoots de totale marktkapitalisatie van alle bedri- jven genoteerd op de AEX. Het totaal van uitstaande woninghypotheken in de Verenigde Staten is ruim driekwart van het Amerikaanse Bruto Nationaal Product.

Tijdens de laatste jaren van het "tijdperk Greenspan" stimuleerde de Verenigde Staten de woningmarkt door goedkoop krediet om zowel de dot-com crisis als de economische schok na de aanslagen op $9 /$ II te verzachten. Woningprijzen leken oneindig te kunnen groeien. Tussen 2000 en 2006 nam de Case/Shiller huizenprijsindex voor de 20 grootste Amerikaanse steden toe met I05 procent. Deze prijsstijging leidde tot oververhitting voor de rest van de economie en inmiddels kennen wij het einde van deze sage: ineenstortende woningprijzen in de Verenigde Staten luidden het begin in van een wereldwijde economische crisis die de financiële industrie verlamde, en leidde tot "The Great Recession". Deze crisis heeft op een pijnlijke manier duidelijk gemaakt dat kennis van de dynamiek van woningmarkten onontbeerlijk is.

Dit proefschrift onderzoekt risico's op de woningmarkt 
vanuit vier verschillende perspectieven. Allereerst gaan wij nader in op de lange termijn relatie tussen huren en prijzen van woningen in Amsterdam - van 1650 tot 2005. Met een periode van 355 jaar kan dit onderzoek waarschijnlijk het wereldrecord claimen voor het analyseren van de langste tijdreeks in de literuur over de waardering van financiële activa (om over de vastgoedliteratuur maar niet te spreken). Hoofdstuk I laat zien dat woningprijzen op de lange termijn verklaard kunnen worden door een theoretische fundamentele waarde, berekend op basis van huren en rente niveaus. De huur-prijs verhouding laat over de eeuwen heen niet alleen een indrukwekkende stabiliteit zien, maar keert ook telkens terug naar een theoretische basis. Maar, indien woningen over- of ondergewaardeerd zijn in vergelijking met de huurstromen die ze genereren, dan is de vraag of de prijzen zich aanpassen, of juist de huren. De resultaten van een error-correctie model tonen aan dat het evenwicht voornamelijk hersteld wordt doordat woningprijzen veranderen. Huurstromen zijn stabieler en minder gevoelig voor marktveranderingen. Echter, het evenwichtsherstel kan tientallen jaren duren. Gedurende de tweede helft van de negentiende eeuw bleven woningen bijvoorbeeld overgewaardeerd voor meer dan vijftig jaar.

Het tweede deel van dit proefschrift is een eerste, unieke verkenning in de wetenschappelijke literatuur naar de relatie tussen de volatiliteit van woningprijzen en de waardeveranderingen van zogenoemde reële opties ("real options"). Een voorbeeld van een reële optie is de mogelijkheid om de om- vang of inhoud van een bestaande woning te vergroten door het toevoegen van een aanbouw, of door de bestaande woning af te breken en een grotere woning te bouwen. Reële opties hebben financiële waarde omdat deze de eigenaar van een woning een bepaalde flexibiliteit geven. Op het moment dat de woningmarkt aantrekt en de vraag naar additionele ruimte of grotere woningen toeneemt, kan de eigenaar zijn optie uitoefenen en gaan bouwen. In het geval dat de vraag naar (grotere) woningen beperkt is, kan de eigenaar de investering simpelweg uitstellen.

Hoofdstuk 2 meet de waarde van de reële optie in de woningmarkt tijdens verschillende marktomstandigheden. De reële optie wordt meegenomen in een standaard hedonisch regressiemodel om wijken en woningen met ongerealiseerd waardepotentieel te kunnen identificeren. De studie gebruikt een nog niet onderzochte steekproef van woningtransacties in West-Berlijn van 1978 tot en met 2007. West-Berlijn biedt een ideale onderzoeksituatie, omdat daar gedetailleerde data over de maximale woningomvang (als gedefinieerd in het bestemmingsplan) voor iedere woningtransactie beschikbaar zijn. Daarnaast leent de dynamische historie van de stad Berlijn zich uitstekend voor de vergelijking van de optiewaarde ten tijde van zeer diverse - positieve en negatieve - marktomstandigheden. De empirische resultaten tonen een elasticiteit van woningprijzen ten opzichte van ontwikkelingspotentieel van 0.15, waar ontwikkelingspotentieel gemeten wordt door de verhouding tussen het maximale aantal vierkante meters als toegestaan 
in het bestemmingsplan en het huidige aantal vierkante meters in de woning. Voor woningen met een hoge optiewaarde neemt de elasticiteit toe tot 0.23 . De resultaten suggereren dat Berlijn's bloeiperiode - van I989 tot 1994 - voor woningen met een substantieel ontwikkelingspotentieel tot een significante toename van optiewaarde leidde; zo'n veertig procent van de waardevermeerding in de woningmarkt kan worden verklaard door optiewaarde. Er is echter ook een keerzijde: gedurende de tien jaar malaise op de woningmarkt na 1994 was ongeveer vijftig procent van de prijsdaling te wijten aan optiewaarde. Volatiliteit van deze omvang geldt voor ongeveer tien procent van de verkochte woningen, maar gedurende de vastgoedcyclus heeft ruim 68 procent van alle woningtransacties een toegenomen volatiliteit door ongerealiseerde optiewaarde.

Hoofdstuk 3 van dit proefschrift heeft tot doel om de invloed van demografie op kwantiteit en kwaliteit van woningvraag te onderzoeken. Gebaseerd op een zeer gedetailleerde cross-sectie van Britse huishoudens laat dit hoofdstuk zien dat menselijk kapitaal ("human capital") een bepalende factor is voor woningvraag. Variabelen die positief gecorreleerd zijn met menselijk kapitaal leiden tot een toenemende vraag naar woningen. Met iedere stap dat bijvoorbeeld het scholingsniveau van een huishouden toeneemt, vermeerderd de betalingsbereidheid voor woningvraag. Echter, factoren die menselijk kapitaal beperken, zoals bijvoorbeeld chronische ziekten, hebben een negatieve impact op de consumptie van woningen. Het hoofdstuk laat zien dat, aangezien iedere generatie beter is opgeleid dan de voorgaande, vergrijzing een toenemende totale vraag naar woningen tot effect zal hebben, zelfs als de omvang van het aantal huishoudens stabiliseert. Een scenario analyse aan de hand van verschillende officiële bevolkingsprojecties demonstreert dit effect: zelfs in het meest negatieve vergrijzingscenario zal de totale vraag naar woningen blijven groeien, er vanuit gaande dat inkomen en kapitaal van de vergrijzende leeftijdscohorten niet afneemt.

Het vierde empirische hoofdstuk van dit proefschrift bestudeert hoe de verdeling van woningkapitaal binnen een stad veranderd op het moment dat de woningwaarde van de stad als geheel veranderd. Deze studie vindt zijn grondslag in de anekdotische observatie dat bepaalde wijken in Berlijn, zoals Prenzlauer Berg, Friedrichshain en Mitte, de afgelopen jaren floreerden, terwijl de stad Berlijn als geheel te maken had met substantiële vermindering van het woningkapitaal. De beschikbaarheid van data veranderde de geografische focus van deze studie naar Nederland. Echter, de vraagstelling bleef hetzelfde: hoe verandert de dynamiek van woningprijzen binnen een stad in opwaartse en neerwaartse markten? En wat is de rol van demografie in dit proces?

Dit hoofdstuk draagt bij aan de literatuur over stadsindeling door het theoretisch onderbouwen en empirisch testen van hypothesen betreffende prijscurven in verschillende wijken, in verschillende marktomstandigheden en onder verschillende demografische condities. De resultaten laten zien dat een neergang in de bevolkingsomvang van een stad, 
gecombineerd met een negatieve, externe schok op woningprijzen, tot een polarisatie van woningwaarden in een stad leidt. In een dergelijk scenario neemt het verschil in woningprijzen tussen arme en rijke wijken toe. Een neerwaartse prijsspiraal staat huishoudens toe om op te klimmen op de woningmarkt, omdat zij "meer woning" voor hetzelfde geld krijgen, waardoor de arme wijken afglijden tot verval.

Eerdere onderzoeken ontwikkelden een gesloten model dat een vicieuze cirkel voor woningprijsontwikkelingen voorspelt. Dit impliceert simpelweg dat rijke huishoudens gelijkgestelde buren prefereren en hiervan profiteren. Deze voorkeur leidt tot een zichzelf versterkende segmentatie van steden in arme en rijke wijken, hetgeen een groot effect heeft op woningprijzen in de deze wijken. Hoofdstuk 4 borduurt voort op deze literatuur door de modererende rol van demografie in ogenschouw te nemen. Nieuwe inwoners in een stad versnellen het segmentatie-effect, omdat de welgestelden dicht bij elkaar gaan wonen en de minder bedeelden kiezen voor meer betaalbare woningen in de arme wijken. De resultaten laten zien dat gebiedsverbetering en verslechtering vooral plaatsvinden in gebieden met een meer robuuste bevolkingsgroei.

De belangrijkste boodschap van dit proefschrift is dat woningmarkten risicovoller zijn dan ze op het eerste gezicht lijken. Toen ik mijn onderzoek in 2007 begon werden woningmarkten als een veilige belegging ervaren, gekarakteriseerd door consistente, positieve rendementen en een laag risico. De daarop volgende jaren weerlegden deze per- ceptie, net als dit proefschrift. Incorrecte waarderingen zijn aan de orde van de dag en zetten vaak voor een langere periode door. Reële opties versterken deze afwijkingen van de fundamentele waarde en daardoor de volatiliteit van woningprijzen. Demografie bepaalt uiteindelijk de vraag naar het product "woning". Geheel tegen algemene veronderstellingen in hoeft een vergrijzende maatschappij niet per definitie een afnemende vraag naar woningen te impliceren. Menselijk kapitaal is de bepalende factor, niet leeftijd. Tenslotte heeft een woningmarkt gekarakteriseerd door prijsdalingen een toename in ongelijkheid binnen steden met een krimpende populatie tot gevolg. Gegeven Europa's uitdagende demografische vooruitzichten is dit is een verontrustende bevinding. 


\section{Curriculum Vitae}

\section{Academic Career}

\begin{tabular}{ll}
\hline $\begin{array}{l}\text { Name } \\
\text { Place and date of birth }\end{array}$ & $\begin{array}{l}\text { Thies Lindenthal } \\
\text { Hamburg, April 21st, 1979 }\end{array}$ \\
\hline Sep. 2007-Sep. 2010 & $\begin{array}{l}\text { Maastricht University, PhD candidate } \\
\text { Uan. 2009-June 2009 } \\
\text { of Public Policy }\end{array}$ \\
Dec. 2008 & $\begin{array}{l}\text { Harvard School of Public Health, PGDA Visiting } \\
\text { Fellow for the month of December }\end{array}$ \\
Sep. 2005-Aug. 2007 & $\begin{array}{l}\text { Maastricht University, M.Phil. program in Eco- } \\
\text { nomic and Financial Research } \\
\text { Jan. 2005-Aug. 2005 }\end{array}$ \\
$\begin{array}{l}\text { Hong Kong University of Science and Technol- } \\
\text { ogy, Exchange semester as part of the under- } \\
\text { graduate studies } \\
\text { Maastricht University, B.Sc. in International Busi- } \\
\text { ness Administration }\end{array}$ \\
Oct. 1999-Jun. 2000 & $\begin{array}{l}\text { Christian Albrechts Univeristät, Kiel, undergrad- } \\
\text { uate studies in Computer Science }\end{array}$ \\
\hline
\end{tabular}

\section{Distinctions}

\begin{tabular}{ll}
\hline 2010 & $\begin{array}{l}\text { Aareal Award of Excellence in Real Estate Re- } \\
\text { search in the category Research Paper }\end{array}$ \\
2007 & $\begin{array}{l}\text { European Real Estate Society ERES - Doctoral } \\
\text { Prize, best paper presented at the PhD ses- } \\
\text { sions at the ERES Annual Conference }\end{array}$ \\
\hline
\end{tabular}




\section{Bibliography}

Abreu, D. and Brunnermeier, M. (2003). Bubbles and crashes. Econometrica, 7I(I):I73-204.

Alonso, W. (1964). Location and land use: toward a general theory ofland rent. Harvard University Press.

Ayuso, J. and Restoy, F. (2006). House prices and rents: an equilibrium asset pricing approach. Journal of Empirical Finance, I3(3):371-388.

Bailey, M. , Muth, R. , and Nourse, H. (1963). A regression method for real estate price index construction. Journal of the American Statistical Association, 58(304):933-942.

Bartik, T. (1987). The Estimation of Demand Parameters in Hedonic Price Models. The Journal of Political Economy, 95(I):8I-88.

Basu, S. and Thibodeau, T. (1998). Analysis of spatial autocorrelation in house prices. The Journal of Real Estate Finance and Economics, I7(I):6I-85.
Black, A. , Fraser, P. , and Hoesli, M. (2006). House prices, fundamentals and bubbles. Journal of Business Finance \& Accounting, 33(9-IO):I535-I555.

Bostic, R. , Gabriel, S. , and Painter, G. (2009). Housing wealth, financial wealth, and consumption: New evidence from micro data. Regional Science and Urban Economics, 39(I):79-89.

Brounen, D. , Neuteboom, P. , and Xu, J. (2009). Countryside living: Pricing preferences perfectly. Erasmus University Working Paper.

Brueckner, J. and Rosenthal, S. (2009). Gentrification and neighborhood housing cycles: will America's future downtowns be rich? The Review of Economics and Statistics, 9I(4):725-743.

Brunnermeier, M. and Julliard, C. (2008). Money illusion and housing frenzies. Review of Financial Studies, $2 \mathrm{I}(\mathrm{I}): \mathrm{I} 35$. 
Bulan, L. , Mayer, C. , and Somerville, C. (2009). Irreversible investment, real options, and competition: Evidence from real estate development. Journal of Urban Economics, 65(3):237-25I

Butler, R. (1982). The specification of hedonic indexes for urban housing. Land Economics, 58(I):96-IO8.

Cameron, A. , Gelbach, J. , and Miller, D. (2008). Bootstrap-based improvements for inference with clustered errors. The Review of Economics and Statistics, 9O(3):4I4-427.

Campbell, J. , Cocco, J. , Gomes, F. , and Maenhout, P. (200I). Investing Retirement Wealth, A Life-Cycle Model. Risk Aspects of Investment-Based Social Security Reform.

Campbell, J. and Shiller, R. (1988). Stock prices, earnings, and expected dividends. Journal of Finance, 43(3):66I-676.

Campbell, J. and Shiller, R. (200I). Valuation ratios and the long-run stock market outlook: An update. NBER working paper, W822I.

Campbell, S. , Davis, M. , Gallin, J. , and Martin, R. (2009). What moves housing markets: A variance decomposition of the rent-price ratio. Journal of Urban Economics, 66(2):90-IO2.
Capozza, D. and Li, Y. (1994). The intensity and timing of investment: The case of land. The American Economic Review, 84(4):889-904.

Carroll, C. , Otsuka, M. , and Slacalek, J. (2006). How large is the housing wealth effect? A new approach. NBER Working Paper Series, 12746.

Case, K. , Quigley, J. , Shiller, R. , and Quigley, J. (200I). Comparing wealth effects: the stock market versus the housing market. NBER working paper.

Case, K. and Shiller, R. (1989). The efficiency of the market for single-family homes. The American Economic Review, 79(I):I25-I37.

Case, K. and Shiller, R. (1990). Forecasting prices and excess returns in the housing market. Real Estate Economics, I8(3):253-273.

Case, K. and Shiller, R. (2003). Is there a Bubble in the Housing Market? Brookings Papers on Economic Activity, 2:299-363.

Case, K. and Shiller, R. S\&P/Case-Shiller Home Price Indices [online]. (2010) [cited I5/12/20IO]. Available from: http://www.standardandpoors.com/indices/ sp-case-shiller-home-price-indices/.

Central Bureau of Statistics (1939). De Nederlandse volkshuishouding, I9I4-I9I8. Een 
economisch-statistische schets. In Nederlandse conjunctuur speciale onderzoekingen, volume 3 . Voorburg, The

Netherlands: CBS.

Central Bureau of Statistics (1948). Het nationale inkomen van Nederland, 192 I-1939. In Monografieën van de Nederlandse conjunctuur, volume 7 . Voorburg, The Netherlands: CBS, Voorburg, The Netherlands.

Central Bureau of Statistics (1999). De raming van diensten uit eigenwoningbezit. In Sector Nationale Rekeningen. Voorburg, The Netherlands: CBS, Voorburg, The Netherlands.

Central Bureau of Statistics (2007). Land usage in The Netherlands 2006 (Bestand bodemgebruik 2006). http://easy.dans.knaw.nl.

Central Bureau of Statistics. De gemiddelde verhoging woninghuur in Nederland 1978-2005 [online]. (2008) [cited 2/19/2009]. Available from:

http: / / www.cbs.nl/en-GB/menu/cijfers/statline/default.htm.

Central Bureau of Statistics. Cbs wijk- en buurtkaart 2009 [online]. (2010) [cited I5/I2/20IO]. Available from: http://cbs.nl.

Central Bureau of Statistics. Consumer Price Index for The Netherlands [online]. (2010) [cited 3/18/20IO]. Available from: http://www.statline.cbs.nl.
Central Bureau of Statistics (2OIOc). Statline database. Available from: http://www.cbs.nl.

Central Bureau of Statistics. Tijdreeksen Finaciële instellingen en markten; geld- en kapitaalmarkt [online]. (2010) [cited 3/18/20IO]. Available from:

http: //www.statline.cbs.nl.

Christensen, L. , Jorgenson, D. , and Lau, L. (1975). Transcendental Logarithmic Utility Functions. The American Economic Review, 65(3):367-383.

Chung, H. and Kim, J. (2004). Housing speculation and housing price bubble in Korea. KDI School Working Paper, 04-06.

Claessens, S. , Kose, M. , and Terrones, M. (2009). What happens during recessions, crunches and busts? Economic Policy, 24(60):653-700.

Clapp, J. (2004). A semiparametric method for estimating local house price indices. Real Estate Economics, 32(I):I 27-I6O.

Clapp, J. , Jou, J. , and Lee, T. (2007). Buy to Scrape? Hedonic Pricing with redevelopment Options. Draft paper at SSRN. Available from:

http: //papers.ssrn.com/sol3/papers.cfm?abstract_id=1048801.

Clapp, J. and Salavei, K. (2010). Hedonic pricing with redevelopment options: A new approach to estimating 
depreciation effects. Journal of Urban Economics, $67(3): 362-377$.

Clapp, J. and Wang, Y. (2006). Defining neighborhood boundaries: Are census tracts obsolete? Journal of Urban Economics, 59(2):259-284.

Clayton, J. (1996). Rational expectations, market fundamentals and housing price volatility. Real Estate Economics, 24(4):44I-470.

Coulson, N. and McMillen, D. (2008). Estimating time, age and vintage effects in housing prices. Journal of Housing Economics, I7(2):I38-I5I.

Cressie, N. (1993). Statistics for Spatial Data, revised edition. Wiley Interscience: New York, USA.

Cunningham, C. (2007). Growth controls, real options, and land development. The Review of Economics and Statistics, $89(2): 343-358$.

Davis, M. (2009). The price and quantity of land by legal form of organization in the United States. Regional Science and Urban Economics, 39(3):350-359.

Destatis - German National Statistics. Statistics on Students at German Universities [online]. (2009) [cited IO/IO/2009]. Available from: http//www.destatis.de.
Dickey, D. and Fuller, W. (198I). Likelihood ratio statistics for autoregressive time series with a unit root. Econometrica: Journal of the Econometric Society, 49(4):IO57-IO72.

Dimson, E. , Marsh, P. , and Staunton, M. (2003). Global Evidence on the Equity Risk Premium. Journal of Applied Corporate Finance, I5(4):27-38.

Dixit, A. , Pindyck, R. , and Davis, G. (1994). Investment under uncertainty, volume I5. Princeton University Press Princeton, NJ.

Dixit, A. and Stiglitz, J. (1977). Monopolistic competition and optimum product diversity. The American Economic Review, 67(3):297-308.

Dubin, R. (1988). Estimation of regression coefficients in the presence of spatially autocorrelated error terms. The Review of Economics and Statistics, 70(3):466-474.

Dye, R. and McMillen, D. (2007). Teardowns and land values in the Chicago metropolitan area. Journal of Urban Economics, 6I $(\mathrm{I}): 45-63$.

Eeghen, I. v. , Roosegaarde Bisschop, G. , and Wijnman, H. (1976). Vier eeuwen Herengracht. Het Genootschap Amstelodanum, Stadsdrukkerij Amsterdam, Amsterdam.

Eichholtz, P. (1997). A long run house price index: the Herengracht index, 1628-1973. Real Estate Economics, 25(2):I75-I92 
Eichholtz, P. and Koedijk, K. (1996). Het lange termijn rendement van Nederlandse obligaties, I8I4-I994. Economisch Statistische Berichten, 8I(4052):298-30I.

Eichholtz, P. , Kok, N. , and Quigley, J. (20I0). Doing Well by Doing Good? Green Office Buildings. American Economic Review, IOO(5):2492-2509.

Eichholtz, P. and Lindenthal, T. (2008). Behoeftes en belemmeringen in de woningbouw: een lange termijn perspectief. In Preadvies. Koninklijke Vereniging voor de Staathuishoudkunde (Royal Dutch Economic Society).

Eichholtz, P. and Theebe, M. (2007). Housing Market Rents in the Long Run, Amsterdam, I550-I850. Working Paper, Maastricht University.

Ellison, G. and Glaeser, E. (1999). The geographic concentration of industry: Does natural advantage explain agglomeration? American Economic Review, 89(2):3II-3I6.

Engelhardt, G. and Poterba, J. (I99I). House prices and demographic change* I:: Canadian evidence. Regional Science and Urban Economics, 2 I (4):539-546.

Ermisch, J. (1996). The Demand for Housing in Britain and Population Ageing: Microeconometric Evidence. Economica, 63(25I):383-404.
European Commission. State of the Cities Report [online]. (2007) [cited I5/12/2010]. Available from:

http://ec.europa.eu/regional_policy/sources/docgener/studies/pdf/ urban/stateofcities_2007.pdf.

Francke, M. and Vos, G. (2004). The hierarchical trend model for property valuation and local price indices. The Journal of Real Estate Finance and Economics, 28(2):179-208.

Fujita, M. , Krugman, P., Kilkenny, M. , and Glaeser, E. (2000). The spatial economy: cities, regions, and international trade. Journal of Regional Science, 4O(3).

Fujita, M. and Ogawa, H. (1982). Multiple equilibria and structural transition of non-monocentric urban configurations. Regional science and urban economics, I2(2):I6I-I96.

Gallin, J. (2008). The Long-Run Relationship Between House Prices and Rents. Real Estate Economics, 36(4):635-658.

Glaeser, E. (2005). Reinventing Boston: I630-2003. Journal of Economic Geography, 5(2):II9.

Glaeser, E. and Gyourko, J. (2005). Urban decline and durable housing. Journal of Political Economy, II3(2).

Glaeser, E. and Gyourko, J. (2009). Arbitrage in housing. In Quigley, J. and Glaeser, E. , editors, Housing Markets and the 
Economy: Risk, Regulation, and Policy. Lincoln Institute of Land Policy, Cambridge MA.

Google. Google Maps API [online]. (20I0) [cited I5/I2/2010/2010]. Available from:

http://code.google.com/apis/maps/.

Government Actuary's Department (2007). Projections database. Available from: http://www.gad.gov.uk/population/.

Green, R. and Hendershott, P. (1996). Age, Housing Demand, and Real House Prices. Regional Science and Urban Economics, 26(5):465-480.

Greene, W. and Zhang, C. (2003). Econometric analysis, volume 5. Prentice Hall Upper Saddle River, NJ.

Grenadier, S. (1999). Information revelation through option exercise. Review of Financial Studies, I2(I):95.

Grenadier, S. (2002). Option exercise games: An application to the equilibrium investment strategies of firms. Review of Financial Studies, 15(3):691.

Guerrieri, V. , Hartley, D. A. , and Hurst, E. (20I0). Endogenous Gentrification and Housing Price Dynamics. NBER Working Paper Series.

Gutachterauschuss für Grundtückstwerte (2008). Bericht über den Berliner Grundstücksmarkt 2007-2008. Kulturbuch-Verlag, Berlin.
Harding, J., Rosenthal, S. , and Sirmans, C. (2003). Estimating bargaining power in the market for existing homes. Review of Economics and Statistics, 85(I):I78-I88.

't Hart, M. , Jonker, J. , and van Zanden, J. (1997). A Financial History of The Netherlands. Cambridge University Press.

Helbling, T. and Terrones, M. (2003). Chapter II: When Bubbles Burst. World Economic Outlook, pages 6I-95.

Hendershott, P. (199I). Are Real House Prices Likely to Decline by 47 Percent? Regional Science and Urban Economics, 2I(4):553-563.

Higgins, M. and Olser, C. (1997). Asset market hangovers and economic growth: U.S. Housing Markets. Federal Reserve Bank of New York Research Paper, 980I.

Himmelberg, C. , Mayer, C. , and Sinai, T. (2005). Assessing high house prices: bubbles, fundamentals and misperceptions. Journal of Economic Perspectives, I9(4):67-92.

Hoffmann, J. and Lorenz, A. (2006). Real estate price indices for Germany: past, present and future. Available at SSRN. Available from: http://ssrn. com/abstract $=970241$.

Hott, C. and Monnin, P. (2008). Fundamental real estate prices: an empirical estimation with international data. The Journal of Real Estate Finance and Economics, $36(4): 427-450$. 
Hwang, M. and Quigley, J. (2006). Economic fundamentals in local housing markets: Evidence from US metropolitan regions. Journal of Regional Science, 46(3):425-453.

Krugman, P. (I99I). Geography and trade. MIT Press.

Krugman, P. (1993). First nature, second nature, and metropolitan location. Journal of Regional Science, 33(2):I29-I44.

Lai, R. and van Order, R. (2006). An Analysis of the recent Housing Bubble in the U.S. Economy. University of Michigan Working Paper.

Leamer, E. (2002). Bubble Trouble? Your Home Has a P/E Ratio Too. UCLA Anderson Forecast.

Lee, G. , Schmidt-Dengler, P. , Felderer, B. , and Helmenstein, C. (200I). Austrian Demography and Housing Demand: Is There a Connection? Empirica, 28(3):259-276.

Lesger, C. (1986). Huur en conjunctuur: De woningmarkt in Amsterdam, I550-I850. In Amsterdam historic series. University of Amsterdam.

Lindenthal, T. and Eichholtz, P. (2010). Prolonged Crisis: Housing in Germany and Berlin. In Bardok, A., Edelstein, R. , and Kroll, C. , editors, Global Housing: Markets, Crises, Institutions, and Policies. John Wiley \& Sons, New Jersey.
Lindh, T. and Malmberg, B. (1999). Demography and Housing Demand-What Can We Learn From Residential Construction Data. Workshop on Age Effects on the Economy, Stockholm.

Malpezzi, S. and Maclennan, D. (200I). The Long-Run Price Elasticity of Supply of New Residential Construction in the United States and the United Kingdom. Journal of Housing Economics, IO(3):278-306.

Mankiw, N. and Weil, D. (1989). The Baby Boom, the Baby Bust, and the Housing Market. Regional Science and Urban Economics, I9(2):235-58.

McCarthy, J. and Peach, R.(2004). Are home prices the next bubble? Economic Policy Review, Io(3).

McMillen, D. and Smith, S. (2003). The number of subcenters in large urban areas. Journal of Urban Economics, 53(3):32I-338.

Mills, E. (1972). Studies in the Structure of the Urban Economy. The Johns Hopkins Press, Baltimore, Maryland.

Mufson, S. In China, Fear of a Real Estate Bubble [online]. (2010) [cited I5/12/2010]. Available from:

http://www.washingtonpost.com/wp-dyn/content/article/2010/01/10/ AR2010011002767.html.

Muth, R. (1969). Cities and housing: the spatial pattern of urban residential land use. University of Chicago Press. 
Myers, D. (1999). Cohort Longitudinal Estimation of Housing Careers. Housing Studies, I 4(4):473-490.

Nederlandse Vereniging voor Makelaars, N. Historische marktcijfers [online]. (2008) [cited I2/2I/2008]. Available from: http:

//www.nvm.nl/nvm/index.jsp?navid=nvm099023\&doelgroep=woningmarkt.

Nederlandse Vereniging voor Makelaars, N. (20I0). Overview on transaction prices for existing residential real estate. http://www.nvm.nl.

Neuteboom, P. and Brounen, D. (2007). Demography and Housing Demand - Dutch Cohort Evidence. Erasmus University Working Paper.

Nijssen, G. (2000). De prijs van het wonen: huurstakingen in Amsterdam. In Keesom, J., editor, Wonen. Woning. Wet: wij wonen - IOO jaar Woningwet. Stedelijke Woningdienst, Amsterdam.

Nusteling, H. (1985). Welvaart en werkgelegenheid in Amsterdam 1540-I860. De Bataafsche Leeuw.

Office of the Deputy Prime Minister (2003). English Housing Condition Survey: Main Report 200I. Queen's Printer and Controller of Her Majesty's Stationery Office.

Ohtake, F. and Shintani, M. (1996). The Effect of Demographics on the Japanese Housing Market. Regional Science and Urban Economics, 26(2):I89-20I.
Openstreetmap Project. GIS Maps for Berlin [online]. (2009) [cited 3/2/2009]. Available from:

http: //openstreetmap.org.

Oswalt, P. and Rieniets, T. (2006). Atlas of shrinking cities. Hatje Cantz Ostfildern.

Ozanne, L. and Malpezzi, S. (1985). The efficacy of hedonic estimation with the annual housing survey. Evidence from the demand experiment. Journal of Economic and Social Measurement, I3(2):I53-I72.

Pace, R. , Barry, R. , Clapp, J. , and Rodriquez, M. (1998a). Spatiotemporal autoregressive models of neighborhood effects. The Journal of Real Estate Finance and Economics, I7(I):I5-33.

Pace, R. , Barry, R. , and Sirmans, C. (1998b). Spatial statistics and real estate. The Journal of Real Estate Finance and Economics, I7(I):5-13.

Pebesma, E. (2004). Multivariable geostatistics in S: the gstat package. Computers \& Geosciences, 30(7):683-69I.

Peek, J. and Wilcox, J. (I99I). The Measurement and Determinants of Single-Family House Prices. Real Estate Economics, I9(3):353-382.

Phillips, P. and Perron, P. (1988). Testing for a unit root in time series regression. Biometrika, 75(2):335. 
Porter, M. (1996). Competitive advantage, agglomeration economies, and regional policy. International regional science review, I9(I-2):85.

Quigg, L. (1993). Empirical testing of real option-pricing models. Journal of Finance, 48(2):62 I-640.

Redfearn, C. (2007). The topography of metropolitan employment: Identifying centers of employment in a polycentric urban area. Journal of Urban Economics, 6I(3):5I9-54I.

Redfearn, C. (2009). How informative are average effects? Hedonic regression and amenity capitalization in complex urban housing markets. Regional Science and Urban Economics, 39(3):297-306.

Riel, A. v. (2006). Prices and economic development in the netherlands, I800-I9I3; markets, institutions and policy restraints. Utrecht University.

Roehner, B. (1999). Spatial analysis of real estate price bubbles: Paris, 1984-1993. Regional Science and Urban Economics, 29(I):73-88.

Rosen, S. (1974). Hedonic Prices and Implicit Markets: Product Differentiation in Pure Competition. The Journal of Political Economy, 82(I):34-55.
Rosenthal, S. (2008). Old homes, externalities, and poor neighborhoods. A model of urban decline and renewal. Journal of Urban Economics, 63(3):816-840.

Rosenthal, S. and Helsley, R. (1994). Redevelopment and the urban land price gradient. Journal of Urban Economics, 35(2):182-200.

Stichting ROZ Vastgoedindex. ROZ Kwartaal Index - full history Q4 I999-QI 2007 [online]. (2007) [cited I/28/2008]. Available from: http://www.rozindex.nl/Downloads/ Nederlands/Kwartaal\%20Index/Kwartaalcijfers\%2OFull\%20history\% 20041999\%20-\%20012007.xls.

Scheinkman, J. and Xiong, W. (2003). Overconfidence and speculative bubbles. Journal of Political Economy, III(6):II83-I2I9.

Schmemann, S. (1989, November I0). Clamor in the east: East germany opens frontier to the west for migration and travel; thousands cross.

Schulz, R., Sofyan, H. , Werwatz, A., and Witzel, R. (2003). Online Prediction of Berlin Single-Family House Prices. Computational Statistics, I8(3):449-462.

Schulz, R. and Werwatz, A. (2004). A state space model for Berlin house prices: Estimation and economic interpretation. The Journal of Real Estate Finance and Economics, 28(I):37-57. 
Shiller, R. (2007). Understanding recent trends in house prices and home ownership. NBER working paper.

Spies, P. , Kleijn, K. , Smit, J. , and Kurpershoek, E. (1993). Het Grachtenboek. SDU Uitgeverij, The Hague.

Thüringer Landesamt für Statistik (2008). Entwicklung der Bevölkerung ab I950. Available from:

http://www.tls. thueringen.de.

Titman, S. (1985). Urban land prices under uncertainty. The American Economic Review, 75(3):505-5I4.

United Nations Population Division (2007). World Population Prospects: The 2006 Revision Population

Database. Available from: http://esa.un.org/unpp/.

Vermeulen, W. and Rouwendal, J. (2007). Housing Supply in The Netherlands, Centraal Planbureau. CPB Discussion Paper 87.

de Vries, J. (1984). European urbanization 1500-I800. Taylor \& Francis.

de Vries, J. and van der Woude, A. (1984). Nederland I5OO-I815; De eerste ronde van moderne economische groei. Uitgeverij Balans.

van Zanden, J. (1993). The rise and decline of Holland's economy: merchant capitalism and the labour market. Manchester University Press. van Zanden, J. and Riel, A. (2000). Nederland I780-I9I4. Staat, instituties en economische ontwikkeling. Balans, Amsterdam.

Zhou, W. and Sornette, D. (2003). 2000-2003 real estate bubble in the UK but not in the USA. Physica A: Statistical Mechanics and its Applications, 329(I-2):249-263. 